\title{
HYDROGEN PRODUCTION FOR FUEL CELLS VIA REFORMING COAL-DERIVED METHANOL
}

\section{R04.pdf}

Annual Technical Progress Report

Reporting Period Start Date: October 1, 2003

Reporting Period End Date: September 30, 2004

Principal Author: Paul A. Erickson

Report Issue Date: October 2004

DOE Award Number: DE-FC26-03NT41850

Submitting Organization:

The Regents of the University of California, Davis

One Shields Avenue

Davis, California 95616 


\section{DISCLAIMER}

This report was prepared as an account of work sponsored by an agency of the United States Government. Neither the United States Government nor any agency thereof, nor any of their employees, makes any warranty, express or implied, or assumes any legal liability or responsibility for the accuracy, completeness, or usefulness of any information, apparatus, product, or process disclosed, or represents that its use would not infringe privately owned rights. Reference herein to any specific commercial product, process, or service by trade name, trademark, manufacturer, or otherwise does not necessarily constitute or imply its endorsement, recommendation, or favoring by the United States Government or any agency thereof. The views and opinions of authors expressed herein do not necessarily state or reflect those of the United States Government or any agency thereof. 


\section{ABSTRACT}

Hydrogen can be produced from many feed stocks including coal. The objectives of this project are to establish and prove a hydrogen production pathway from coal-derived methanol for fuel cell applications.

This progress report is the fourth report submitted to the DOE reporting on the status and progress made during the course of the project. This report covers the time period of July 1 -Sept 30, 2004 along with a recap of progress from the start of the project on Oct 1 , 2003 to Sept 30, 2004. All of the projects are proceeding on or slightly ahead of schedule. This year saw progress in several areas. These areas are:

1. External and internal evaluation of coal based methanol and a fuel cell grade baseline fuel,

2. Design set up and initial testing of three (3) laboratory scale steam reformers.

3. Design, set up and initial testing of a laboratory scale autothermal reactor,

4. Hydrogen generation from coal-derived methanol using steam reformation.

5. Experiments to determine the axial and radial thermal profiles of the steam reformers,

6. Initial catalyst degradation studies with steam reformation and coal based methanol,

7. Experimental investigations of heat and mass transfer enhancement methods by flow field manipulation.

All of the projects are proceeding on or slightly ahead of schedule. 


\section{TABLE OF CONTENTS}

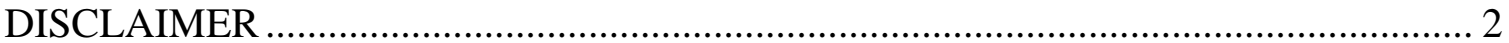

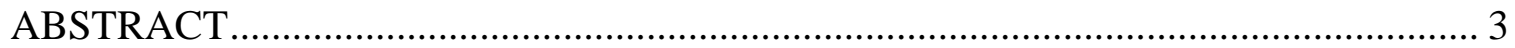

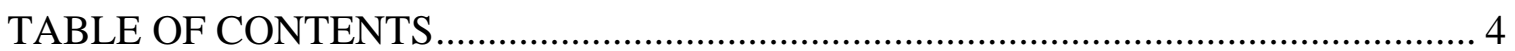

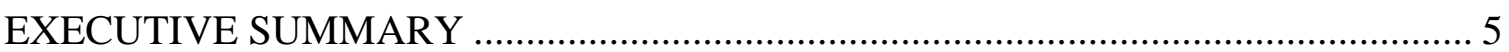

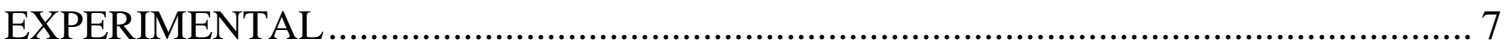

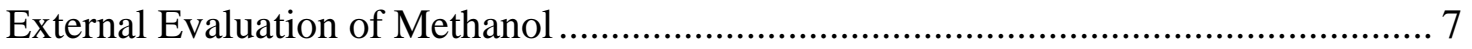

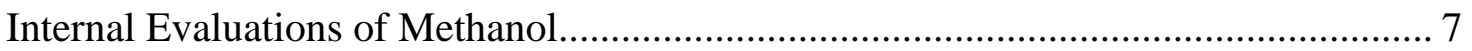

Steam-Reforming Baseline Study ...................................................................... 8

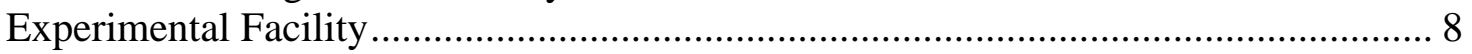

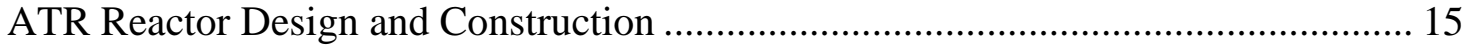

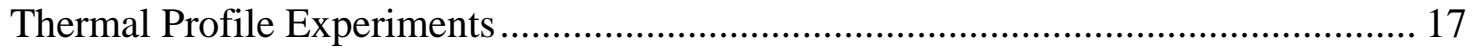

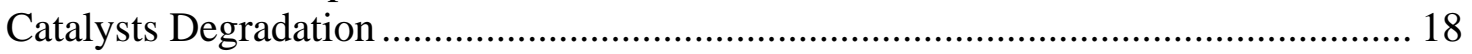

Steam Reformation Enhancement Methods................................................................ 22

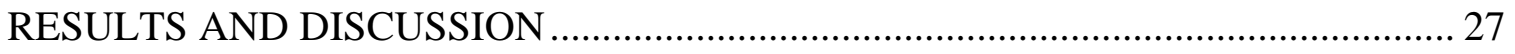

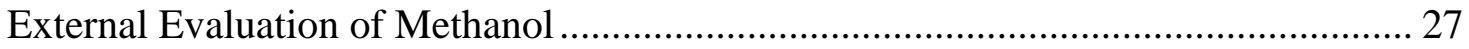

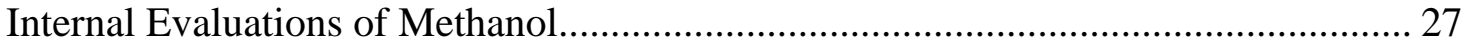

Sample Results from Steam Reformation.................................................................. 31

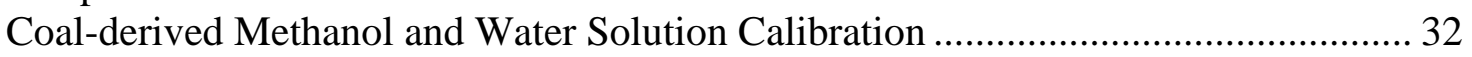

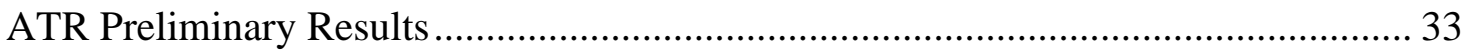

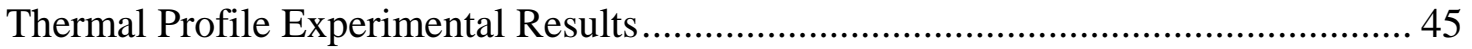

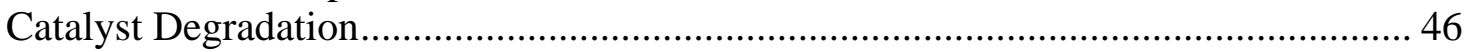

Steam Reformation Enhancement Methods................................................................ 58

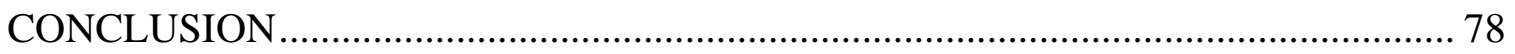

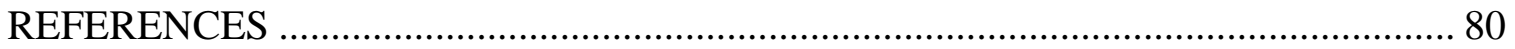




\section{EXECUTIVE SUMMARY}

Hydrogen can be produced from many feed stocks including coal. The objectives of this project are to establish and prove a hydrogen production pathway from coal-derived methanol for fuel cell applications.

This progress report is the fourth report submitted to the DOE reporting on the status and progress made during the course of the project. This report covers the time period of July 1 -Sept 30, 2004 along with a recap of progress from the start of the project on Oct 1, 2003 to Sept 30, 2004.

Much progress has been made on the project funded by the Department of Energy during the first year. All of the projects are proceeding on or slightly ahead of schedule.

This year saw progress in several areas. These areas are:

1. External and internal evaluation of coal based methanol and a fuel cell grade baseline fuel,

2. Design set up and initial testing of three (3) laboratory scale steam reformers.

3. Design, set up and initial testing of a laboratory scale autothermal reactor,

4. Hydrogen generation from coal-derived methanol using steam reformation.

5. Experiments to determine the axial and radial thermal profiles of the steam reformers,

6. Initial catalyst degradation studies with steam reformation and coal based methanol,

7. Experimental investigations of heat and mass transfer enhancement methods by flow field manipulation.

Internal and external evaluations of coal-derived and fuel cell grade methanol are now complete. The two methanols are quite similar in sulfur, and chloride levels with a small but significant difference in trace level higher hydrocarbons. The coal based methanol has approximately 3 times the amount of petroleum hydrocarbons than the fuel cell grade methanol.

Construction of three (3) steam reformers has taken place. Each reformer has a different geometry in order to test the geometric dependencies of reformation. Studies showing a strong dependence of fuel conversion on geometry have taken place. These reformer systems also are utilized for the studies of catalyst degradation and passive heat transfer enhancement. The steam reformers have been used to generate hydrogen from the coalderived methanol supplied. Construction of the autothermal reformer (ATR) is now completed and preliminary testing has begun with fuel cell grade methanol. Initial tests are complete with a catalytic converter grade catalyst to validate the test procedures and have given the research team valuable experience with analyzing both the data and control schemes. Start-up, operation and shut-down procedures have been tested and validated and data collection is proceeding using a specially designed proprietary catalyst specifically designed for autothermal reformation. Parameters of oxygen to carbon ratio 
have been investigated as well as reaction progression in the catalyst. Theoretical oxygen to carbon ratio underestimates the amount of oxygen required for peak hydrogen efficiency. With the fuel cell grade methanol the autothermal reaction takes place quickly within the first fifteen percent (15\%) of the catalyst bed. The upper level of flow rate has yet to be determined regarding fuel conversion to hydrogen and this ATR method appears very promising for reforming coal-derived methanol.

Due to a careful evaluation of the steam reformer temperature profile it was determined that significant sheath conduction from the wall was biasing the temperature measurements close to the reactor wall. A new thermocouple design utilizing a miniature sheath embedded into an external housing with insulating material was tested. This new thermocouple design had more reliable results than the standard design for determining an accurate temperature profile. This new thermocouple design is being implemented throughout the steam reforming reactors and also into the ATR reactor.

Investigations into methods of enhancing the heat transfer characteristics were also performed. Data has been collected showing enhancement of heat transfer and mass transfer by bluff bodies. This data is being analyzed and is being expanded to include an empirical model of the enhancement process. Several packing densities have been evaluated in steady state with the bluff bodies. Results are very encouraging to the research team and show significant enhancement of conversion.

In addition to the above projects catalyst degradation projects have been started. The catalyst degradation study has monitored conversion while operating in steady state for the two methanol fuels over several continuous 70 hour periods. With heat transfer minimized by using a specially designed steam reformer with an internal heater, the coalderived methanol showed significantly faster catalyst degradation than the fuel cell grade methanol. The research team speculates that the increased degradation is due to the higher levels of trace hydrocarbons. This catalyst degradation study will expand as more data become available.

Several projects are scheduled for the next project period including use of the coal-based methanol in the ATR reactor, continued evaluation of coal-based methanol in the steam reformers, validation of heat transfer enhancement methods by use of bluff bodies and measuring the difference in catalyst degradation using the various methanols with combination with the enhancement methods studied.

One paper outlining the overall research direction was presented by the PI to the ASME Power Conference in Baltimore March, 2004. Several papers are in works regarding the steam reformer and the autothermal reformer performance. 


\section{EXPERIMENTAL}

The following section describes the experimental methods used and developed during the reporting period for the following areas: external evaluation of methanol, internal evaluation of methanol, steam-reforming baseline study, experimental facility, autothermal reactor design and construction, thermal profile experiments, catalyst degradation, and steam reforming enhancement methods.

\section{External Evaluation of Methanol}

Severn Trent Laboratories - Mobile (STL-Mobile) has performed the $2^{\text {nd }}$ round of the external blind analysis comparing the fuel cell grade methanol to the coal-derived methanol. The analysis covered the amounts of total sulfur and chloride. For the $1^{\text {st }}$ round external analysis, chloride and sulfur showed suspicious results. Chloride in the coal-derived methanol showed 100 times greater than in fuel cell grade methanol. A $2^{\text {nd }}$ sample set was sent to STL-Mobile to verify the results, which are reported below in the Results and Discussion section.

\section{Internal Evaluations of Methanol}

Several different techniques were used to analyze the coal-derived methanol and the fuel cell grade methanol. The techniques are introduced below and the results are presented in the Results and Discussion section.

Nuclear Magnetic Resonance (NMR) spectroscopy Test

$1 \mathrm{ml}(0.034 \mathrm{oz})$ samples of coal derived methanol and fuel cell grade methanol were added to $5 \mathrm{~mm}$ (0.197in) Series 300 NMR tubes $17.8 \mathrm{~cm}$ (7in) in length with $10 \mathrm{ml}(0.334 \mathrm{oz})$ deuterated water (D2O). Bruker DRX 500 operates at 11.746 Tesla or $500 \mathrm{MHz}$. The temperature range is from -150 to $180^{\circ} \mathrm{C}\left(-302\right.$ to $\left.356^{\circ} \mathrm{F}\right)$ and stability is $\pm 0.2^{\circ} \mathrm{C}$. Under a strong magnetic field, structures of compounds and dynamic information with regard to injected samples were achieved by means of analysis of signals acquired by injected electromagnetic wave at microsecond.

Liquid Chromatography-Mass Spectrometer (LC-MS) Test

The samples of coal derived methanol and fuel cell grade methanol were injected into a $150 \mathrm{mM}$ X $2.3 \mathrm{mM} \mathrm{C} 18$ column running $0.1 \%$ formic acid and acetonitrile at 200 micro liters/minute. Both UV (220nM) and mass spectral data were acquired on a LCQ running in the positive mode. To begin with, spectrogray methanol for setting on the basis standard was used for comparing with fuel cell grade methanol and coal-derived methanol. However, mass spectrometry of spectrogray methanol did not show apparent results because spectroscopy methanol is less pure than both coal-derived methanol and fuel cell grade methanol. 
Gas Chromatography-Mass spectrometer (GC-MS)

The samples of coal derived methanol and fuel cell grade methanol were injected into a DB-5MS column which have $0.32 \mathrm{~mm}$ (0.0126in) I.D., 30 meters $(98.4 \mathrm{ft})$ length, and $0.25 \mu \mathrm{m}$ film thickness manufactured running Helium as the carrier gas at $1 \mathrm{~mL} / \mathrm{min}$ $(0.0159 \mathrm{gal} / \mathrm{h})$. Mass spectral data was acquired. For each run, a $1 \mathrm{ml}(0.034 \mathrm{oz})$ sample was injected into a Gas chromatograph. GC-MS tests were carried out 5 times to get rid of column bleed and increase the accuracy. Mass range was from 50 to $550 \mathrm{amu}$ and acquiring time was 17 minutes. Initial column temperature was $75^{\circ} \mathrm{C}\left(167^{\circ} \mathrm{F}\right)$ and final column temperature increased up to $260^{\circ} \mathrm{C}\left(500^{\circ} \mathrm{F}\right)$.

\section{Steam-Reforming Baseline Study}

Data collection with baseline fuel (fuel cell grade) monitoring reactor performance was accomplished with the two existing steam reformer set ups. The flow rate was varied to allow multiple space velocities. Preliminary studies present the large effect that geometry and corresponding flow fields can have on the hydrogen production process and add fundamental knowledge that will aid the construction and development of hydrogen production reactors. The data presented here establishes the baseline performance with fuel cell grade methanol and explains the experimental facilities that will be used in reforming coal-derived methanol. Further investigations into the proper parameter for capturing the geometry in steam reformers are planned as are methods of enhancing the heat transfer characteristics as outlined in the original proposal.

\section{Experimental Facility}

The experimental facility used in this study includes three methanol-steam reformers, and an autothermal reformer, all incorporating a scale, pump, vaporizers, superheater, catalyst bed housings and a condensing unit, as shown in Figure 1. The methanol-steam reformers are located at the University of California at Davis in the Hydrogen and Production and Utilization Laboratory. 


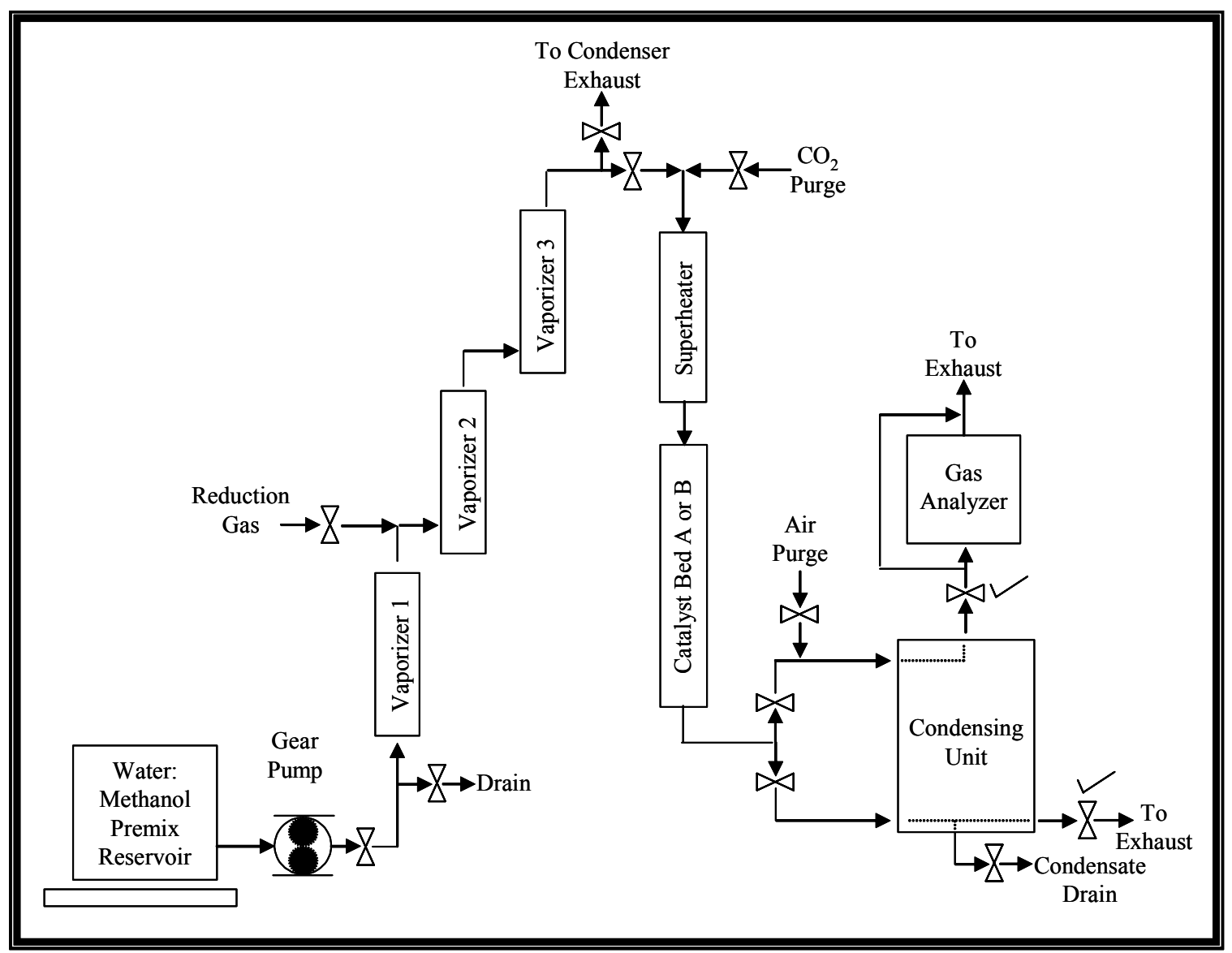

Figure 1: Simplified drawing of the steam reformer.

The process of reformation begins with a reservoir filled with a specific amount of deionized water and methanol, called "premix," on a mass scale. Stoichiometry of the premix will be discussed in the following section. The premix was then pumped into a three-stage vaporizer, changing the premix from liquid to gas, and bringing it up to a desired temperature. Depending on the experimental procedure, the gaseous species can then be routed into an exhaust, or directed through a superheater by utilizing valves placed in the system. The superheater then holds the species at a constant temperature as it is routed into the catalyst bed housing. For the purpose of this study the catalyst bed housing was designed to be interchangeable with three other housings of varying dimensions. These catalyst bed housings will be referred to as reactor $\mathrm{A}$, reactor $\mathrm{B}$, reactor $\mathrm{C}$, and the autothermal reactor. After passing through the catalyst bed, the gaseous species are then directed into two tubes via a system of valves. One route was for analysis and the other was for exhausting the reactor products. Both routes lead to the condensing unit where the species, now called "reformate," reduces in temperature. Liquid water and un-reacted methanol are separated from the mixture of dry gases by a condenser and condensate trap. The dry gases are then routed to the gas analyzer. More specific details of the methanol-steam reformer are given below. 


\section{Pumping Subassembly}

The pumping assembly began with a 4 liter $(1$ gal. $)$ polyethylene carboy reservoir containing a liquid at room temperature composed of 1.5:1, water: methanol mixture ratio (on a molar basis). This stoichiometric ratio is verified based on the density and temperature of the premix. This is done with a handheld density meter with a resolution of $0.0001 \mathrm{~g} / \mathrm{cm}^{3}$. The reservoir rests upon a scale with a 0.1 gram resolution. The scale had a 9 pin bidirectional RS-232 port, which allows the user to electronically record the scale reading during operation. The premix was then drawn out of the carboy by way of a gear pump and driver and enabled the user a resolution of $0.1 \mathrm{ml} / \mathrm{min}(0.00159 \mathrm{gal} / \mathrm{h})$ with a premix flow rate range from 2.6 to $85 \mathrm{ml} / \mathrm{min}(0.0412 \mathrm{gal} / \mathrm{h}$ to $1.35 \mathrm{gal} / \mathrm{h})$. The pump driver was equipped with a frequency output signal, which allowed the user to correspond a frequency (or gear pump RPM) to a flow rate. The user can then electronically record the instantaneous flow rate and control the pump with a voltage signal during operation. Calculations for the mass flow rate could be verified by both the recorded pump flow rate and by recording the change in mass of the scale divided by the time the experiment ran (both were recorded via a computer control program).

\section{Vaporizer Subassembly}

Each vaporizer was made of a $20.3 \mathrm{~cm}$ (8 in) stainless-steel pipe (nominal 1/2" Dia., schedule 40). The energy for vaporization was supplied from $120 \mathrm{~V}$ cartridge heaters. The first vaporizer contained a $24.1 \mathrm{~cm}(9.5 \mathrm{in}), 525 \mathrm{~W}$ cartridge heater, while the last two stages contained $12.7 \mathrm{~cm}(5 \mathrm{in}), 400 \mathrm{~W}$ cartridge heaters. Each vaporizer was monitored for temperature by two, stainless-steel-sheathed, ungrounded K-type thermocouples. The superheater housing material was a $30.5 \mathrm{~cm}$ (12 in) stainless-steel pipe (nominal 3/4" Dia., schedule 40). External heating was applied to the superheater using four nozzle band heaters $(2.5 \mathrm{~cm}(1 \mathrm{in}) \mathrm{I} . \mathrm{D} ., 5.1 \mathrm{~cm}(2 \mathrm{in})$ width), each with a $120 \mathrm{~V}, 275 \mathrm{~W}$ rating. To evenly increase the temperature distribution throughout the superheater, a highly thermal conductive aluminum tape was wrapped around the exterior. Three $0.159 \mathrm{~cm}(0.0625 \mathrm{in})$, stainless-steel-sheathed, ungrounded K-type thermocouples were strategically adapted to the superheater to monitor performance.

\section{Catalyst Bed Housing Subassemblies}

\section{Reactor A}

The housing material for reactor A was a $61 \mathrm{~cm}$ (24 in) stainless-steel pipe (nominal $3 / 4$ in Dia., schedule 40), as shown in Figure 2. External heating was applied to reactor A using 8 nozzle band heaters $(2.5 \mathrm{~cm}$ ( 1 in) I.D., $5.1 \mathrm{~cm}$ ( 2 in) width), each with a $120 \mathrm{~V}, 275 \mathrm{~W}$ rating. In a similar fashion as the superheater, a highly thermal conductive aluminum tape was wrapped around the exterior of the pipe to evenly increase the temperature distribution throughout the reactor. An array of seventeen $0.159 \mathrm{~cm}$ (0.0625 in) Dia. stainless-steel-sheathed, ungrounded K-type thermocouples was used to monitor the temperature within the reactor. 


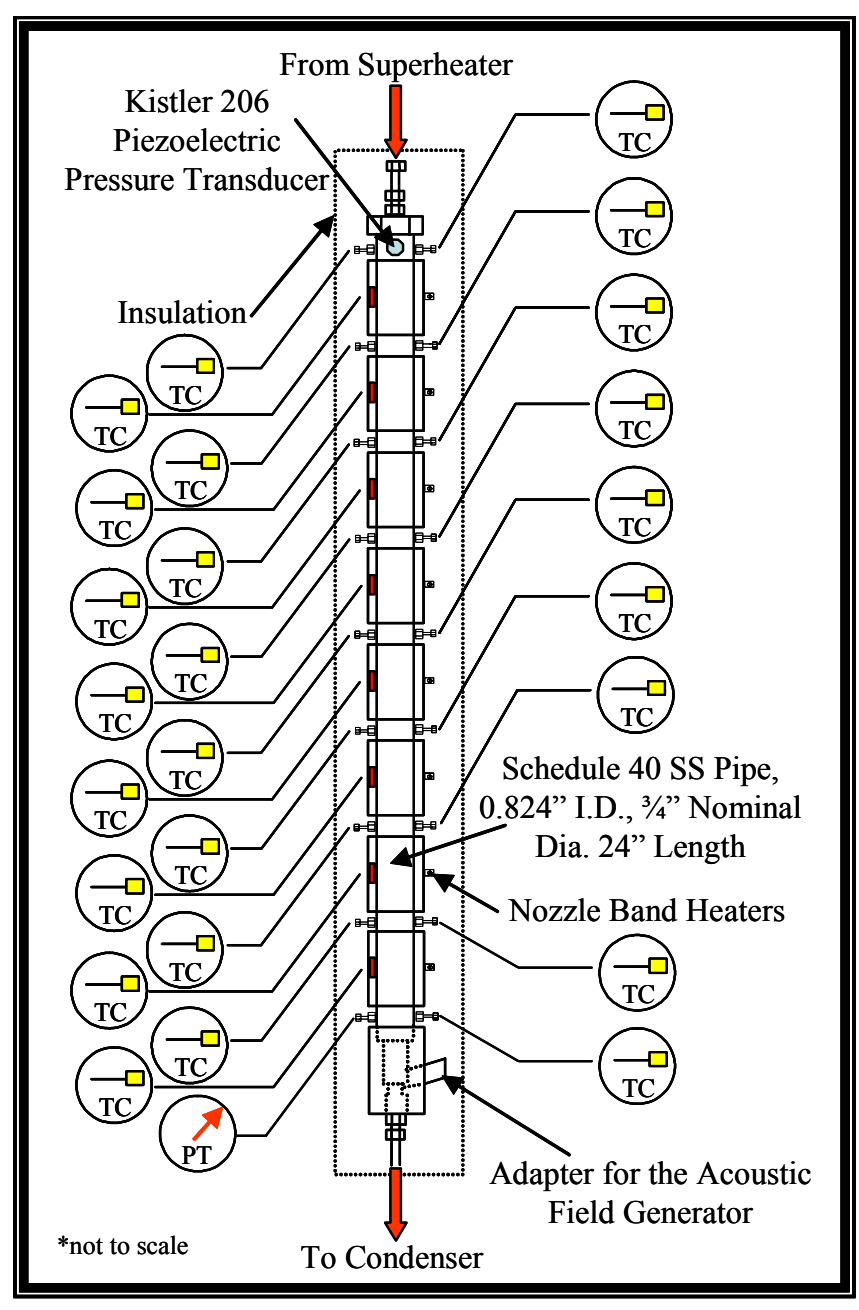

Figure 2: Schematic of reactor $A$.

To observe the temperature of the heat bands, eight $0.025 \mathrm{~cm}(0.010 \mathrm{in})$ Dia., ungrounded K-type thermocouples were placed between the heat bands and the exterior reactor wall. The reactor pressure was monitored using a 0-103.4 $\mathrm{kPa}$ (0-15 PSI) pressure gauge and was located at the exit of the reactor (identified as PT in Figure 6).

\section{Reactor $B$}

Reactor B was constructed with a similar design and purpose as reactor A, but with differing dimensions. The housing material for reactor B was a $25.4 \mathrm{~cm}$ (10 in) stainlesssteel pipe (nominal 1 1/4" Dia., schedule 40) and is represented in Figure 3. To account for the change in outer diameter $(1.5 \mathrm{~cm}(0.61 \mathrm{in}))$ and length $(35.6 \mathrm{~cm}(14 \mathrm{in}))$ of the reactor, only four nozzle band heaters with a larger interior diameter (3.8 cm (1.5 in) I.D., $3.8 \mathrm{~cm}$ (1.5 in) width) were utilized, each with a $120 \mathrm{~V}, 350 \mathrm{~W}$ rating. Also, fewer thermocouples (nine- $0.159 \mathrm{~cm}(0.0625 \mathrm{in}) \mathrm{Dia}$. and four-0.025 cm (0.010 in) Dia.) were used to monitor the reactor. 


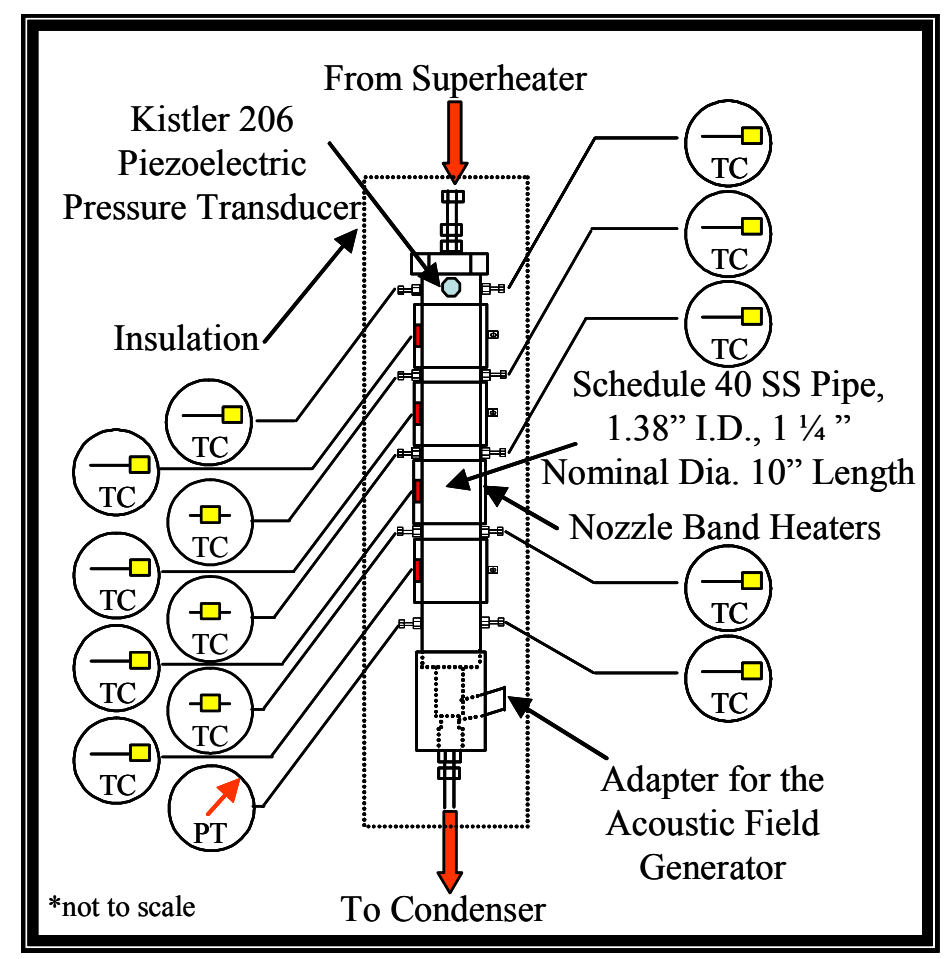

Figure 3: Schematic of reactor $B$.

\section{Reactor $C$}

Figure 4 shows a schematic of a reactor with an internal cartridge heater, which has been labeled Reactor $\mathrm{C}$. The housing material for reactor was a $12.7 \mathrm{~cm}$ (5 in) stainless-steel pipe (nominal $3 / 4$ in Dia., schedule 40) threaded at both ends. The bottom cap was machined to adapt a $0.635 \mathrm{~cm}(0.25 \mathrm{in})$ MNPT fitting on the side as well as on the bottom to make gas pathway and place internal cartridge heater inside the reactor. Two nozzle band heaters $(2.5 \mathrm{~cm}$ ( 1 in) I.D., $5.1 \mathrm{~cm}$ ( $2 \mathrm{in})$ width), each with a $120 \mathrm{~V}, 275 \mathrm{~W}$ rating were used for external heating. Furthermore, internal cartridge heater (0.25in Dia. 8 in length), with a $120 \mathrm{~V}, 600 \mathrm{~W}$ rating was also applied to this reactor. Reactor surface was wrapped with aluminum tape with high thermal conductivity to increase heat transfer from the nozzle band heaters to the reactor. Six $0.159 \mathrm{~cm}$ (0.0625 in) Dia. stainless-steelsheathed, ungrounded K-type thermocouples were applied to monitor temperatures inside the reactor at each zone. In addition, three $0.0508 \mathrm{~cm}$ (0.020 in) Diä: ungrounded K-type thermocouples were used for controlling reactor exterior surface temperature between the nozzle heater band and the exterior wall of the reactor. Six $0.32 \mathrm{~cm}(0.125 \mathrm{in}) \mathrm{MNPT}$ to $0.32 \mathrm{~cm}(0.125 \mathrm{in})$ pipe fittings were used for holding the six thermocouples. 


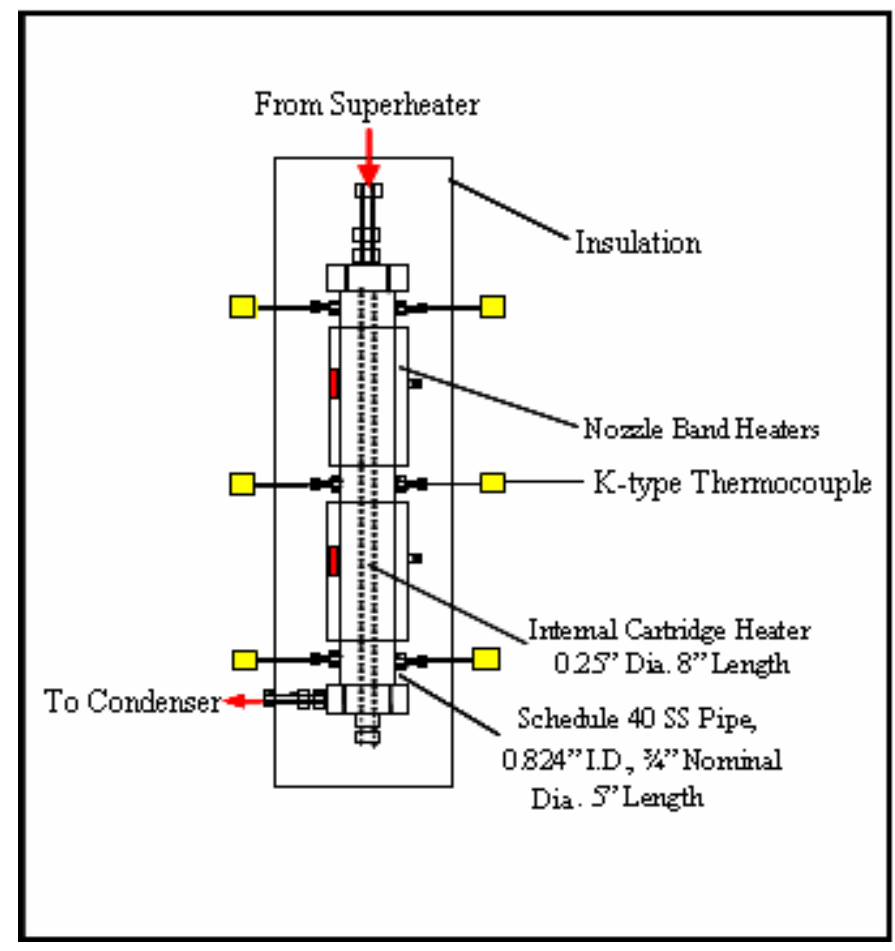

Figure 4: Schematic of reactor $C$.

Moreover, to block leaks around the thermocouples and to be reusable, graphite ferrules were used instead of stainless steel ferrules. Insulation for the reactors are composed of a 3 " thick calcium silicate material with a temperature tolerance of $649^{\circ} \mathrm{C}\left(1200^{\circ} \mathrm{F}\right)$.

The catalyst used in this study was a pelletized commercial-grade copper-zinc catalyst on an alumina substrate. This catalyst is recommended for an operating temperature range of $250-280^{\circ} \mathrm{C}\left(482-536^{\circ} \mathrm{F}\right)$. The catalyst was cylindrical in shape and had dimensions consisting of $0.47 \mathrm{~cm}(0.187 \mathrm{in})$-diameter and $0.25 \mathrm{~cm}(0.100 \mathrm{in})$-thickness, as stated by the manufacturer. The catalyst in its original state is referred to in this study as pelletized catalyst. Other tests conducted with this catalyst after being crushed and sieved to vary the dimensions and the exposed surface area. This catalyst had an average length of 0.25 $\mathrm{cm}(0.098 \mathrm{in})$ and is referred to as crushed catalyst in this study. Also, Figure 5 displays the designated zones for both reactors and the relative position of the corresponding packed catalyst. The packing factor for the pelletized and crushed catalyst remained constant at $61.7 \%$. The average mass of catalyst used for each run, for both pelletized and crushed, was $253.7 \mathrm{~g}(0.56 \mathrm{lb})$ with a standard deviation of $4.9 \mathrm{~g}(0.01 \mathrm{lb})$. 


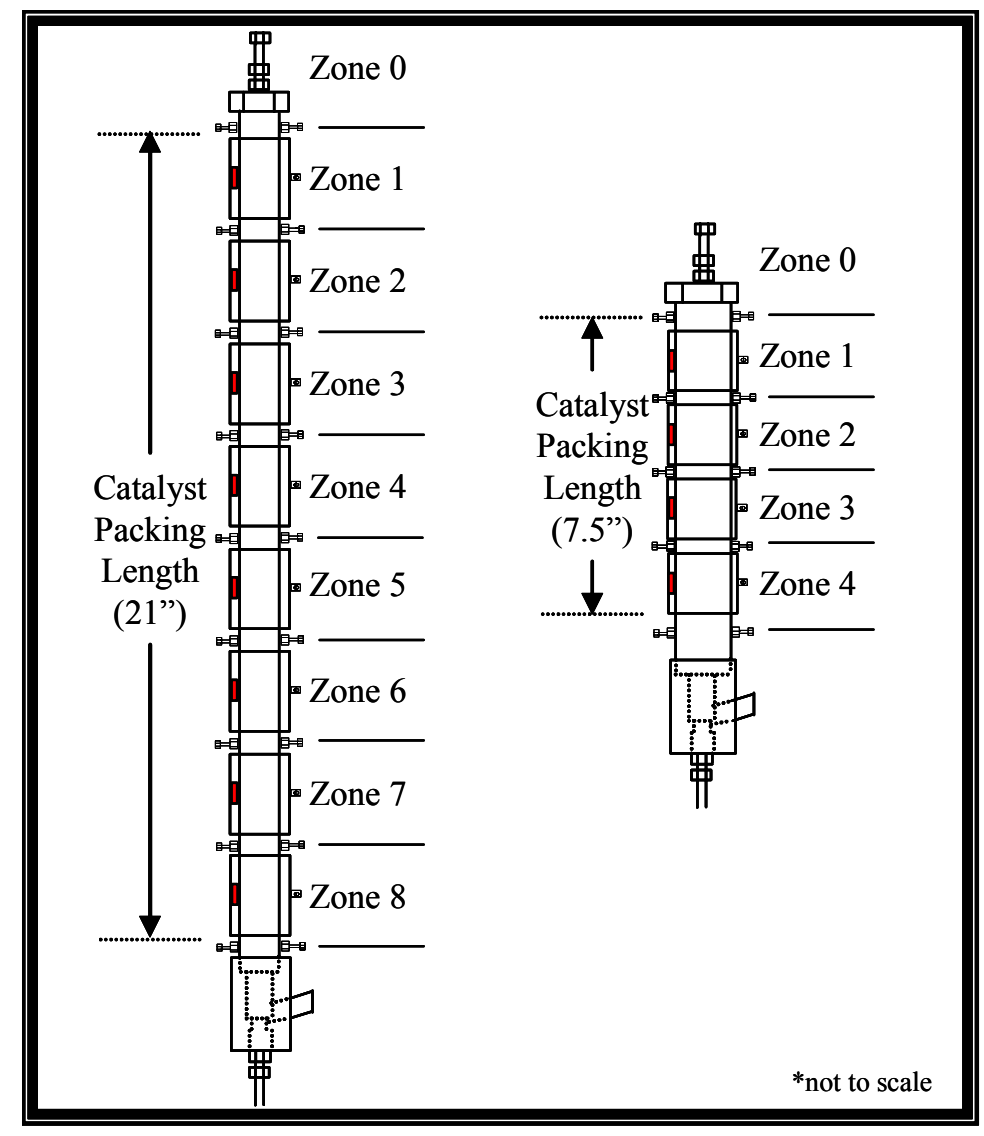

Figure 5: Schematic of zones and catalyst packing lengths for reactors A (left) and B (right).

\section{Condensing Unit Subassembly}

The condensing unit utilized water from an ice bath to lower the gas temperature from $250^{\circ} \mathrm{C}\left(482^{\circ} \mathrm{F}\right)$ to $0^{\circ} \mathrm{C}\left(32^{\circ} \mathrm{F}\right)$. The decrease in temperature promotes a phase change, causing water, methanol and other relevant species to condense. To acquire the condensate from the reactant species for fuel conversion analysis, the collection container can be removed from the unit. The dry product gas on the analysis side was then routed to the gas analyzer, while the exhaust gas was directed to the fume hood.

\section{Percent Conversion of Methanol}

Percent conversion $(\% \mathrm{C})$ of methanol to a hydrogen-rich gas is presented in Equation 1. The methanol input and output are on a mass basis.

$$
\% \mathrm{C}=\left(\frac{\mathrm{CH}_{3} \mathrm{OH}_{\text {input }}-\mathrm{CH}_{3} \mathrm{OH}_{\text {output }}}{\mathrm{CH}_{3} \mathrm{OH}_{\text {input }}}\right) \times 100
$$

Equation 1

For each run, the mass of the water: methanol premix consumed was recorded. From this value, the mass of methanol input $\left(\mathrm{CH}_{3} \mathrm{OH}_{\text {input }}\right)$ could be calculated once the initial mass fraction of methanol in the premix was found. The mass fraction of methanol input was known based on the mass of methanol used to create the premix (1.5:1 water: methanol 
ratio on a molar basis). This water: methanol ratio was calculated based on the premix density at $24^{\circ} \mathrm{C}\left(75^{\circ} \mathrm{F}\right)$. Percent conversion of methanol was independent of time; however, run time did play a role in how much condensate mass was trapped by the condensing unit subassembly. Too short of a run time would yield a small amount of condensate mass which would be more susceptible to error in collection and analysis. Previous studies suggested a minimum of 35 to 40 grams $(0.077$ to $0.088 \mathrm{lb})$ of condensate be collected for each run to minimize analysis error [1]. Condensate was emptied from the trap and weighed on an $1200 \mathrm{~g}(0.1 \mathrm{~g}$ resolution) scale. To obtain all mass that was left inside the trap, a towel was used to absorb all liquid droplets left behind. Generally for each run, an average of 2.0 grams $(0.0044 \mathrm{lb})$ of condensate was absorbed by the towel. Then, using the previous mass of the towel and mass after collection the residual droplet mass could be collected. To prevent interaction between the condensate and the atmosphere (i.e. evaporation), a density reading was taken within a minute after the condensate mass was collected. The density was recorded using the handheld density meter. The density meter also incorporated a thermocouple allowing the user to correspond temperature with density reading. Once the density was measured at $24^{\circ} \mathrm{C}\left(75^{\circ} \mathrm{F}\right)$, this value was implemented into an empirical calculator that produced the mass fraction of methanol within the condensate. The mass fraction was calculated from the density, as shown in Equation 2, and was verified for this study with empirical data. Using the methanol mass fraction $\left(\mathrm{Y}_{\mathrm{CH}} \mathrm{OH}\right)$ and the mass on condensate allowed for calculation of $\mathrm{CH}_{3} \mathrm{OH}_{\text {output, }}$ which subsequently was used for calculating percent conversion with Equation 1.

$$
Y_{\text {СН } 3 \mathrm{OH}}=3859.9 \cdot \rho^{2}-8231.1 \cdot \rho+4370.0
$$

Equation 2

\section{ATR Reactor Design and Construction}

The ATR reactor is complete and has been tested using catalyst from an automobile catalytic converter as well as proprietary autothermal catalyst. The reactor includes 12 ports along the side of the reactor for measuring temperature and/or pressure. 4 different end caps were manufactured for versatility in testing (see Figure 6 below).

The catalyst housing is a $3.81 \mathrm{~cm}(1.5 \mathrm{in})$ diameter Schedule 40 pipe of $30 \mathrm{~cm}$ (12in) in length. The 12 thermocouple ports are placed in two rows of 6 on opposite sides of the reactor at a spacing of $5.08 \mathrm{~cm}$ (2in). There is a $1 / 4$ " NPT fitting on the front of the housing that will adapt to a dynamic pressure transducer. Five $400 \mathrm{~W}$ mineral insulated, nozzle band heaters wrap around the catalyst housing to supply any necessary heat. 


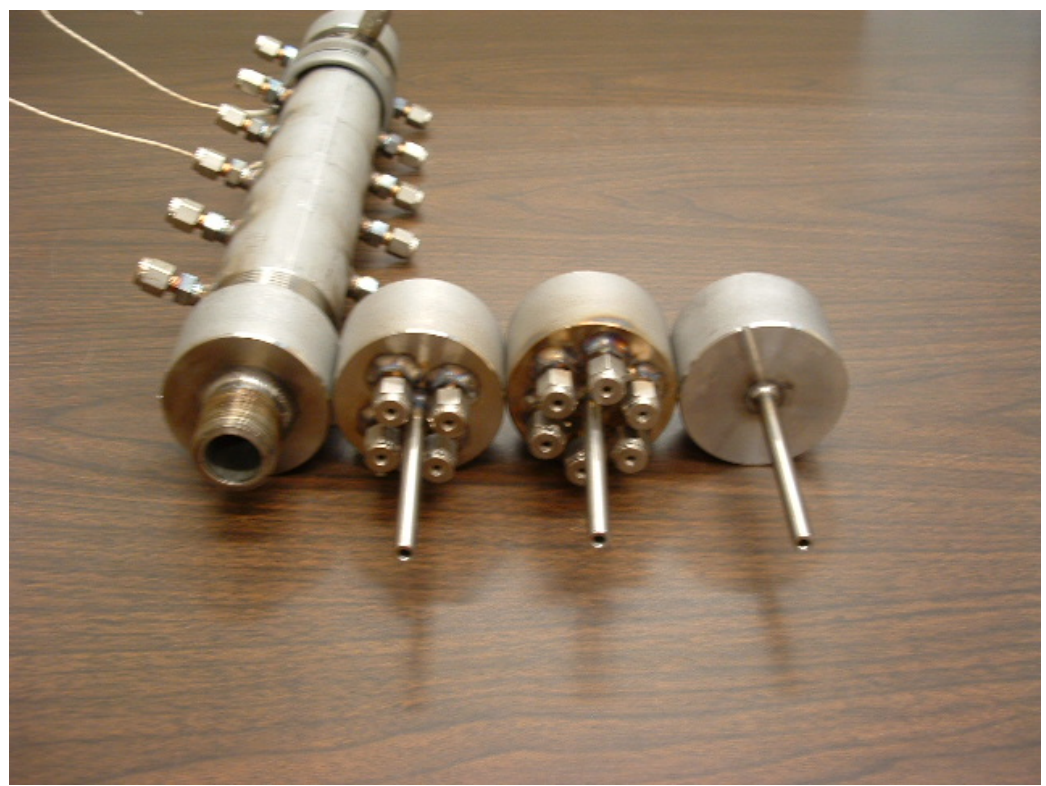

Figure 6: ATR reactor and 4 different end caps (from left to right: acoustic adapter, 4-thermocouple ports, 6-thermocouple ports, regular connection end cap).

The initial air heater for the air supply subsystem was completed. The air heater was originally fitted with a $12.7 \mathrm{~cm}(5 \mathrm{in}), 400 \mathrm{~W}$ cartridge heater which proved insufficient for heating air to $300^{\circ} \mathrm{C}\left(572^{\circ} \mathrm{F}\right)$. Therefore a $24.1 \mathrm{~cm}(9.5 \mathrm{in}), 525 \mathrm{~W}$ cartridge heater was installed for better performance. The air heater pipe was also filled with $.49 \mathrm{~mm}(1 / 8 \mathrm{in})$ aluminum rod that was cut into small, $\sim 5 \mathrm{~mm}(1 / 8 \mathrm{in})$, lengths to aid in heat transfer. After weeks of successful use a severe pressure drop was noticed at the air heater exit. Upon inspection it was discovered that the aluminum particles had melted and clogged the exit. An industry designed and tested, air heater has been ordered as a replacement. To meter the air supply two mass flow controllers (MFC) have been tested and are operational. The low range MFC has a flowrate capacity of 0-1 SLPM, and the high range MFC has a flowrate capacity of 0-10 SLPM. The air clean up and drying unit has been delivered and incorporate into the existing compressed air infrastructure in the laboratory.

For the static pressure monitoring of the autothermal reactor, water-cooled pressure transducer has been donated to support this research. This water-cooled pressure transducer can handle high temperature gas up to $700{ }^{\circ} \mathrm{C}\left(1292^{\circ} \mathrm{F}\right)$ and is able to monitor the high temperature steam reformate inside the reactor.

Also, a High-Speed Voltage Output board and a Shielded Connector Block were purchased. This 8 channels analog voltage output board is used to send the commanding signals of 2 micro gear pumps, 2 air flow meters, and also the exciting voltage of the pressure transducer. It left three extra channels, which allows expending the whole system for further use.

Data has been collected for catalyst bed configurations varying from one, $6.35 \mathrm{~mm}$ (0.25in) length monolithic catalyst section to six, stacked $6.35 \mathrm{~mm}(0.25 \mathrm{in})$ sections for a total catalyst bed length of approximately $38.1 \mathrm{~mm}$ (1.5in). A single $38.1 \mathrm{~mm}$ (1.5in) 
monolithic catalyst was also tested to observe the effects of stacking the $6.35 \mathrm{~mm}(0.25 \mathrm{in})$ length catalyst sections. For each catalyst configuration, the oxygen-to-carbon ratio was varied from 0.10 to 0.40 to investigate the effects on conversion and reactor efficiency. It was found that fuel conversion and reactor efficiency have little or no dependence on catalyst bed length, at the tested flowrate, while $\mathrm{O}_{2} / \mathrm{C}$ greatly affects both conversion and efficiency. Preliminary testing will continue with fuel cell grade methanol and various catalysts. Operating procedures for the ATR reactor are in progress and nearly complete.

A draft of a paper being written for the ASME conference, International Mechanical Engineering Conference and R\&D Expo, titled "Preliminary Modeling and Design of an Autothermal Reformer" has been finished and was submitted on April $30^{\text {th }}$.

\section{Thermal Profile Experiments}

Thermal profile measurements elucidate the limiting factors in reactor design, can be used to diagnose catalyst degradation and offer insight into the effectiveness of reactor design changes. Recent work has identified conduction of heat down the axial thermocouple sheath as a significant source of error in thermal profile measurements. Sheath conduction causes the thermocouple measurements to deviate from the true gas temperature when large radial thermal gradients exist. Large thermal gradients can exist in small diameter reformer reactors and these thermal gradients increase with increasing flow rate and increasing reaction rate.

Using standard $0.0025 \mathrm{~mm}(1 / 16 \mathrm{in})$ thermocouple probes the sheath conduction effect was measured by traversing the probe tip all the way from the opposite wall of the reactor to the near wall of the reactor, see Figure 7. Differences in the measurements on the far side if the reactor and the near side of the reactor are caused by sheath conduction. On the far side of the reactor the true gas temperature is higher than the measured temperature due to sheath conduction away from the hot region near the wall towards the cooler centerline of the reactor. On the near side of the reactor the true gas temperature is lower than the measured temperature due to sheath conduction from the hot region near the wall towards the cooler centerline of the reactor. Very close to the near wall the true gas temperature is most likely higher than the measured temperature due to sheath conduction away from the hot region along the inside wall to the cooler region inside the thermocouple port. 


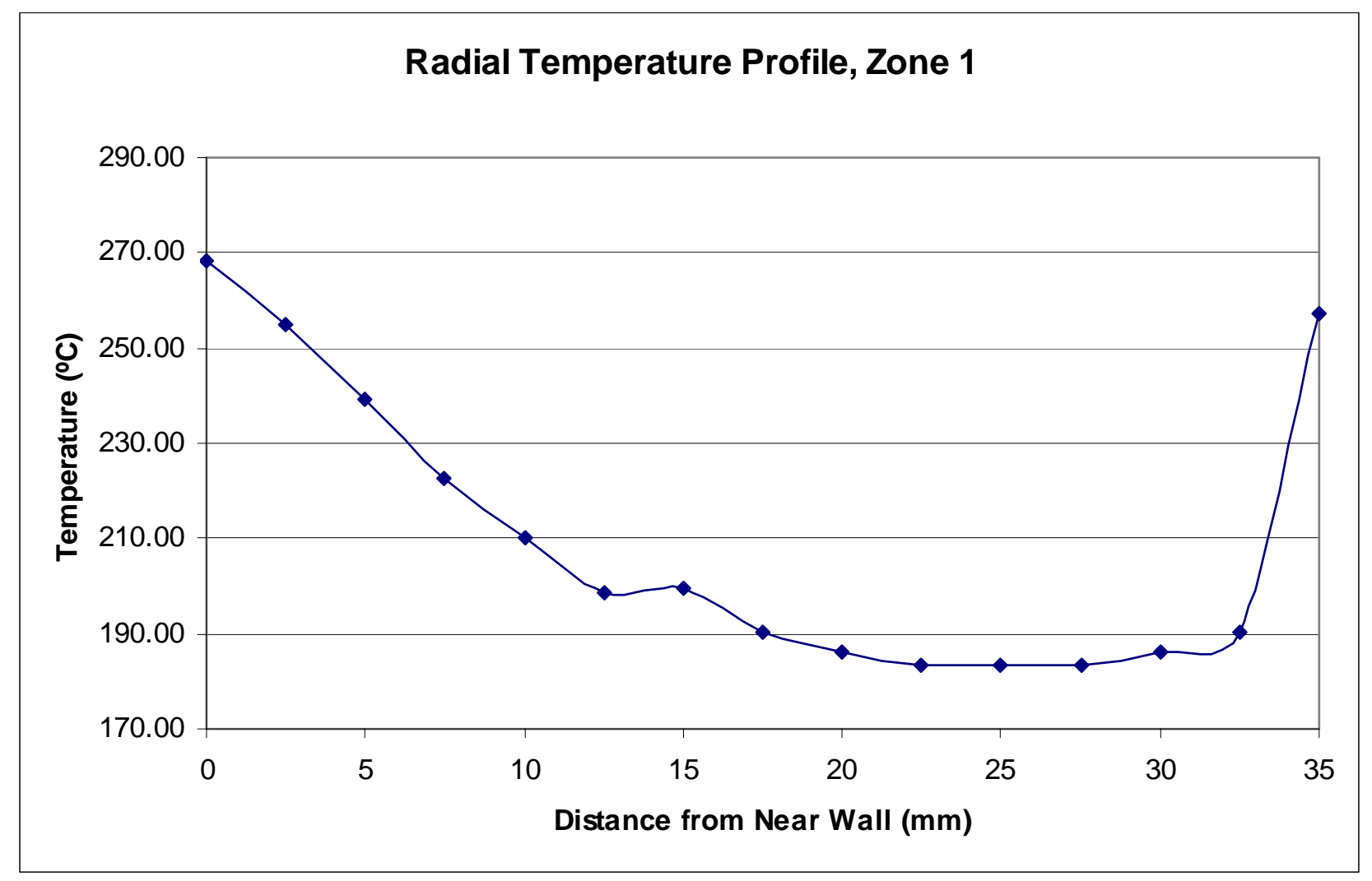

Figure 7 : Radial Temperature Profile of the full diameter of the reactor. Differences between the near side and far side are partly caused by sheath conduction.

Strategies were developed for reducing the axial conductivity of the thermocouple probes including using ceramic sheath materials or using very fine gage thermocouple probes. The ceramic sheath materials proved to be too brittle for the traverse technique and were deemed impractical. The use of fine gage thermocouples is complicated by their low flexural strength. Protecting the fine gage thermocouples with a thermally isolated support tube is the current iteration in this development process. The fine gage thermocouples are inserted into stainless steel support tubes and the support tube is then filled with a thermally insulating ceramic adhesive. A one half inch section of bare thermocouple wire protrudes from the support tube inside the reactor allowing the higher surface to cross-sectional area of the smaller probe to greatly reduce the effects of sheath conduction.

\section{Catalysts Degradation}

Catalyst degradation research must be performed to validate the compatibility of coalderived methanol with fuel cell applications. Copper based catalysts which have been used for this experiment can be deactivated by sulfur and chloride poisoning, thermal sintering, fouling (i.e. coke formation), and physical damage such as attrition caused by vibration and crushing. Furthermore, different phase reaction (i.e. vapor-solid reaction) might be responsible for catalyst degradation [12,13,14,15]. Some researchers suggest 
formation of formaldehyde as by-product might deactivate copper based catalysts [14]. Additionally, copper based catalyst without substrates show weakness in thermal sintering, fouling and physical damage. However, copper based catalysts with substrates and/or sacrificial elements can be resistive to the degradation causes mentioned above. For example, Zinc can remove sulfur by means of forming Zinc Sulfide to protect the copper catalyst.

External analysis of the coal derived methanol shows lower levels of sulfur, increased levels of petroleum hydrocarbons and extremely high chloride levels as compared to fuel cell grade methanol (see external methanol analysis section). The potential of coal based methanol as a source of hydrogen is dependant on the effect of these contaminants on the steam reformation catalyst. Catalyst degradation rates for fuel cell grade methanol and coal based methanol are being measured using the hysteresis technique. A comparison of the rates of degradation will determine the severity of the effect of the higher contaminant levels in the coal based methanol. In order to prioritize the importance of reducing specific kinds of contamination we must understand not only the total amount of catalyst degradation but also the type of degradation that is occurring categorized as poisoning, fouling and sintering. As discussed above poisoning of copper based catalysts can be caused by chloride and sulfur containing compounds. Fouling can be caused by condensation of low volatility hydrocarbons or by solid carbon deposition on catalyst surfaces. Sintering can be caused by hot spots and temperature gradients in the reactor. The catalyst degradation project aims to characterize the catalyst materials in order to develop a means of identifying the dominant type of degradation when using coal derived methanol. The first stage of the project has been to identify analytical techniques and tools to characterize the catalysts. The following list of techniques have been identified as potential candidates and are available on the UC Davis campus.

Analysis Techniques:

- SEM: Scanning Electron Microscopy to measure surface changes

- SEM/EDS: Electron Dispersive Spectroscopy to identify atomic species on the surface

- XRD: X-Ray Diffraction to identify solid solution alloy formation and to measure particle growth caused by sintering

- BET: to measure surface area which could be affected by sintering or fouling of the catalyst

- XPS: X-Ray Photoelectron Spectroscopy to identify and quantify the concentration of catalyst poisons in trace quantities on the catalyst surface

- Mercury Porosymetry: to measure pore volume and pore size distribution

- Light Microscopy: characterize surface

Temperature gradient (See Figure 8) inside the reactor can be caused by heat and mass transfer limitation as well as difference of response time due to power demand during the process of producing hydrogen throughout the reactor. However, either catalyst degradation or secondary reaction inside the reactor might be stirred up by temperature gradient inside the reactor. Figure 8 shows heat flow and expected resulting reactor temperatures in a steam reformer. 


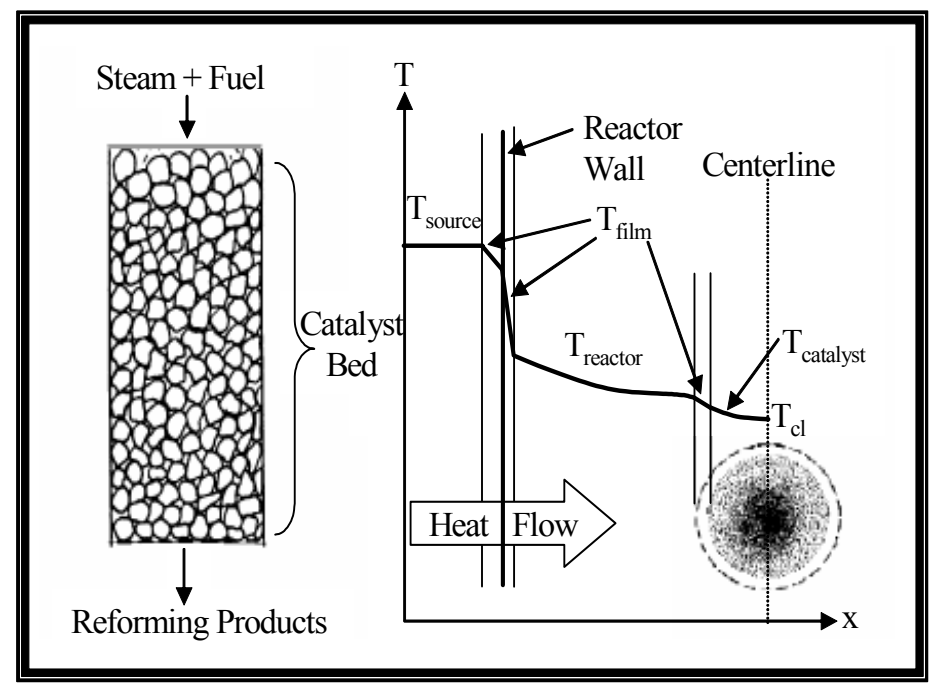

Figure 8: Heat flow and expected resulting reactor temperatures in a steam reformer.

Temperature gradient inside the reactor could be minimized by means of another heat source from the center of reactor. On the other hand, reactor volume could be smaller than the other reactors due to internal cartridge heater so that secondary reaction pathway (i.e. unexpected by-product), which could happen due to temperature gradient inside the reactor, should be reduced. Both preconditions could be sufficient for evaluation of different types of fuels in terms of catalyst degradation and fuel efficiency. Consequently, an internal cartridge heater in the center of the reactor can meet the requirements to evaluate fuel quality as well as investigate catalyst degradation to compare coal-derived methanol with chemical grade methanol.

Catalyst degradation tests have been performed for both coal-derived methanol as well as chemical grade methanol for 70 hour durations each using reactor C. 39g (0.0861b) of crushed catalyst for each experiment was loaded inside reactor $\mathrm{C}$, and three degradation tests for both grades of methanol were performed in order to shrink the uncertainty of the degradation results. Each experiment was performed using the same measurement time intervals (data points), same temperature set-point, same reduction time (3 hours), and same space velocity to minimize the hidden variables in the measurement of degradation. Those conditions should be kept not only to reduce the variable of degradation but also to evaluate only fuel quality itself.

First of all, catalyst degradation would not be expected during the first 24 hours, so an initial data point interval was selected to be 3 hour increments for this period. After 24 hours, the data point interval was decreased to every 2 hours, which is the smallest time interval for our degradation test. Furthermore, after 24 hours, greater catalyst degradation is expected, so it is desired to minimize the amount of data points representing the first 24 hours. 
Table 1: Temperature Set-Point Matrix for Reactor C.

\begin{tabular}{|c|c|c|c|c|}
\hline Location & $\begin{array}{c}\text { Temperature } \\
\text { Set-Point }\end{array}$ & $\mathrm{dT} / \mathrm{dt}\left({ }^{\circ} \mathrm{C} / \mathrm{s}\right)$ & Location & $\begin{array}{c}\text { Max Time } \\
\text { On(\%) }\end{array}$ \\
\hline Vaporizer 1Surface & 220 & 5 & Vaporizer 1 & 7 \\
\hline Vaporizer 1Exit & 325 & 20 & Vaporizer 2 & 6 \\
\hline Vaporizer 2 Surface & 290 & 5 & Vaporizer 3 & 5 \\
\hline Vaporizer 2 Exit & 295 & 1.9 & Superheater 1 & 7 \\
\hline Vaporizer 3 Surface & 267 & 5 & Superheater 2 & 7 \\
\hline Vaporizer 3 Exit & 280 & 1 & Superheater 3 & 7 \\
\hline Superheater Interior & 290 & 3 & Superheater 4 & 7 \\
\hline Superheater Exit & 255 & 3 & Zone 1 Heat Band & 3 \\
\hline Superheater Surface & 270 & 1 & Zone 2 Heat Band & 3 \\
\hline Zone 1 Surface & 280 & 3 & Internal Cartridge Heater & 1 \\
\hline Zone 1 Exit Right & 275 & 1 & & \\
\hline Zone 2 Surface & 280 & 3 & & \\
\hline Zone 2 Exit Right & 275 & 1 & & \\
\hline Internal Cartridge Heater & 244 & 1 & & \\
\hline
\end{tabular}

The temperature set-point should always be identical for every degradation test. Table 1 displays the temperature set-point matrix for reactor $\mathrm{C}$, which has been adapted for degradation tests. Moreover, as already mentioned in a previous report, $\mathrm{Cu} / \mathrm{Zn} / \mathrm{Al}_{2} \mathrm{O}_{3}$ catalyst should be reduced by means of a hydrogen gas mixture comprised mostly of nitrogen gas for safety. This takes the catalyst from $\mathrm{CuO}$ to $\mathrm{Cu}$ to make it activate with methanol-water premix gas. As usual, this chemical process is a totally exothermic reaction. In addition, the process of reduction might be time-dependent which means it could be one of unreliability for degradation tests. If the $\mathrm{Cu} / \mathrm{Zn} / \mathrm{Al}_{2} \mathrm{O}_{3}$ catalyst is not fully reduced, it would be one of the reasons for greater degradation of the catalyst. With regards to reduction time, a 3 hour reduction time was chosen because there was no detectible temperature fluctuation after the premix gas flow was introduced into the reactor. If there exits non-reduced copper oxide inside the reactor, there would have been a noticeable temperature fluctuation once the methanol premix was introduced. Finally, a packing density of $0.101 \mathrm{~g} / \mathrm{cm}^{3}\left(0.00365 \mathrm{lb} / \mathrm{in}^{3}\right)$ and a space velocity of $2.5 \mathrm{~s}^{-1}$ was selected for the degradation tests.

\section{Conversion of Coal-derived and Chemical Grade Methanol}

This test was performed based on different space velocities during steady-state operation. Figure 9 shows percent conversion of both coal-derived and chemical grade methanol using reactor A. The coal-derived methanol shows a slightly higher conversion compared to chemical grade methanol based on a different density equation. This could be due to the amount of different hydrocarbon compounds in methanol. Coal-derived methanol has a slightly larger amount of hydrocarbons than does chemical grade methanol, which might affect the overall percent conversion of methanol. Through an error analysis based on standard deviation it was seen that the percent conversion of both methanols could be same. 


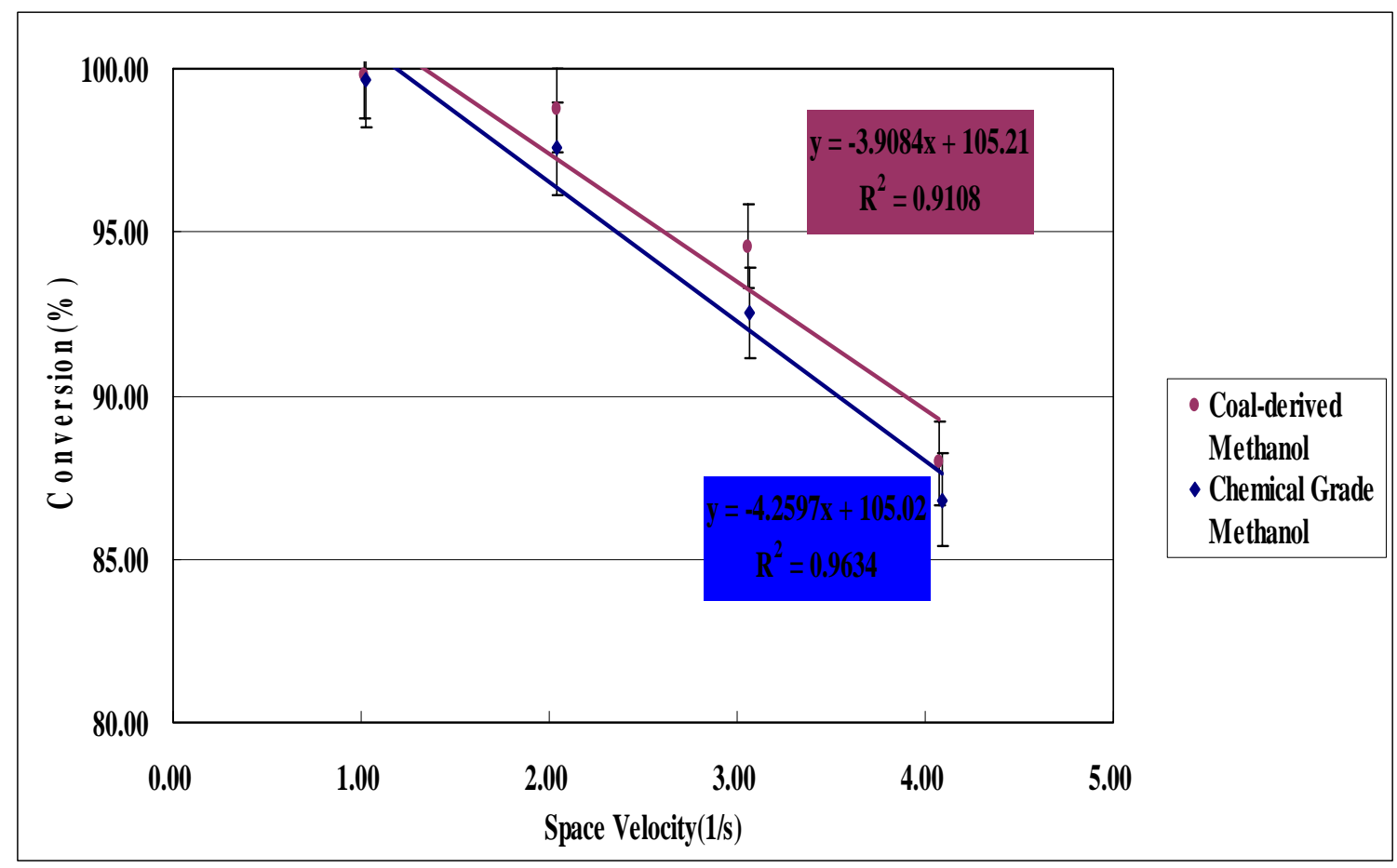

Figure 9: Conversion of coal-derived and chemical grade methanol.

\section{Steam Reformation Enhancement Methods}

In a steam reforming process, heat transfers between reformate species and the heat source can deeply affect the performance of the reaction. Changing the flow pattern and extending the residence time of the reformate inside the catalyst bed are expected to improve the heat transfer and decrease the temperature gradient inside the reactor. Placing bluff bodies inside the reformate pathways of the two steam-reforming reactors is expected to achieve this result. In this study, we designed one bluff body structure composing of a disk and a ring to form a package. The material of the bluff body is made of 316 stainless steel metal plates, which is the same material as the reactor. Two sizes of bluff body structures were made to fit for two reactor dimensions. [For Reactor A, the disk diameter is $1.27 \mathrm{~cm}(0.5 \mathrm{in})$; I.D. of the ring is $1.27 \mathrm{~cm}(0.5 \mathrm{in})$, and its O.D. is $2.075 \mathrm{~cm}(0.817 \mathrm{in})$. For Reactor B, the disk diameter is $2.54 \mathrm{~cm}$ (1.0in); ring: I.D. of the ring is $1.905 \mathrm{~cm}(0.75 \mathrm{in})$, and its O.D. is $3.475 \mathrm{~cm}(1.368 \mathrm{in})]$. The thickness dimensions of the two bluff body sizes are both $.6096 \mathrm{~mm}(0.024 \mathrm{n})$. Pictures of the two sizes of bluff body structures are shown in Figure 10 and Figure 11. A schematic of bluff body placement inside reactor B is shown in Figure 12. 


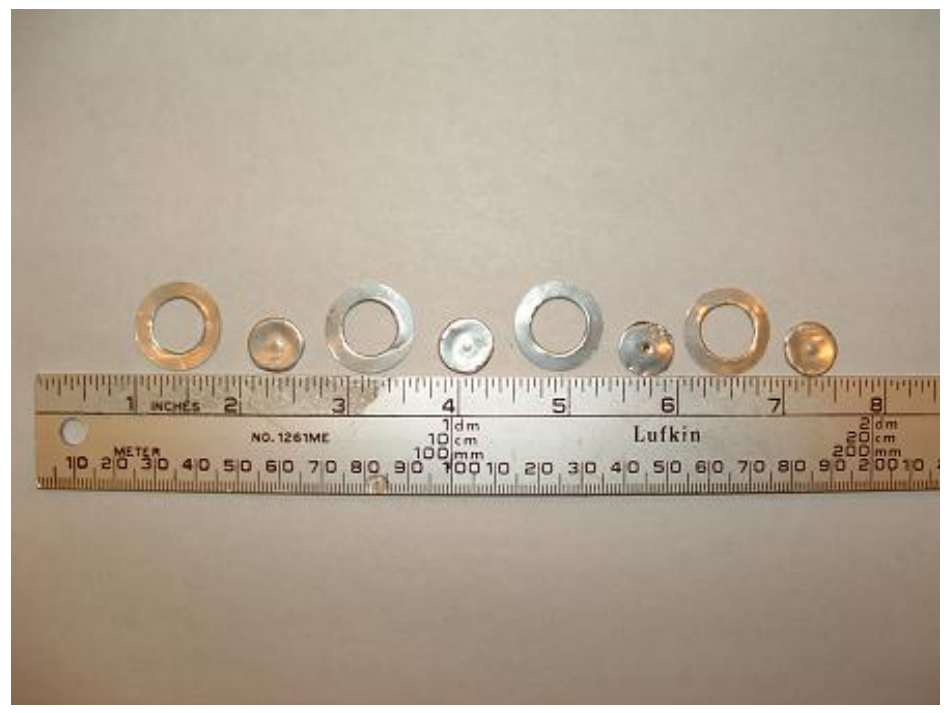

Figure 10: Bluff body structures for Reactor A.

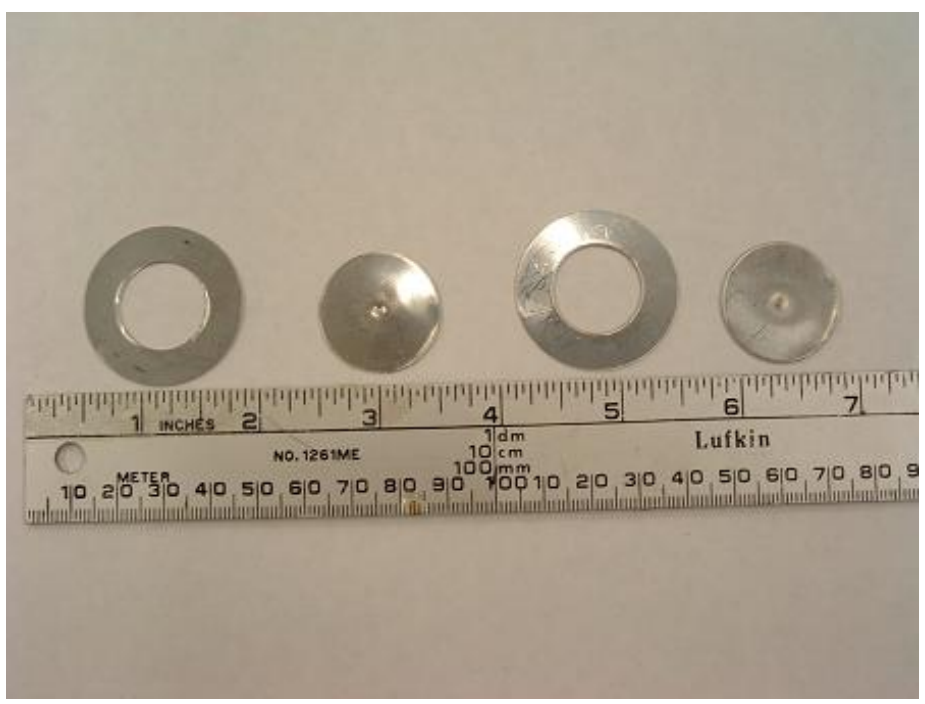

Figure 11: Bluff body structures for Reactor B. 


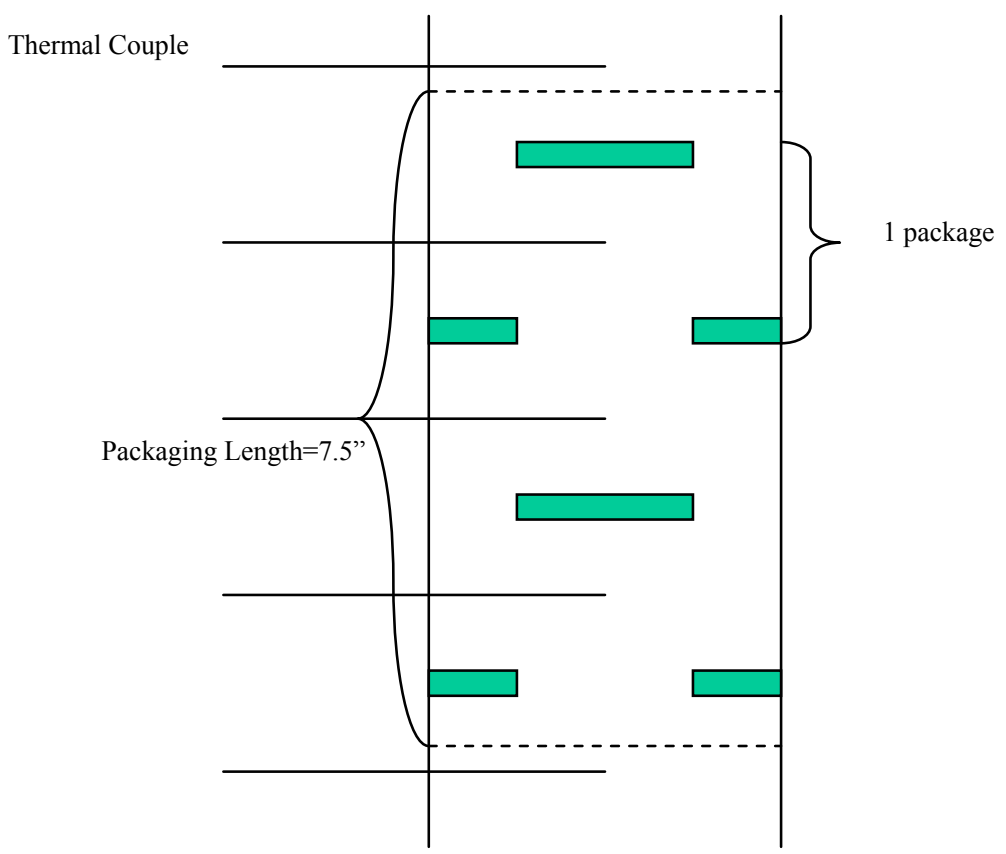

Figure 12: Cross section of bluff body arrangement inside Reactor $B$.

\section{Experiment method}

This bluff body enhancing investigation has been completed. The investigation method was based on a $2^{3}$ factorial experiment design. This $2^{3}$ factorial experiment design gave the ability to analyze the effect of bluff bodies' package density on a steam reforming process combined with space velocity and catalyst dimension interactions. This study used reactor $B$ as a base reactor to investigate the effect of bluff bodies, and utilized chemical grade methanol as the fuel in steam reforming reaction, initially. Coal based methanol will be used in a future study to test the catalyst degradation for a period of running time and give a comparison with one using chemical grade methanol.

In this factorial experiment design, three factors including bluff body package density, catalyst dimension and flow rate (space velocity) were chosen as three independent variables. Methanol fuel conversion was chosen as the dependent variable and statistically investigated to analyze the effects and interactions of the three factors on the steam reforming process. These three factors were set at high and low levels respectively to run the factorial experiment and see the effect on methanol fuel conversion.

Table 2 lists the independent variable factors and their corresponding levels in factorial experiment. Table 3 shows the experiment matrix and the run order. The experiment run order was randomly arranged to decrease unknown effects on the experiment results such as catalyst degradation. 
Table 2: Factors and Levels 1.

\begin{tabular}{lcc}
\multicolumn{1}{c}{ Factors (inputs) } & Low level: $(-)$ & High level: $(+)$ \\
\hline X1 (Flow rate) & $5 \mathrm{ml} / \mathrm{min}(1.0$ LHSV-M) & 20 $\mathrm{ml} / \mathrm{min}(4.0 \mathrm{LHSV}-\mathrm{M})$ \\
$\mathrm{X}$ (Catalyst dimension) & Crushed [0.25 cm & Pelletized [0.47 cm ( \\
& $(0.098 \mathrm{in})]$ & $0.185 \mathrm{in})]$ \\
$\mathrm{X} 3$ (Package density) & 2packs & 8 packs
\end{tabular}

Table 3: Experiment Design.

\begin{tabular}{|c|c|c|c|c|c|c|c|}
\hline & \multicolumn{3}{|c|}{ Code Value } & \multicolumn{3}{c|}{ Run Order } & $\begin{array}{c}\text { Degrees of } \\
\text { Freedom }\end{array}$ \\
\hline $\begin{array}{c}\text { Run (Exp. } \\
\text { Config.) }\end{array}$ & $\begin{array}{c}\text { X1 } \\
\text { Rate } \\
\text { Rate }\end{array}$ & $\begin{array}{c}\text { Catalyst } \\
\text { Dimension }\end{array}$ & $\begin{array}{c}\text { X3 } \\
\text { Package } \\
\text { Density }\end{array}$ & \multicolumn{3}{c|}{ Tot: 24 run } & V=r-1 \\
\hline (1) $2 \mathrm{P}$ & - & + & - & 1 & 4 & 6 & 2 \\
\hline (2) $8 \mathrm{P}$ & - & + & + & 21 & 20 & 23 & 2 \\
\hline (3) $2 \mathrm{P}$ & + & + & - & 2 & 3 & 5 & 2 \\
\hline (4) $8 \mathrm{P}$ & + & + & + & 22 & 24 & 19 & 2 \\
\hline (5) $2 \mathrm{C}$ & - & - & - & 18 & 13 & 16 & 2 \\
\hline (6) $8 \mathrm{C}$ & - & - & + & 7 & 10 & 11 & 2 \\
\hline (7) $2 \mathrm{C}$ & + & - & - & 15 & 17 & 14 & 2 \\
\hline (8) $8 \mathrm{C}$ & + & - & + & 12 & 8 & 9 & 2 \\
\hline
\end{tabular}

From the factorial experiment results, a conversion model was developed to predict conversion using the independent variables as inputs. To verify the accuracy of the model, and investigate more about bluff body package densities' effects, further data points were taken. These data points included zero packages, four packages and six packages with crushed and pelletized catalyst respectively. A total of ten experiment configurations were taken for the entire study. They are tabulated in Table 4. 
Table 4: Total experiment configurations .

\begin{tabular}{|c|c|c|c|}
\hline $\begin{array}{c}\text { Experiment } \\
\text { Config. }\end{array}$ & $\begin{array}{c}\text { Flow Rate: } \\
(\mathrm{ml} / \mathrm{min})\end{array}$ & $\begin{array}{c}\text { Catalyst } \\
\text { Dimension: } \\
(\mathrm{mm})\end{array}$ & $\begin{array}{c}\text { Pack } \\
\text { Number: (\# } \\
/ 7.5 \text { in. })\end{array}$ \\
\hline $2 \mathrm{P}$ & $5,10,15,20$ & Pelletized & 2 \\
\hline $4 \mathrm{P}$ & $5,10,15,20$ & Pelletized & 4 \\
\hline 2C & $5,10,15,20$ & Crushed & 2 \\
\hline $8 \mathrm{P}$ & $5,10,15,20$ & Pelletized & 8 \\
\hline $8 \mathrm{C}$ & $5,10,15,20$ & Crushed & 8 \\
\hline 6P & $5,10,15,20$ & Pelletized & 6 \\
\hline 4C & $5,10,15,20$ & Crushed & 4 \\
\hline 6C & $5,10,15,20$ & Crushed & 6 \\
\hline 0P & $5,10,15,20$ & Pelletized & 0 \\
\hline 0C & $5,10,15,20$ & Crushed & 0 \\
\hline & & & \\
\hline & & & 6 \\
\hline
\end{tabular}




\section{RESULTS AND DISCUSSION}

The following section presents results from the reporting period from the following areas: external evaluation of methanol, internal evaluation of methanol, sample results from steam reformation, coal-derived methanol and water solution calibration, preliminary autothermal reformation of fuel cell grade methanol, thermal profile experiments, catalyst degradation, and steam reforming enhancement methods.

\section{External Evaluation of Methanol}

STL-Mobile used different methods to measure the sulfur content for the $1^{\text {st }}$ and $2^{\text {nd }}$ rounds of the external analysis. Table 6 shows coal-derived methanol has $20 \mathrm{mg} / \mathrm{kg}$ more chloride than fuel cell grade methanol rather than $15850 \mathrm{mg} / \mathrm{kg}$ more chloride as shown in Table 5.

Table 5: $1^{\text {st }}$ round External Analysis of Coal-Derived Methanol and Fuel Cell Grade Methanol.

\begin{tabular}{|l|l|l|}
\hline & $\begin{array}{l}\text { Coal-derived } \\
\text { Methanol }\end{array}$ & $\begin{array}{l}\text { Fuel cell grade } \\
\text { Methanol }\end{array}$ \\
\hline Ethanol(mg/l) & $<8000$ & $<8000$ \\
\hline Methanol(mg/l) & 740000 & 750000 \\
\hline Water $(\%)$ & $0.02 \%$ & $0.11 \%$ \\
\hline $\begin{array}{l}\text { Total } \\
\text { Hydrocarbon(mg/l) }\end{array}$ & 17 & 5.9 \\
\hline Chloride(mg/kg) & 16000 & 150 \\
\hline Sulfur(mg/kg) (ASTM-D-129-64) & 112 & 298 \\
\hline
\end{tabular}

Table 6: $2^{\text {nd }}$ Round External Analysis of Coal-Derived Methanol and Fuel Cell Grade Methanol.

\begin{tabular}{|l|l|l|}
\hline & $\begin{array}{l}\text { Coal-derived } \\
\text { Methanol }\end{array}$ & $\begin{array}{l}\text { Fuel cell grade } \\
\text { Methanol }\end{array}$ \\
\hline Chloride(mg/kg)(EPA 352.2) & 410 & 390 \\
\hline Sulfur(mg/kg) (EPA 375.4) & $<170$ & $<170$ \\
\hline
\end{tabular}

\section{Internal Evaluations of Methanol}

Nuclear Magnetic Resonance (NMR) spectroscopy Test

There were two peaks in coal based methanol spectroscopy. One peak from around 3.3 ppm is methanol and another peak around $4.8 \mathrm{ppm}$ is deuterated water solvent. NMR detection limit is relatively low compared with Liquid Chromatography/Mass Spectrometer (LC/MS) and Gas Chromatography/Mass Spectrometer (GC/MS). There 
are two peaks in NMR spectroscopy of fuel cell grade methanol which is same peak with coal-derived methanol. One peak from around $3.3 \mathrm{ppm}$ is methanol and another peak around $4.8 \mathrm{ppm}$ is deuterated water. Compared coal derived methanol to fuel cell grade methanol, there are no differences between coal-derived methanol and fuel cell grade methanol by means of NMR. Consequently, the NMR analysis method is not sufficient for our methanol analysis because it couldn't detect low concentration impurities in both methanols. Even though there are methods to increase the impurity concentrations to allowable detection by NMR, such as solid phase extraction and evaporation, those methods would require a large amount of methanol.

Liquid Chromatography-Mass Spectrometer (LC-MS) Test

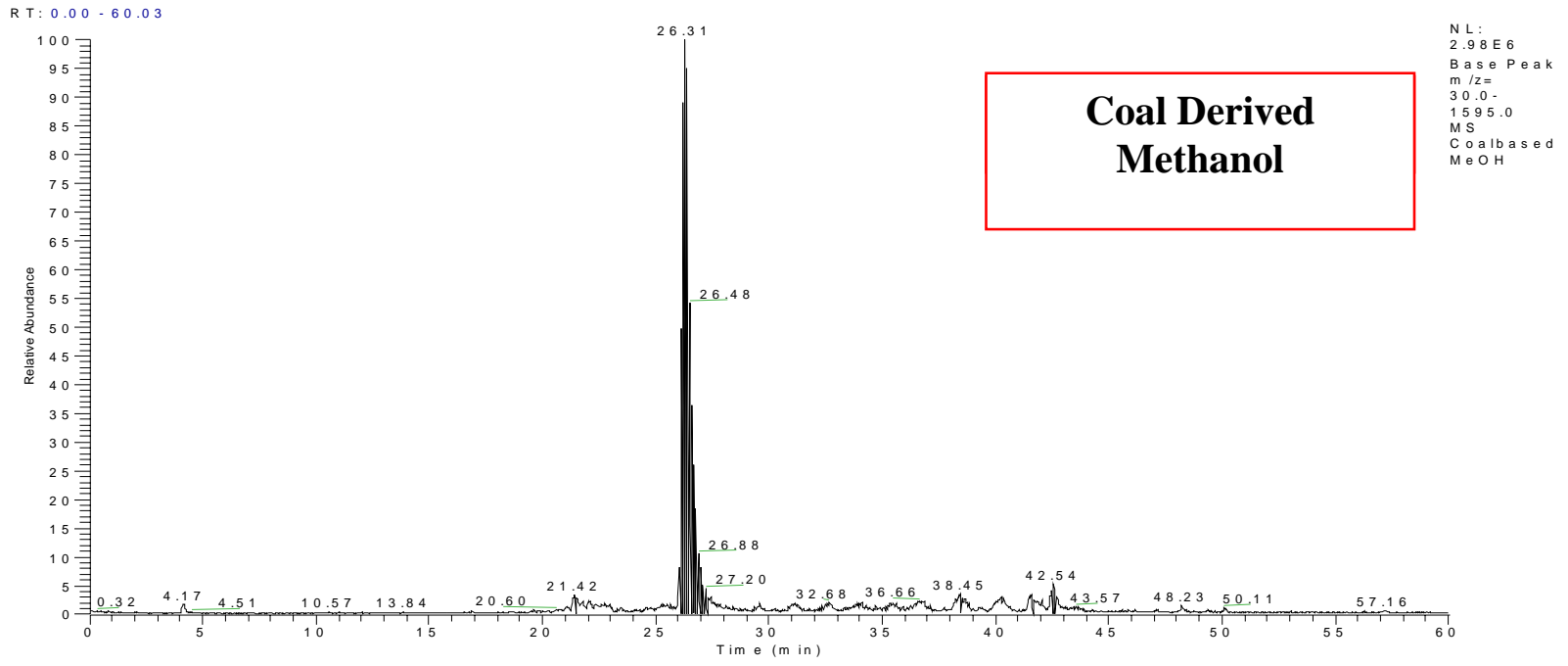

Figure 13: LC-MS time trace of Ionization for Coal-derived Methanol.

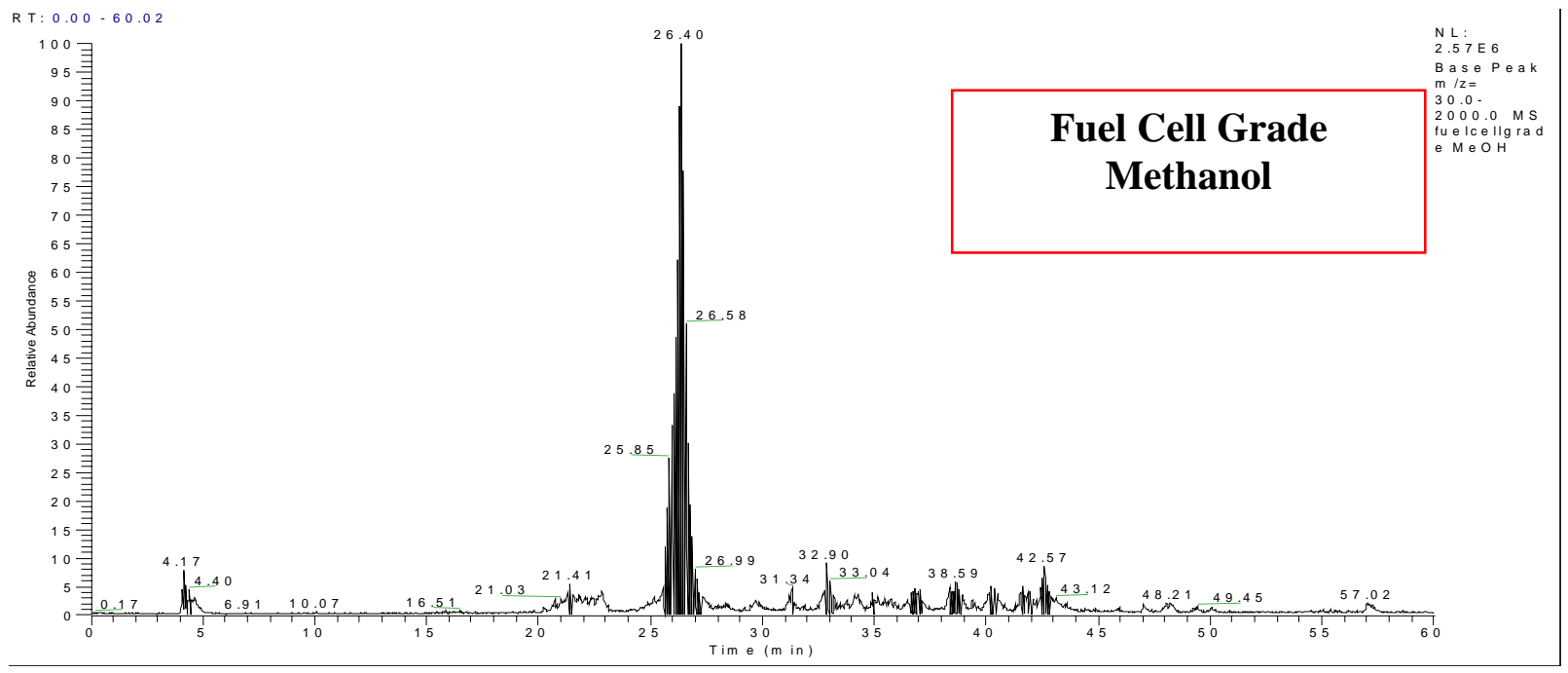

Figure 14: LC-MS time trace of Ionization for Fuel Cell Grade Methanol 
The above graphs represent ionized fraction compounds in methanol impurities. To begin with, C18 polar column was used which is usually applicable for huge molecular weight protein. The molecular weights of impurities we found using LC-MS are over $500 \mathrm{~g} / \mathrm{mol}$ (i.e. higher hydrocarbon) responded by characteristic of column. However, LC-MS can not fully analyze impurity compounds so elementary chemical analysis, Infrared (IR) Spectroscopy, increasing concentration and GC-MS might be needed.

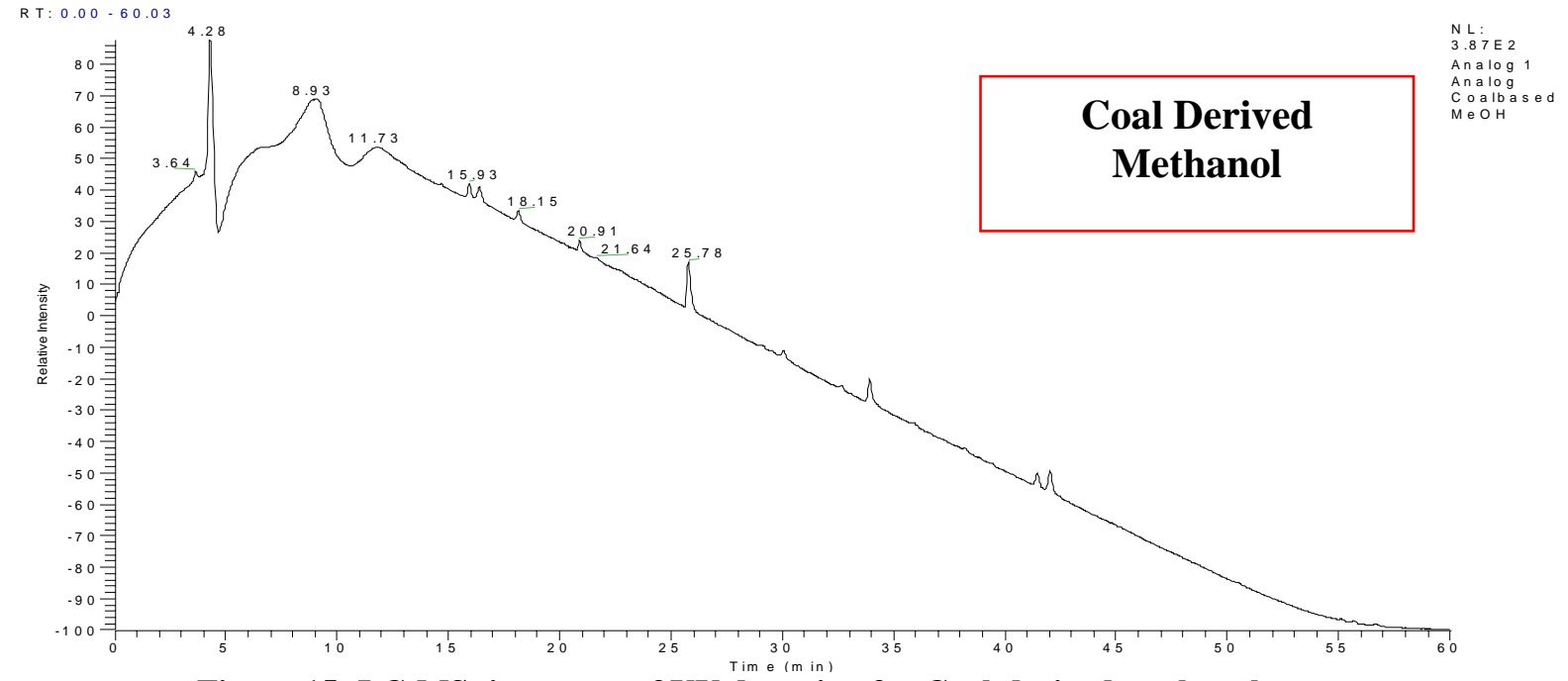

Figure 15: LC-MS time trace of UV detection for Coal-derived methanol.

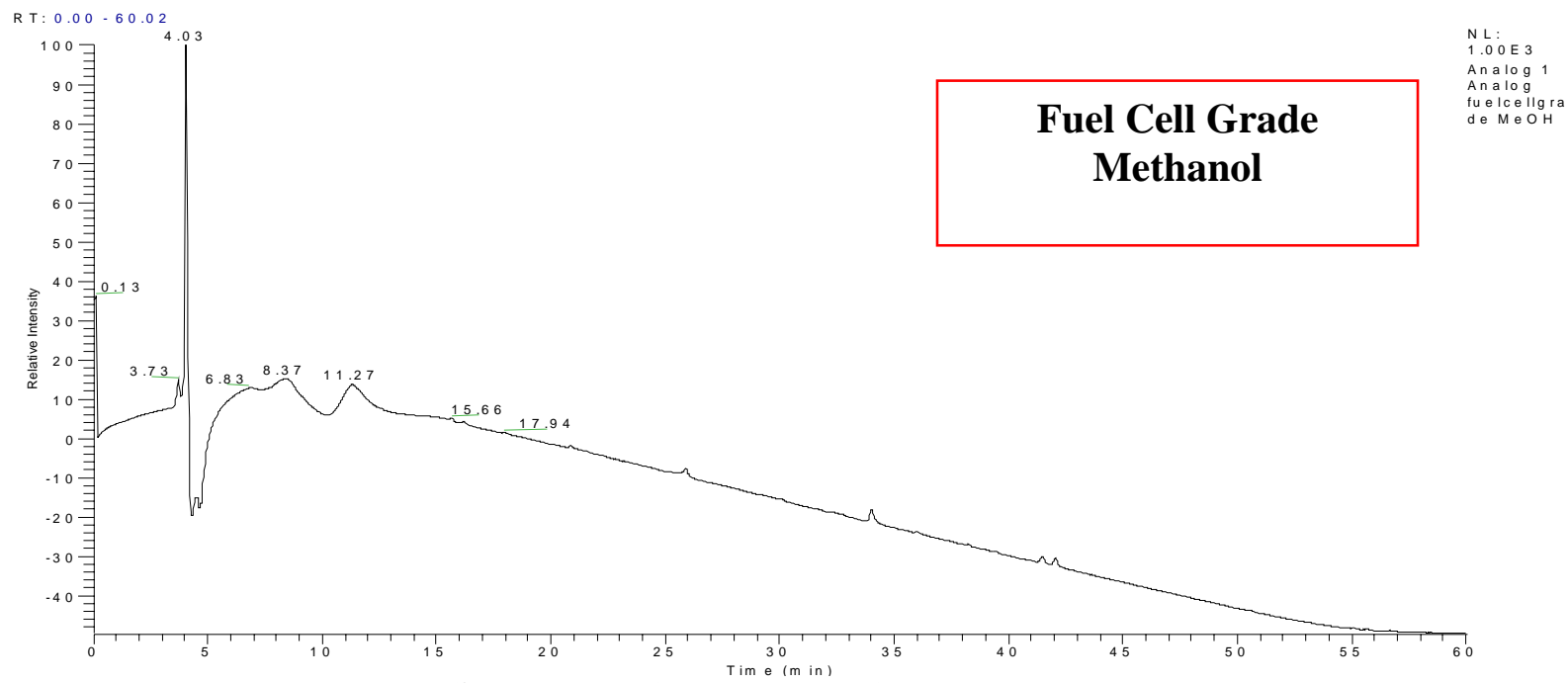

Figure 16: LC-MS time trace of UV detection for Fuel Cell Grade Methanol.

Figure 15 and Figure 16 represents UV detection corresponded by both compounds and ionization over both coal derived methanol and fuel cell grade methanol.

Consequently, there are many spectrograph candidates for above those higher hydrocarbon compounds corresponded by mass spectrograph. Obviously, coal-derived 
methanol and fuel cell grade methanol have the same higher hydrocarbons. Even though LC-MS results indicate there are differences between fuel cell grade methanol and coalderived methanol, it is hardly possible to find out which compounds are in both methanols only using mass spectrograph.

Gas Chromatography-Mass spectrometer (GC-MS)

Figure 17 and Figure 18 represent overall GC-MS time trace both coal-derived methanol and fuel cell grade methanol. What was found by GC-MS test were different types of higher hydrocarbon that might have chloride, sulfur or silane.

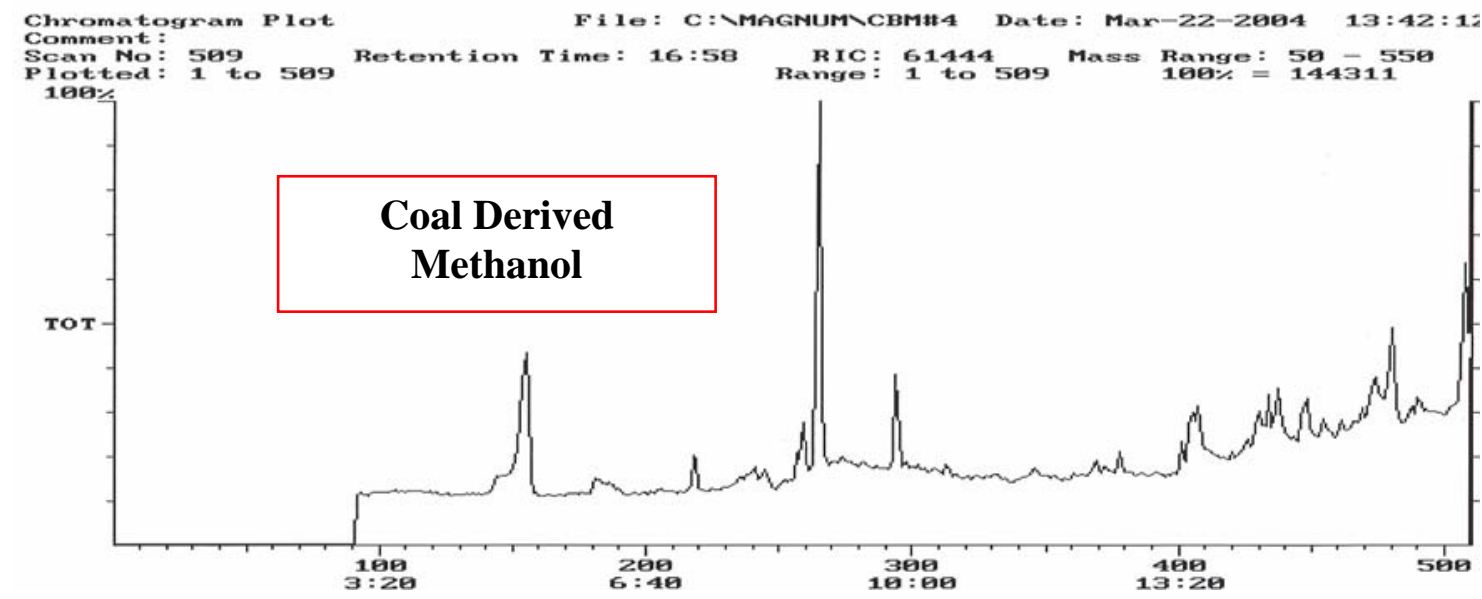

Figure 17: GC-MS time trace of Coal-derived Methanol.

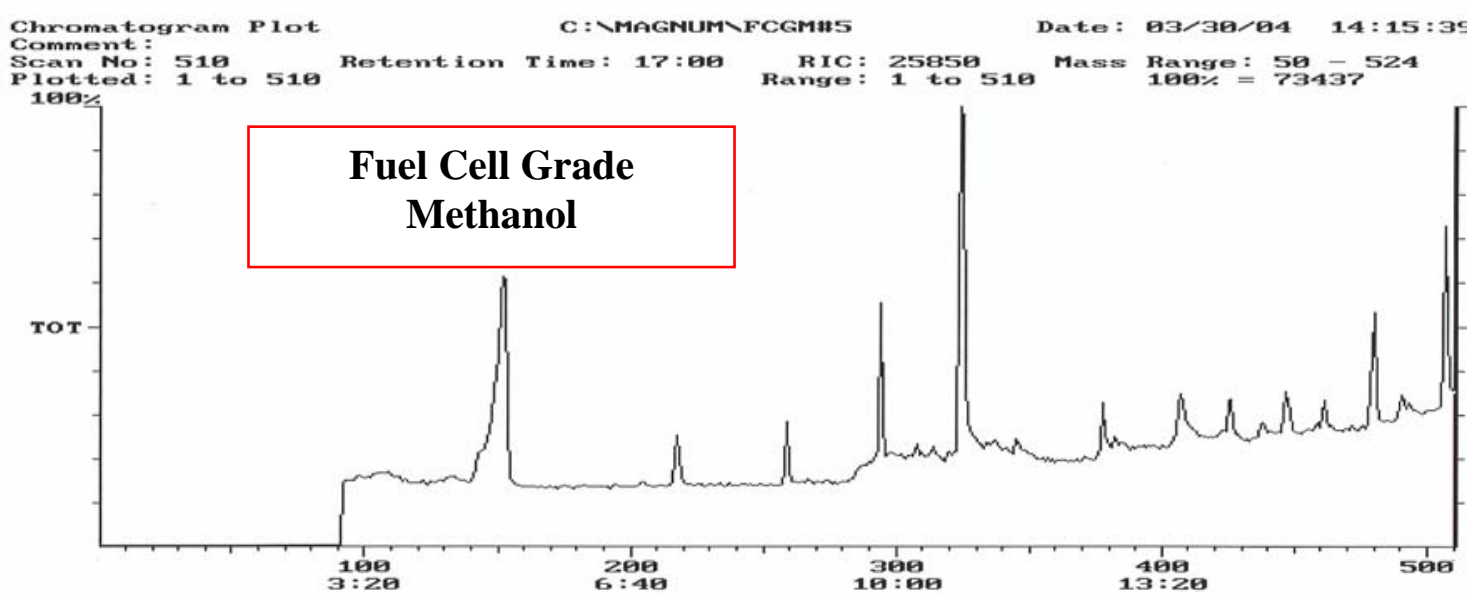

Figure 18: GC-MS time trace of Fuel Cell Grade Methanol.

Note: The following results from the mass spectrometer are based on GC-MS library. 


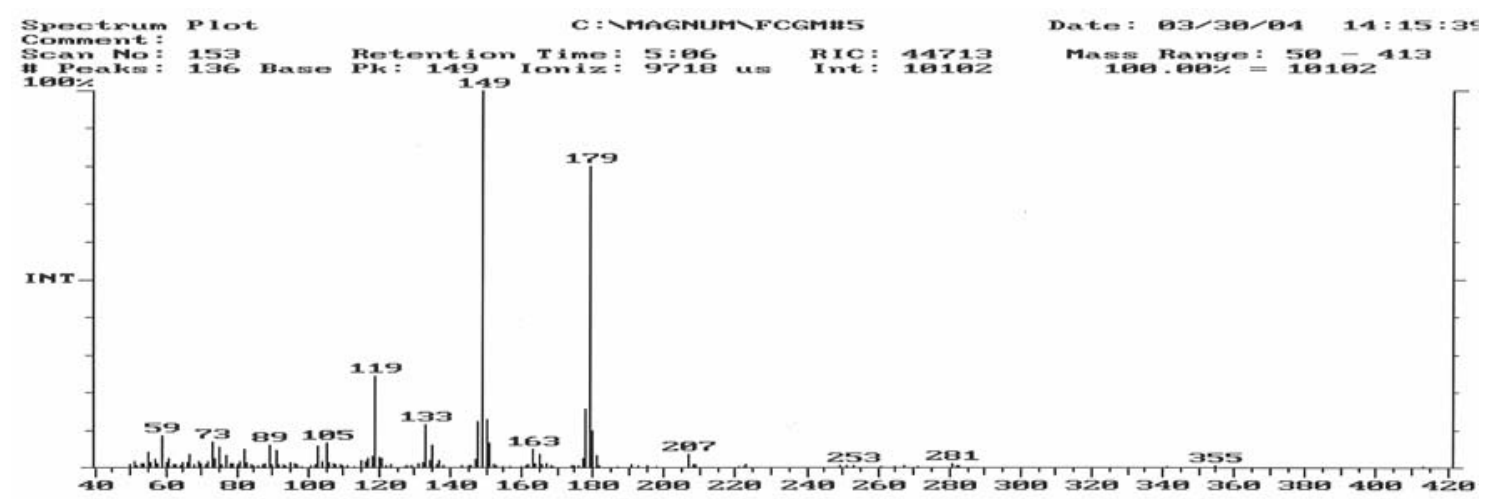

Figure 19: Mass spectrograph of Fuel Cell Grade Methanol at retention time 5:06.

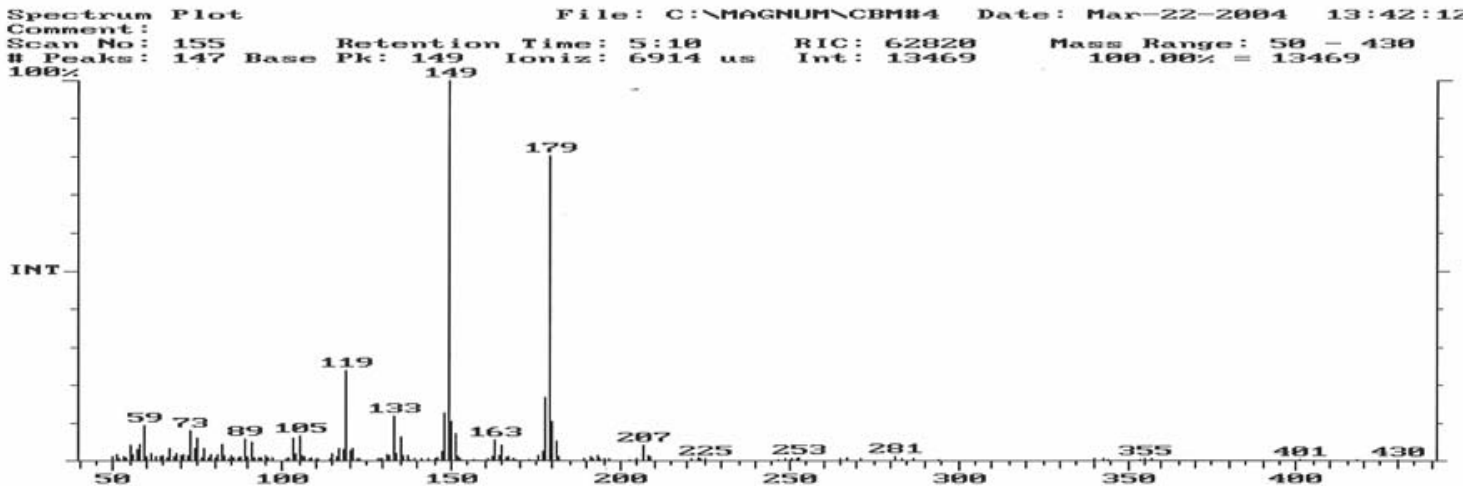

Figure 20: Mass spectrograph of Coal-derived Methanol at retention time 5:10.

In Figure 19 and Figure 20, two compounds have $296 \mathrm{~g} / \mathrm{mol}$ as their molecular weight and a possible molecular formula of $\mathrm{C}_{14} \mathrm{H}_{24} \mathrm{O}_{3} \mathrm{Si}_{2}$ - Benzeneacetic acid, alpha.[(trimethylsilyl) oxy]-,tri. in both fuel cell grade and coal-derived methanol.

We were able to certify the difference of fuel cell grade methanol and coal-derived methanol through GC-MS. Although some compounds have same molecular weight through GC-MS library, they can not be said to be identical compounds because of their different mass fragment patterns. However, most hydrocarbon compounds found by GCMS library have silane which is abundant in the earth. Further research should be required because those silane might be sulfur, chloride or just column bleed. Furthermore, internal evaluation followed by ASTM standard is being on process to completely grasp coal-derived methanol specification. (A more complete presentation of plots can be seen in the second quarter report)

\section{Sample Results from Steam Reformation}

Table 7 shows raw data from a preliminary run of the steam reformer using fuel cell grade methanol. The premix density, condensate density, mass of premix used, and the 
mass of the condensate were reduced using the method described above to determine the percent conversion of methanol.

Table 7: Conversion Results of Fuel Cell Grade methanol.

\begin{tabular}{|c|r|r|r|r|r|r|}
\hline & $\begin{array}{c}\text { Premix } \\
\text { Flow Rate } \\
(\mathrm{mL} / \mathrm{min})\end{array}$ & $\begin{array}{c}\text { Premix } \\
\text { Density } \\
\left(\mathrm{g} / \mathrm{cm}^{3}\right)\end{array}$ & $\begin{array}{c}\text { Mass of } \\
\text { Premix } \\
\text { Used }(\mathrm{g})\end{array}$ & $\begin{array}{c}\text { Mass of } \\
\text { Condensate } \\
(\mathrm{g})\end{array}$ & $\begin{array}{c}\text { Condensate } \\
\text { Density } \\
\left(\mathrm{g} / \mathrm{cm}^{3}\right)\end{array}$ & $\begin{array}{c}\text { Percent } \\
\text { Conversion } \\
(\%)\end{array}$ \\
\hline Run 1 & 15 & 0.9080 & 208.2 & 38.6 & 0.9953 & 99.56 \\
\hline Run 2 & 5 & 0.9080 & 205.8 & 38.9 & 0.9973 & 99.93 \\
\hline Run 3 & 15 & 0.9080 & 208.4 & 34.5 & 0.9965 & 99.81 \\
\hline Run 4 & 15 & 0.9080 & 207.9 & 38.0 & 0.9969 & 99.86 \\
\hline Run 5 & 5 & 0.9080 & 205.7 & 37.0 & 0.9972 & 99.91 \\
\hline Run 6 & 5 & 0.9080 & 205.8 & 35.5 & 0.9973 & 99.93 \\
\hline
\end{tabular}

\section{Coal-derived Methanol and Water Solution Calibration}

Due to the differences between the coal-derived methanol and the fuel cell grade methanol, a new calibration curve to determine the proper density for the coal-derived methanol/water premix for the steam reformer was developed. Figure 21 represents the change of premix density at $24^{\circ} \mathrm{C}\left(75.2^{\circ} \mathrm{F}\right)$ associated with different mass fractions of a coal-derived methanol/water solution. The purpose of this calibration is to calculate the conversion of coal-derived methanol. It is based on the assumption that only methanol and water can be condensed in the products. Other by-products may bias conversion ratio, and all condensate temperatures should be maintained at $0^{\circ} \mathrm{C}\left(32^{\circ} \mathrm{F}\right)$ regardless of sampling time and space velocity. Moreover, before the condensate trap is opened, gas volume fraction indicated by the gas analyzer should be identical with values associated with air. The handheld density meter is used for measuring density. It also has a thermocouple so that we can measure the density and corresponding temperature. After condensate trap is exposed, residual liquid droplets inside the trap is absorbed by a towel. Difference of weight before use towel was approximately $2 \mathrm{~g}$ from previous experiment. Even minute liquid droplets left inside the condensate trap should be absorbed to minimize the uncertainty of the conversion ratio. Then, mass fraction of unused coalderived methanol and deionized water can be calculated by means of density Equation 3 shown below.

$$
Y_{\mathrm{MeOH}}=-5.5198 \rho^{2}+4.5536 \rho+0.9422
$$

Equation 3

Likewise, by means of mass fraction of both liquids, overall conversion can be calculated by the following mass basis in Equation 4.

$$
\text { Converion }(\%)=\frac{m_{\text {used } \cdot \mathrm{MeOH}}-m_{\text {unused } \cdot \mathrm{MeOH}}}{m_{\text {used } \cdot \mathrm{MeOH}}} \times 100
$$




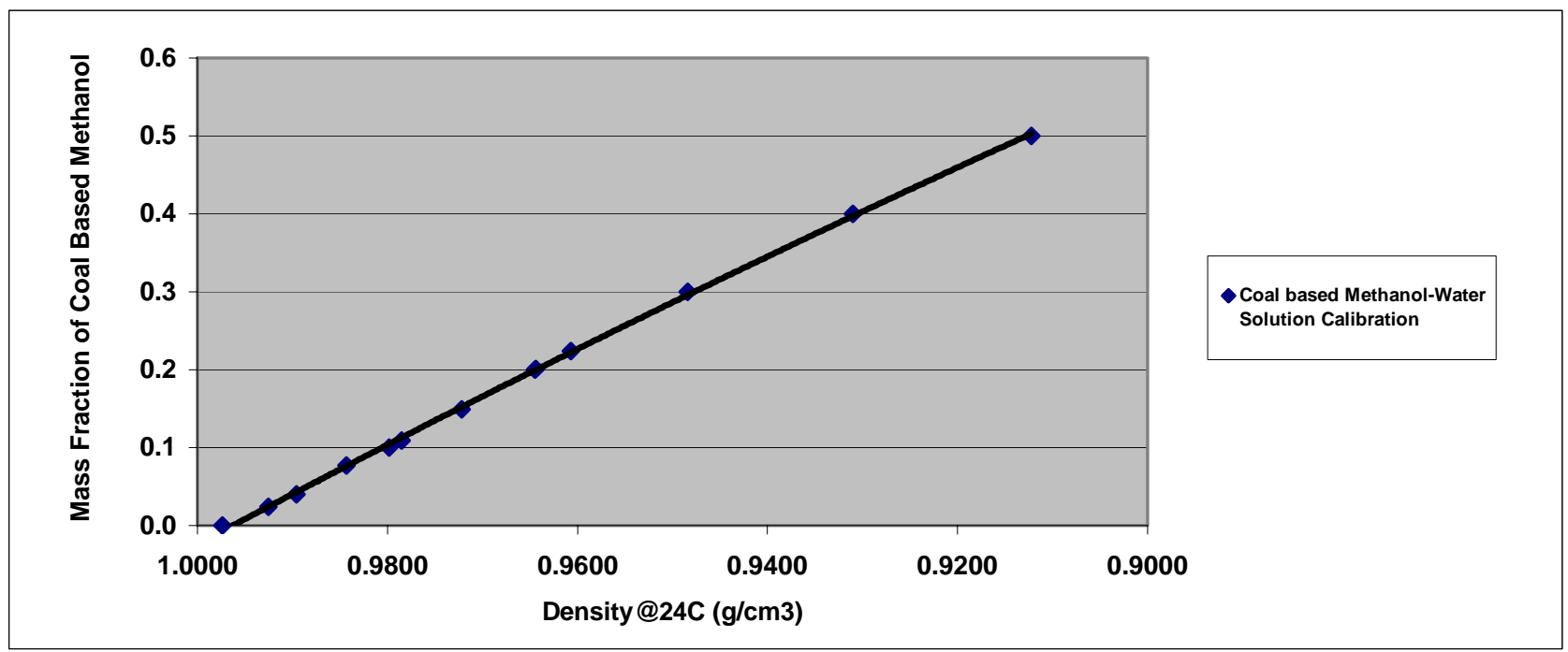

Figure 21: Coal-derived methanol/water solution calibration.

\section{ATR Preliminary Results}

Automobile catalyst baseline tests

Preliminary testing was conducted with wall temperature set points of $350^{\circ} \mathrm{C}\left(662^{\circ} \mathrm{F}\right), \mathrm{S} / \mathrm{C}$ $=1.5$, premix flowrate ranging from 1.4 to $8.5 \mathrm{ml} / \mathrm{min}(0.022 \mathrm{gal} / \mathrm{h}$ to $1.35 \mathrm{gal} / \mathrm{h})$, and $\mathrm{O} / \mathrm{C}$ ranging from 0.0 to 0.40 . Fuel conversion of greater than $90 \%$ has been achieved using the downstream catalyst from an automobile catalytic converter. The used catalyst has a burnt appearance from reaching temperatures of approximately $480^{\circ} \mathrm{C}\left(896^{\circ} \mathrm{F}\right.$ ) (see Figure 22 below). Reformate composition was uncertain due to complications with the gas analyzer.

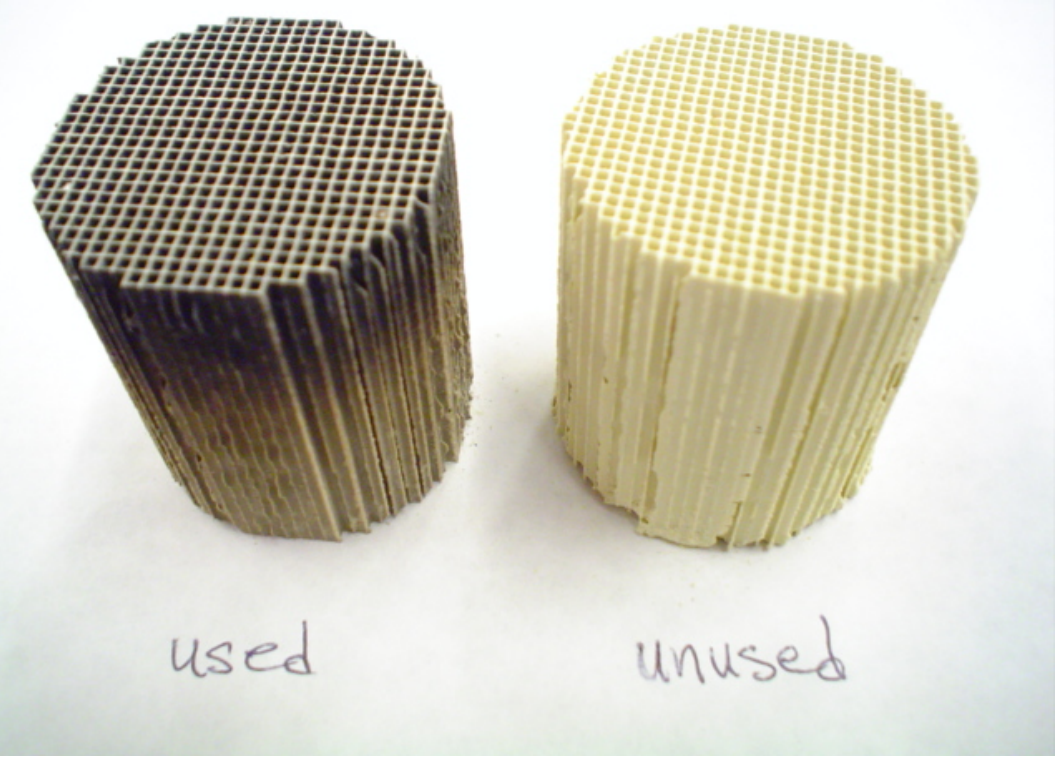

Figure 22: Used and unused catalyst for ATR reactor. 
As seen in Figure 23, fuel conversion increases from $17 \%$ at $\mathrm{O} / \mathrm{C}=0$ to $90 \%$ at $\mathrm{O} / \mathrm{C}=$ 0.25 and then levels off at higher $\mathrm{O} / \mathrm{C}$. The conversion tested at the two different premix flowrates is similar at given $\mathrm{O} / \mathrm{C}$ 's.

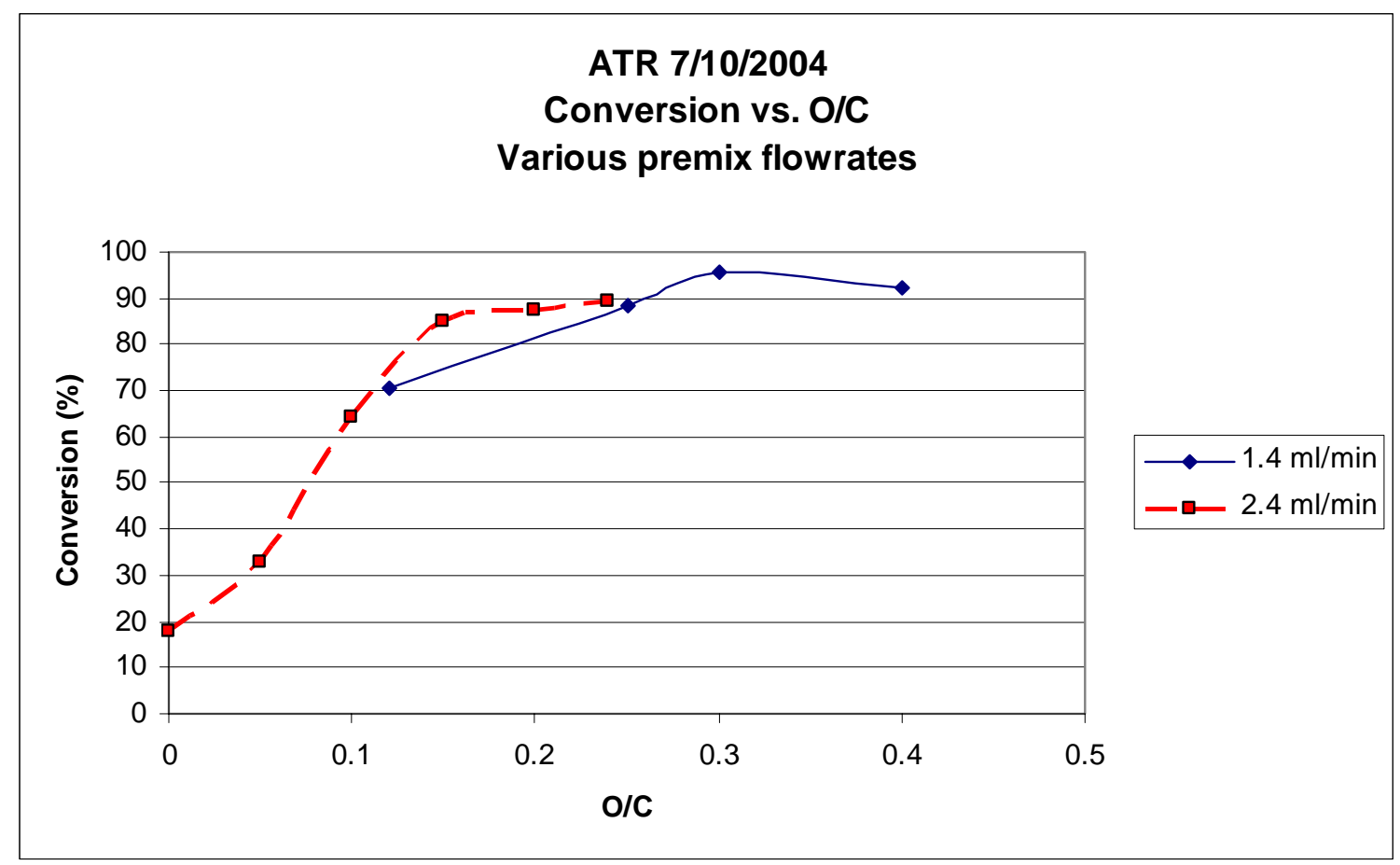

Figure 23: Conversion results in ATR reactor.

Conversion should also be dependent on the reactant flowrates. Conversion is fairly constant above GHSV's of $3000 \mathrm{~h}^{-1}$, as shown in Figure 24. Intuitively, the conversion should increase with decreasing GHSV, because the reactants have a longer residence time in the catalyst bed. However, the opposite result is displayed in Figure 24. This may be due to a laminar flow regime at low flowrates, which could affect reactant mixing upstream and therefore decrease the conversion. 


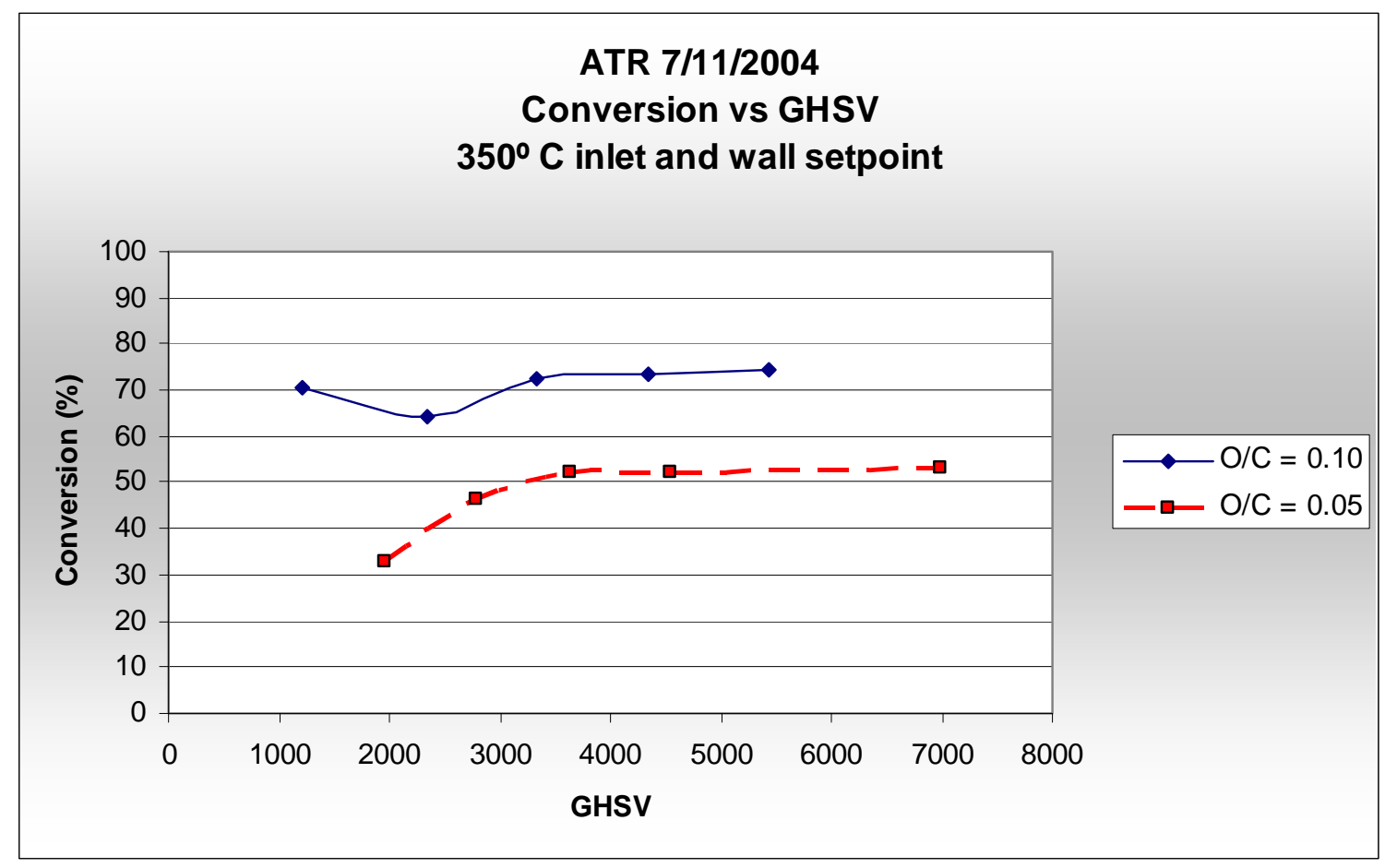

Figure 24: Conversion as a function of gas hourly space velocity.

Catalyst bed temperature increases with $\mathrm{O} / \mathrm{C}$, from $309^{\circ} \mathrm{C}\left(588.2^{\circ} \mathrm{F}\right)$ at $\mathrm{O} / \mathrm{C}=0$ (steam reforming), to $430^{\circ} \mathrm{C}\left(806^{\circ} \mathrm{F}\right)$ at $\mathrm{O} / \mathrm{C}=0.24$ as seen in Figure 25 below. Temperatures in the catalyst bed are even higher at $\mathrm{O} / \mathrm{C}=0.4$, reaching temperatures of around $480^{\circ} \mathrm{C}$ $\left(896^{\circ} \mathrm{F}\right)$. The reactor has axial zones 1 through 5 and the catalyst was located in zone 4 for the experiments shown. The temperatures displayed in Figure 25 are reactor centerline temperatures, and the catalyst interior temperatures. The catalyst interior temperatures are taken at the same axial length inside the catalyst and represent a radial temperature profile. $\mathrm{O} / \mathrm{C}$ has a significant effect on the catalyst bed temperature and less effect on the reactor center line temperature. This implies that the oxidation reaction of methanol is in fact occurring in the catalyst bed as expected. Zones 4 and 5 show a mild increase in temperature with increasing $\mathrm{O} / \mathrm{C}$. This is because of the hot product gases coming from the catalyst bed. 


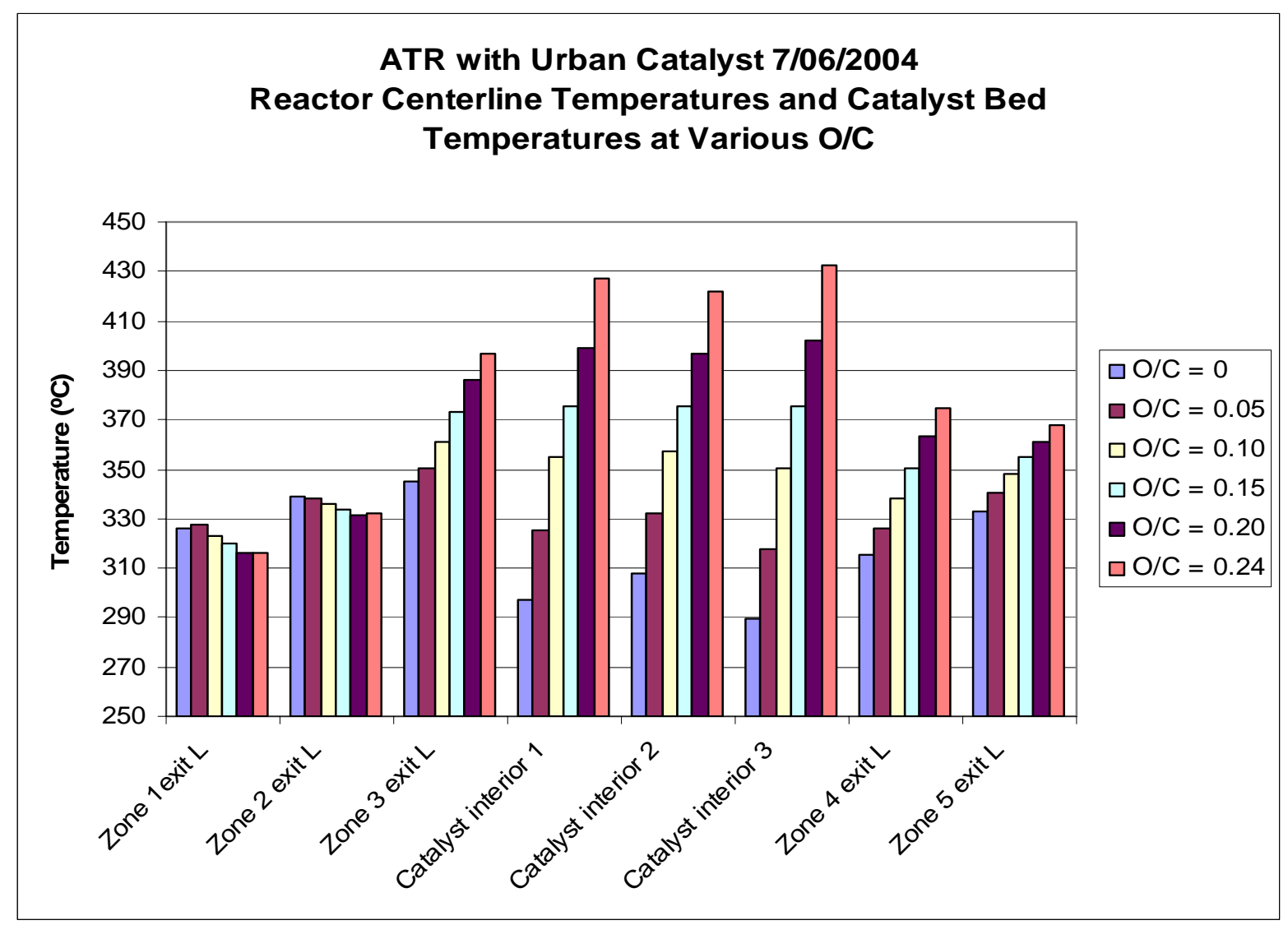

Figure 25: ATR reactor temperature profile at various $\mathrm{O} / \mathrm{C}$.

The temperature response of the catalyst bed to increases in $\mathrm{O} / \mathrm{C}$ is fairly rapid, as shown in Figure 26 below. The catalyst bed temperature rises more rapidly at higher $\mathrm{O} / \mathrm{C}$ ratios. This preliminary experiment is a stepping stone to transient response studies that may be carried out in the future. 


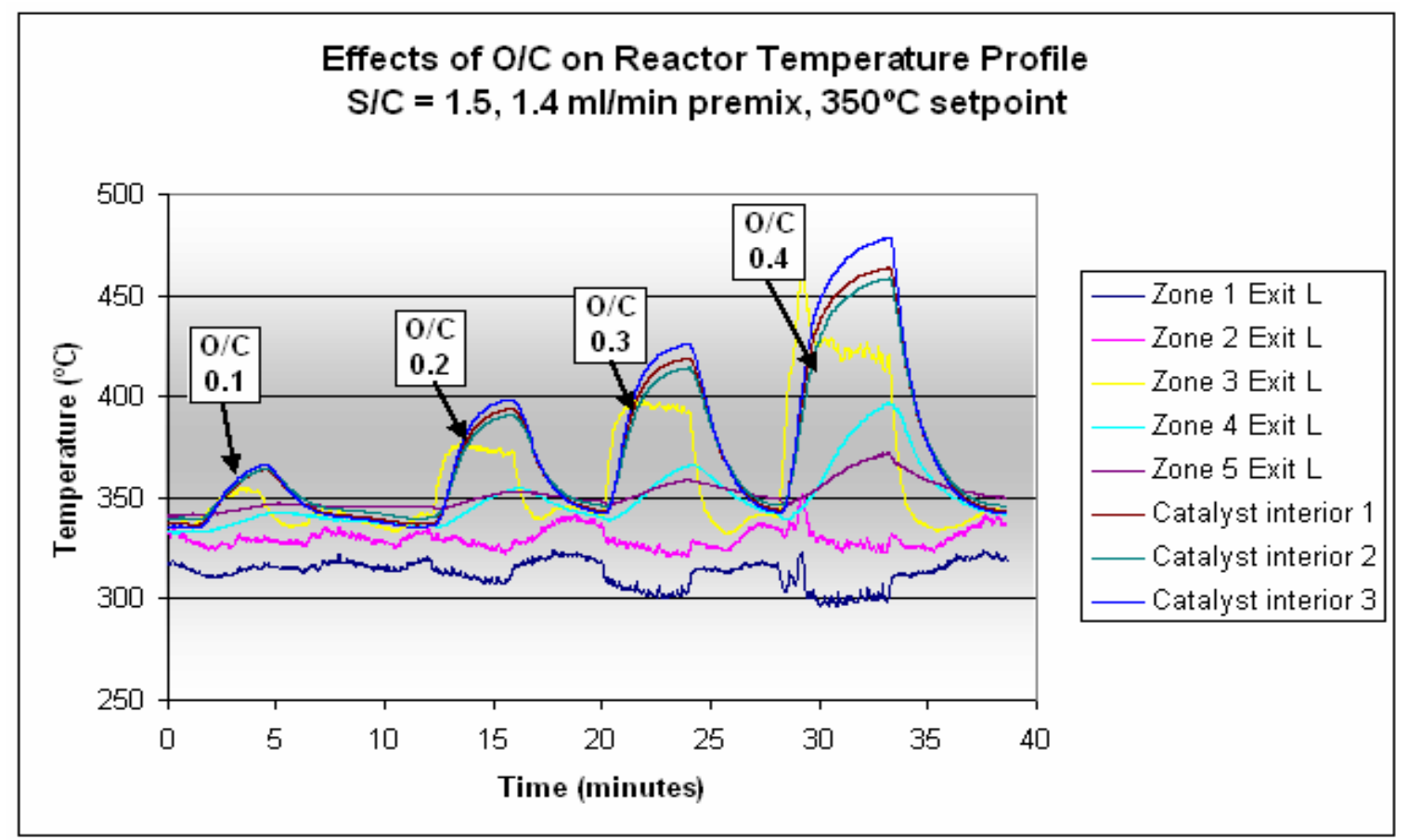

Figure 26: Temperature profile of reactor with oxidant supply pulses for various O/C.

Fuel conversion is dependant on reactant inlet temperatures and reactor set point temperatures. At $350^{\circ} \mathrm{C}\left(662^{\circ} \mathrm{F}\right)$ inlet and reactor wall temperature set points, the conversion of fuel was $74 \%$, compared to $63 \%$ for set points of $260^{\circ} \mathrm{C}\left(500^{\circ} \mathrm{F}\right)$ as shown in Figure 27 below.

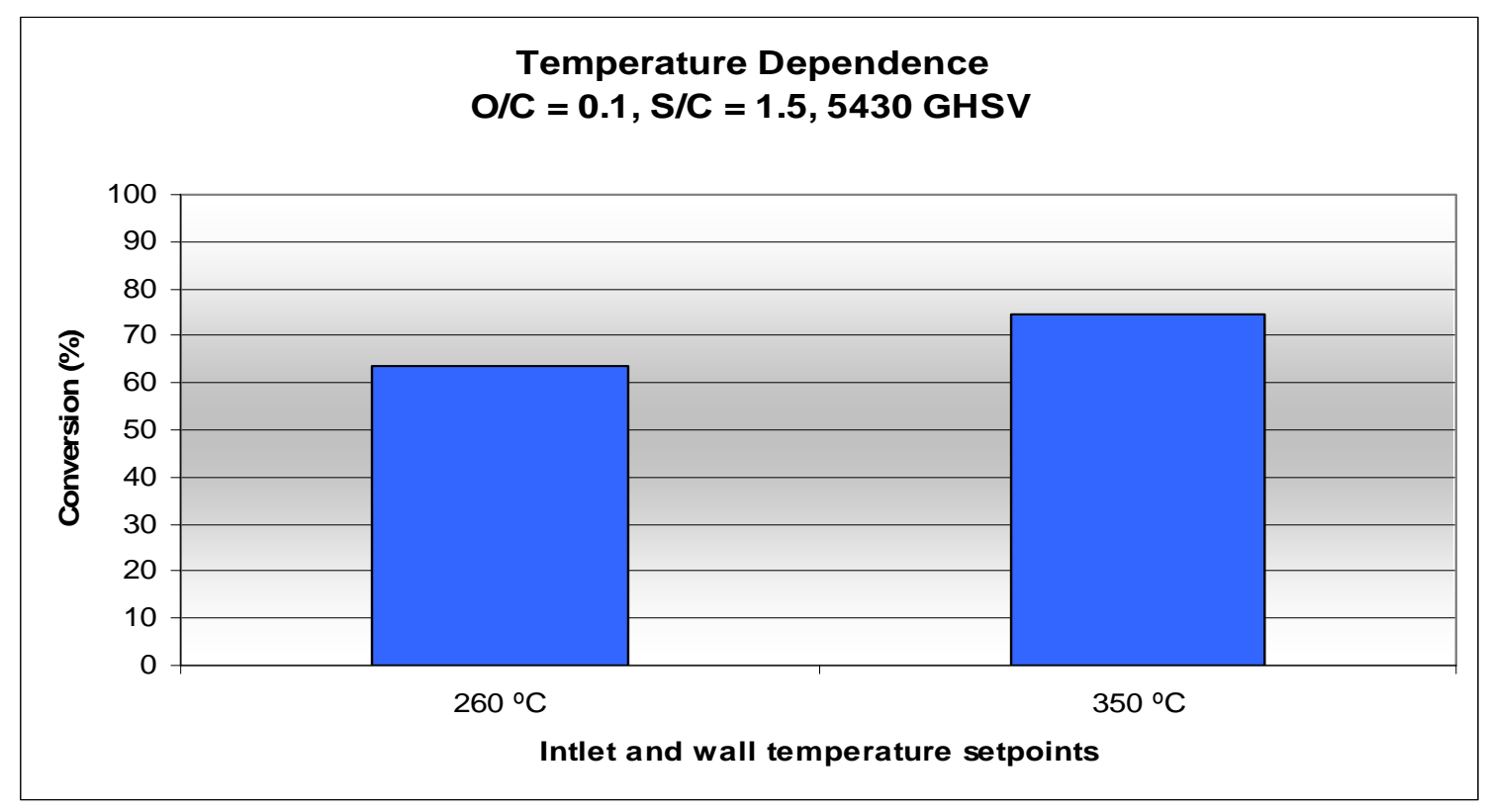

Figure 27: Conversion at two different inlet and reactor temperatures. 
ATR experiments are scheduled for early August for an in depth $\mathrm{O} / \mathrm{C}$ study. Reaction progression through the monolithic catalyst will also be investigated. These are baseline studies which will utilize fuel cell grade methanol as the fuel which will aid in the analysis of reforming coal based methanol.

Proprietary catalyst baseline tests

In past studies oxygen-to-carbon ratio has proven to be a very significant parameter in ATR of hydrocarbon fuels. Therefore, it was deemed necessary to begin an investigation on the effects of $\mathrm{O}_{2} / \mathrm{C}$ on reactor performance. At each catalyst configuration, the $\mathrm{O}_{2} / \mathrm{C}$ was varied from 0.1 to 0.4 , in increments of 0.05 , in order to investigate the effects of $\mathrm{O}_{2} / \mathrm{C}$ on reactor performance, including temperature profile, conversion, and efficiency.

The most notable effect of $\mathrm{O}_{2} / \mathrm{C}$ can be seen at a critical $\mathrm{O}_{2} / \mathrm{C}$ characterized by a sudden increase in catalyst bed temperature. This critical point is known by ATR catalyst suppliers as light off. Figure 28 shows the rapid increase in average catalyst bed temperature as the $\mathrm{O}_{2} / \mathrm{C}$ increases from 0.15 to 0.20 . The average catalyst bed temperatures at each $\mathrm{O}_{2} / \mathrm{C}$ are listed in Table 8. The critical $\mathrm{O}_{2} / \mathrm{C}$ (for the operating parameters used in this experiment) was 0.20 , this is the operating point where light off occurred. Below light off, catalyst bed temperatures are around $300^{\circ} \mathrm{C}\left(572^{\circ} \mathrm{F}\right)$, approximately $50^{\circ} \mathrm{C}\left(90^{\circ} \mathrm{F}\right)$ hotter than the inlet temperature of $250^{\circ} \mathrm{C}\left(482^{\circ} \mathrm{F}\right)$. At light off, the catalyst bed temperature dramatically increased by about $235^{\circ} \mathrm{C}\left(423^{\circ} \mathrm{F}\right)$ to approximately $550^{\circ} \mathrm{C}\left(1022^{\circ} \mathrm{F}\right)$.

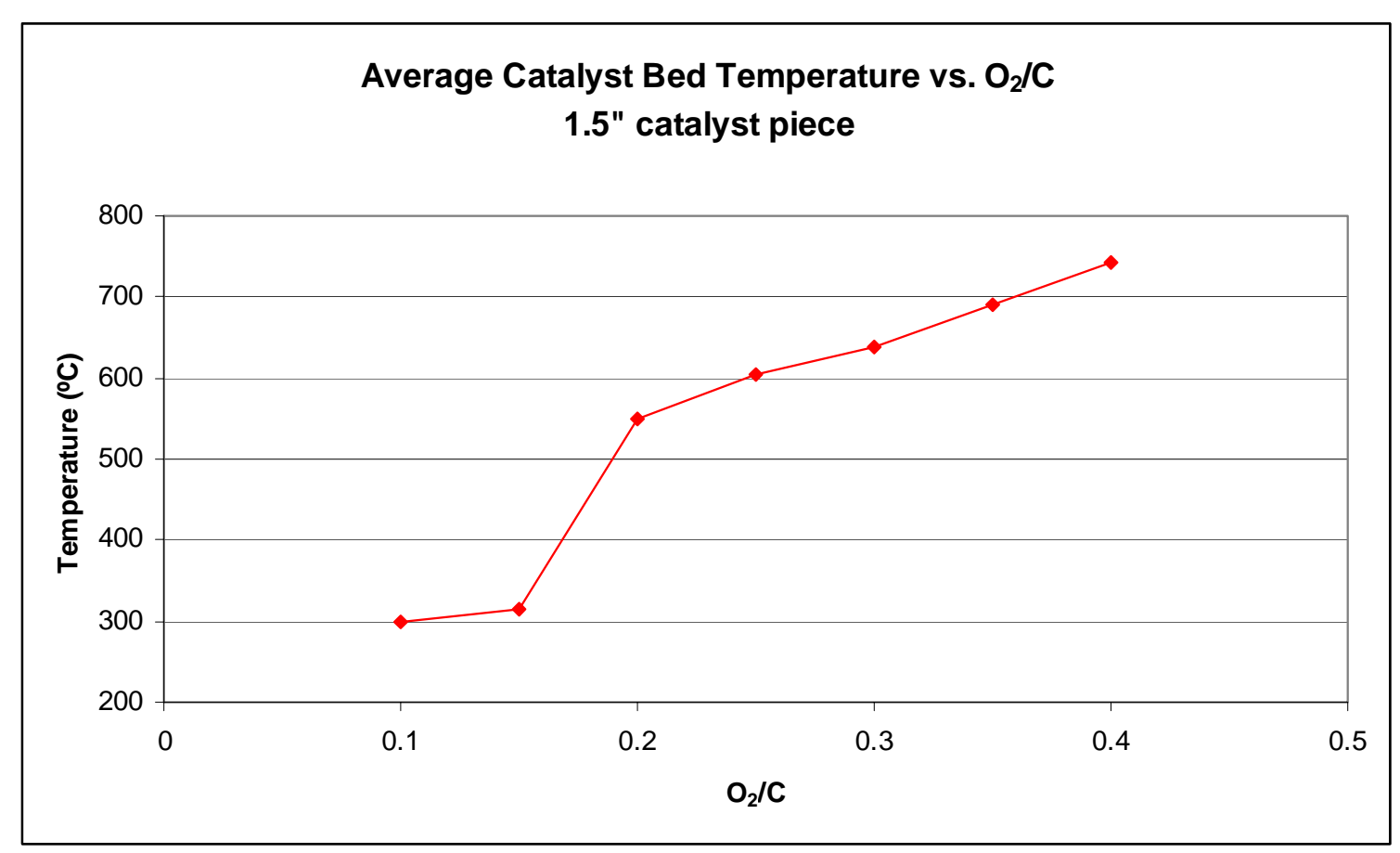

Figure 28: Average catalyst bed temperature as a function of $\mathrm{O}_{2} / \mathrm{C}, 1.5$ ” catalyst piece. 
Table 8: Average catalyst bed temperature at various $\mathrm{O}_{2} / \mathrm{C}$, 1.5” catalyst piece.

\begin{tabular}{|c|c|}
\hline $\mathrm{O}_{2} / \mathrm{C}$ & $\begin{array}{c}\text { Average Catalyst Bed } \\
\text { Temperature }\left({ }^{\circ} \mathrm{C}\right)\end{array}$ \\
\hline 0.10 & 298.6 \\
\hline 0.15 & 314.9 \\
\hline 0.20 & 549.3 \\
\hline 0.25 & 605.3 \\
\hline 0.30 & 637.7 \\
\hline 0.35 & 691.0 \\
\hline 0.40 & 742.5 \\
\hline
\end{tabular}

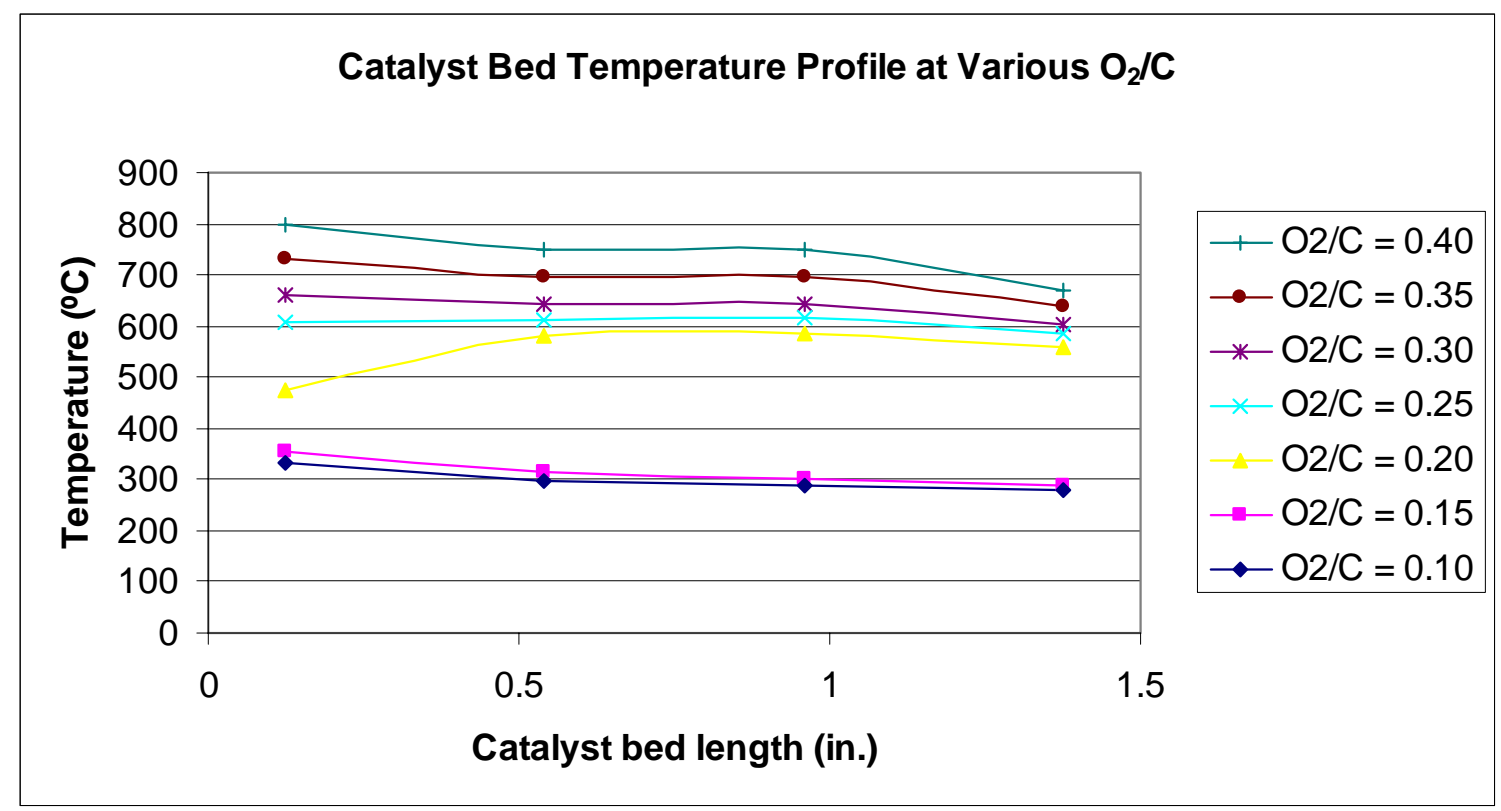

Figure 29: Catalyst bed temperature profile at various $\mathrm{O}_{2} / \mathrm{C}$.

Catalyst bed temperature increased with increasing $\mathrm{O}_{2} / \mathrm{C}$, as the reaction shifted from endothermic to exothermic thus generating excess heat which raised reactor temperatures. Shown in Figure 29 is the catalyst bed temperature profile, measured at 4 axial locations, of the solid $3.81 \mathrm{~cm}(1.5 \mathrm{in})$ catalyst piece at various $\mathrm{O}_{2} / \mathrm{C}$ 's. For a low $\mathrm{O}_{2} / \mathrm{C}$ of 0.15 , the entrance of the catalyst bed was approximately $350^{\circ} \mathrm{C}\left(662^{\circ} \mathrm{F}\right), 100^{\circ} \mathrm{C}\left(180^{\circ} \mathrm{F}\right)$ higher than the reactant inlet temperature of $250^{\circ} \mathrm{C}\left(482^{\circ} \mathrm{F}\right)$. Just $3.175 \mathrm{~cm}(1.25 \mathrm{in})$ downstream from this location the catalyst bed temperature dropped below $300^{\circ} \mathrm{C}\left(572^{\circ} \mathrm{F}\right)$. The decrease in temperature through the catalyst bed indicates a dominating endothermic steam reforming reaction through the latter portion of the catalyst bed. This is consistent for each $\mathrm{O}_{2} / \mathrm{C}$ except at the light off point, $\mathrm{O}_{2} / \mathrm{C}=0.20$, where the catalyst bed inlet temperature is actually lower than the rest of the catalyst bed.

Temperature profile of the catalyst bed helps explain reactor performance, but the actual performance is quantified by fuel conversion and efficiency. Figure 30 shows the fuel 
conversion percentage as a function of $\mathrm{O}_{2} / \mathrm{C}$ for the catalyst arrangement of three, stacked $6.35 \mathrm{~mm}(0.25 \mathrm{in})$ catalyst pieces. Below light off, fuel conversion percentage appears to linearly increase with $\mathrm{O}_{2} / \mathrm{C}$ ratio until it reaches nearly $100 \%$ at the critical $\mathrm{O}_{2} / \mathrm{C}$. The error bars in Figure 30 are a result of the statistical analysis of the data and represent a $95 \%$ confidence interval within which the true mean of the population of data should lie. The error bars at all $\mathrm{O}_{2} / \mathrm{C}$, except 0.20 , are very small, indicating consistent and reproducible data. At light off, the reaction is unsteady and results in less consistent data with associated larger error bars. As seen in Figure 30, above the light off point, $\mathrm{O}_{2} / \mathrm{C}>$ 0.20 , the fuel conversion is a constant at approximately $99.5 \%$. Below light off, $\mathrm{O}_{2} / \mathrm{C}<$ 0.20 , the fuel conversion follows a linear trend. The fuel conversion increases from about $60 \%$ at $\mathrm{O}_{2} / \mathrm{C}=0.10$, to just over $80 \%$ at $\mathrm{O}_{2} / \mathrm{C}=0.15$, to nearly $100 \%$ at $\mathrm{O}_{2} / \mathrm{C}=$ 0.20 . The results for each catalyst bed configuration are very similar, as discussed later in this chapter.

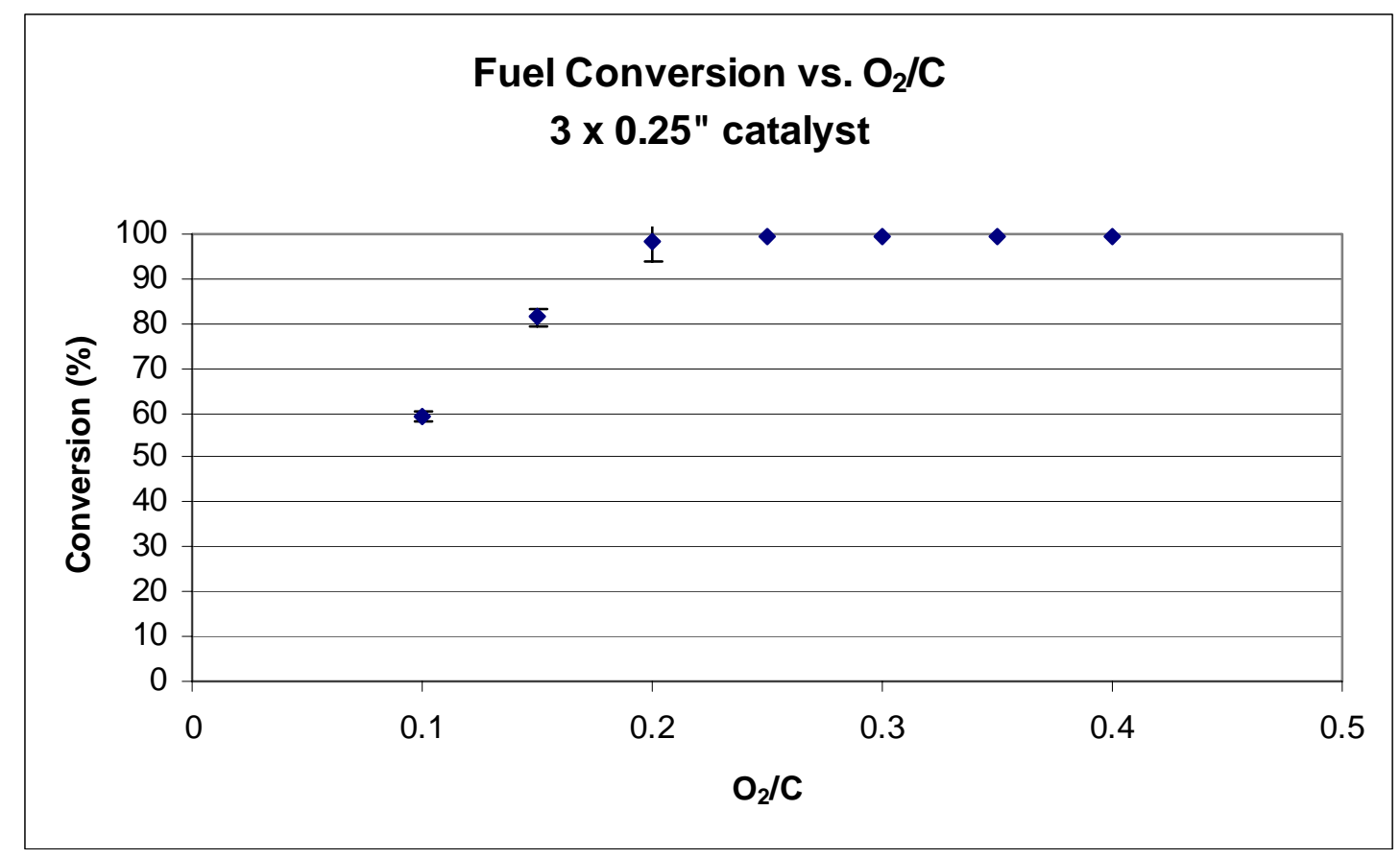

Figure 30: Typical fuel conversion as a function of $\mathrm{O}_{2} / \mathrm{C}$, shown for 3 stacked catalyst pieces.

A discussion of the effects of oxygen-to-carbon ratio would not be complete without investigating reactor power requirements. Heat bands were placed on the reactor in order to provide external heat for start-up and operation below the thermoneutral point. The controls were set to maintain reactor wall temperatures of $250^{\circ} \mathrm{C}\left(482^{\circ} \mathrm{F}\right)$. Electrical power consumed by the five different heat bands is show in Figure 31, as an average over all catalyst configurations. As expected, the most external heat is required at the lowest $\mathrm{O}_{2} /$ C. This is a total of 33.4 Watts at $\mathrm{O}_{2} / \mathrm{C}=0.20$. The heating requirements decrease until they reach zero at approximately $\mathrm{O}_{2} / \mathrm{C}=0.30$. Most of the power was consumed by the heating bands located at the top and bottom of the reactor, Zone 1 and Zone 5 respectively. This may be due to insufficient insulation and excess heat loss through the ends of the reactor. 


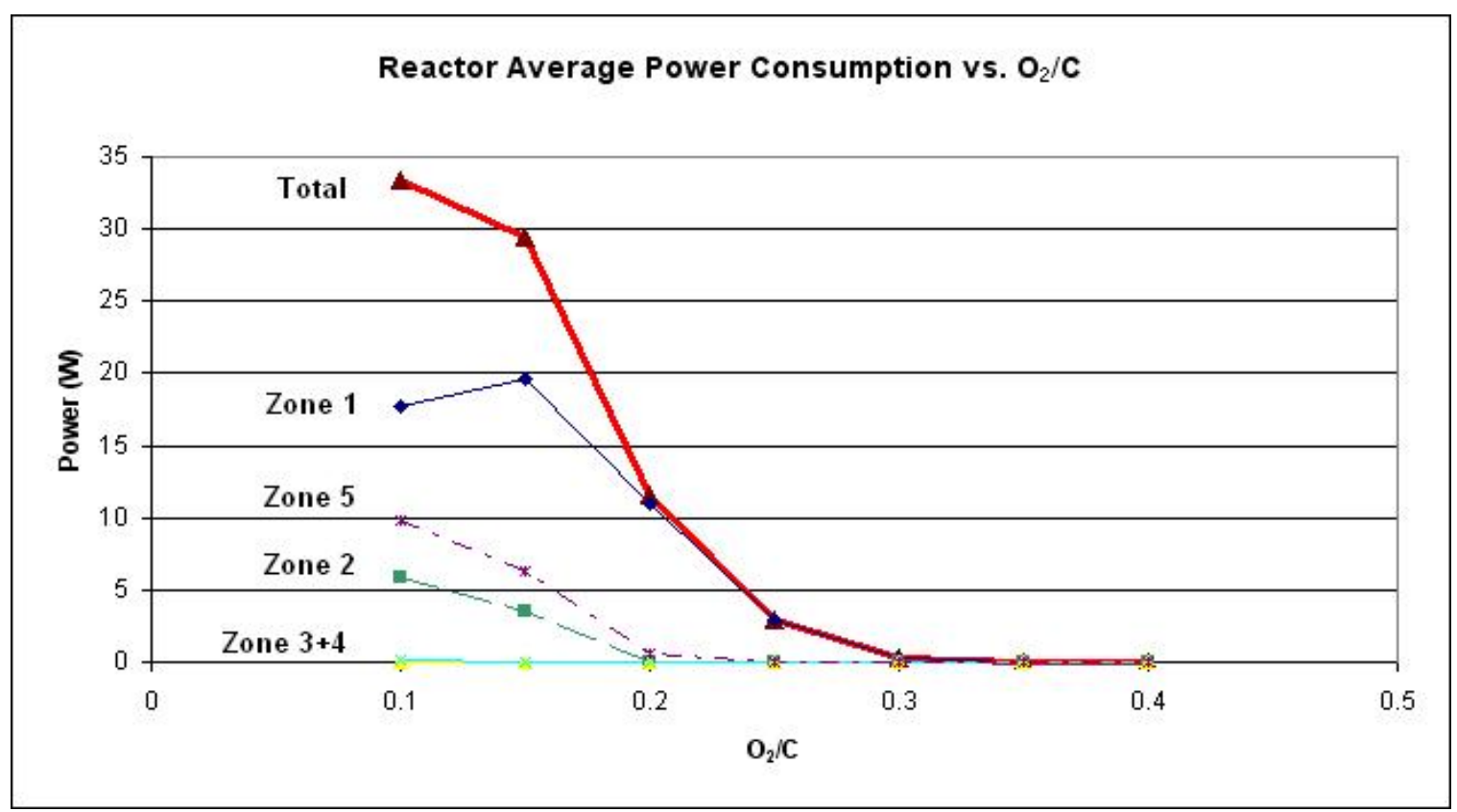

Figure 31: Reactor power consumption vs. $\mathrm{O}_{2} / \mathrm{C}$.

In order to test how the ATR reaction progresses through a monolithic catalyst bed, the catalyst bed length was varied from $6.35 \mathrm{~mm}(0.25 \mathrm{in})$ to approximately $3.81 \mathrm{~cm}(1.5 \mathrm{in})$ by stacking separate $6.35 \mathrm{~mm}(0.25 \mathrm{in})$ length catalyst slices of $3.81 \mathrm{~cm}(1.5 \mathrm{in})$ diameter. It was important to quantify the effects of stacking the catalyst pieces. To establish a baseline, a single, uniform monolithic catalyst of $3.81 \mathrm{~cm}$ (1.5in) length was tested to observe the effects of the discontinuity between stacked catalyst sections. The two catalyst arrangements are show in Figure 32.

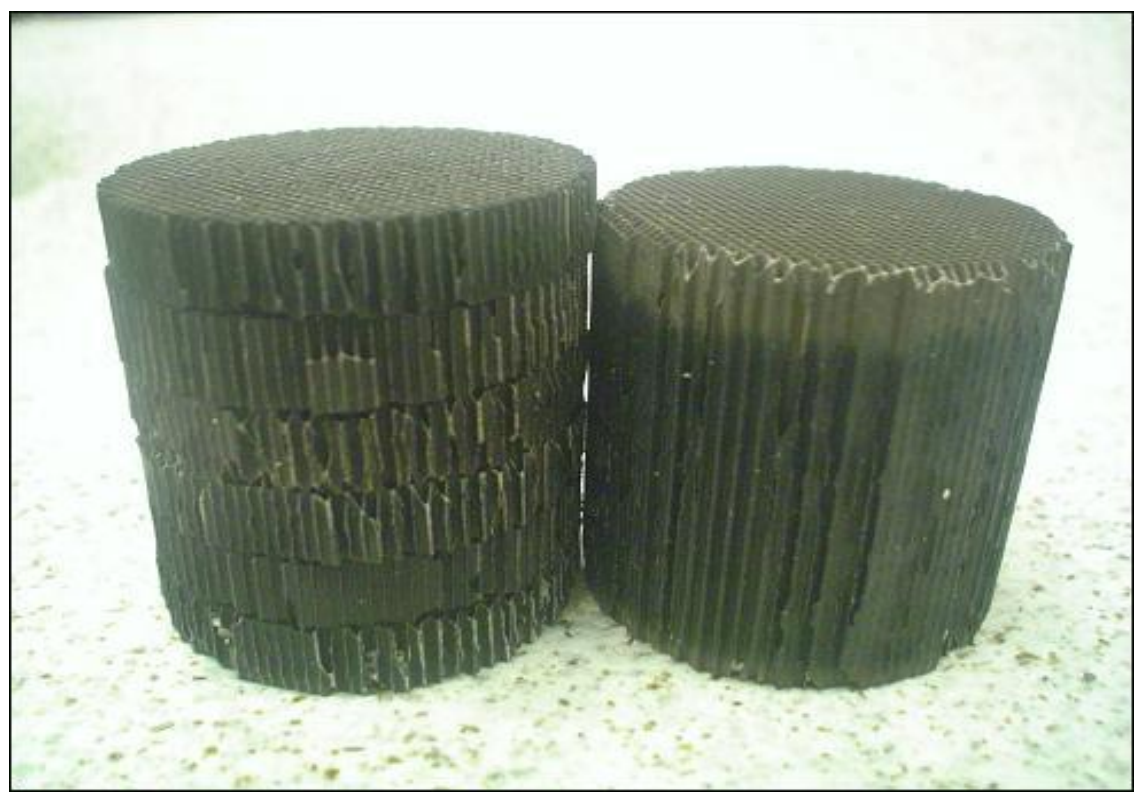

Figure 32: Six, 0.25” catalyst pieces stacked next to a 1.5” catalyst piece. 
The stacked catalyst performed in a very similar manner as the solid $3.81 \mathrm{~cm}(1.5 \mathrm{in})$ catalyst, as evidenced in Figure 33 which shows the reactor efficiency as a function of $\mathrm{O}_{2} / \mathrm{C}$ for both catalyst configurations. For the most part, reactor efficiencies are nearly identical between the solid catalyst bed and the stacked catalyst bed. The most notable difference is at $\mathrm{O}_{2} / \mathrm{C}=0.20$, the light off point. As discussed earlier in this chapter, operating near the light off point is accompanied by unsteady reaction. At the light off point the catalyst bed may undergo extreme temperature fluctuations and concomitantly varying conversion and efficiency. Figure 33 shows that, at $\mathrm{O}_{2} / \mathrm{C}=0.20$, the mean efficiency of the uniform $3.81 \mathrm{~cm}(1.5 \mathrm{in})$ catalyst bed is $20 \%$ higher than that of the stacked catalyst bed. This indicates that the discontinuities between the stacked catalyst pieces could be a contributing factor to the instability of the reaction which results in a decrease of reactor efficiency.

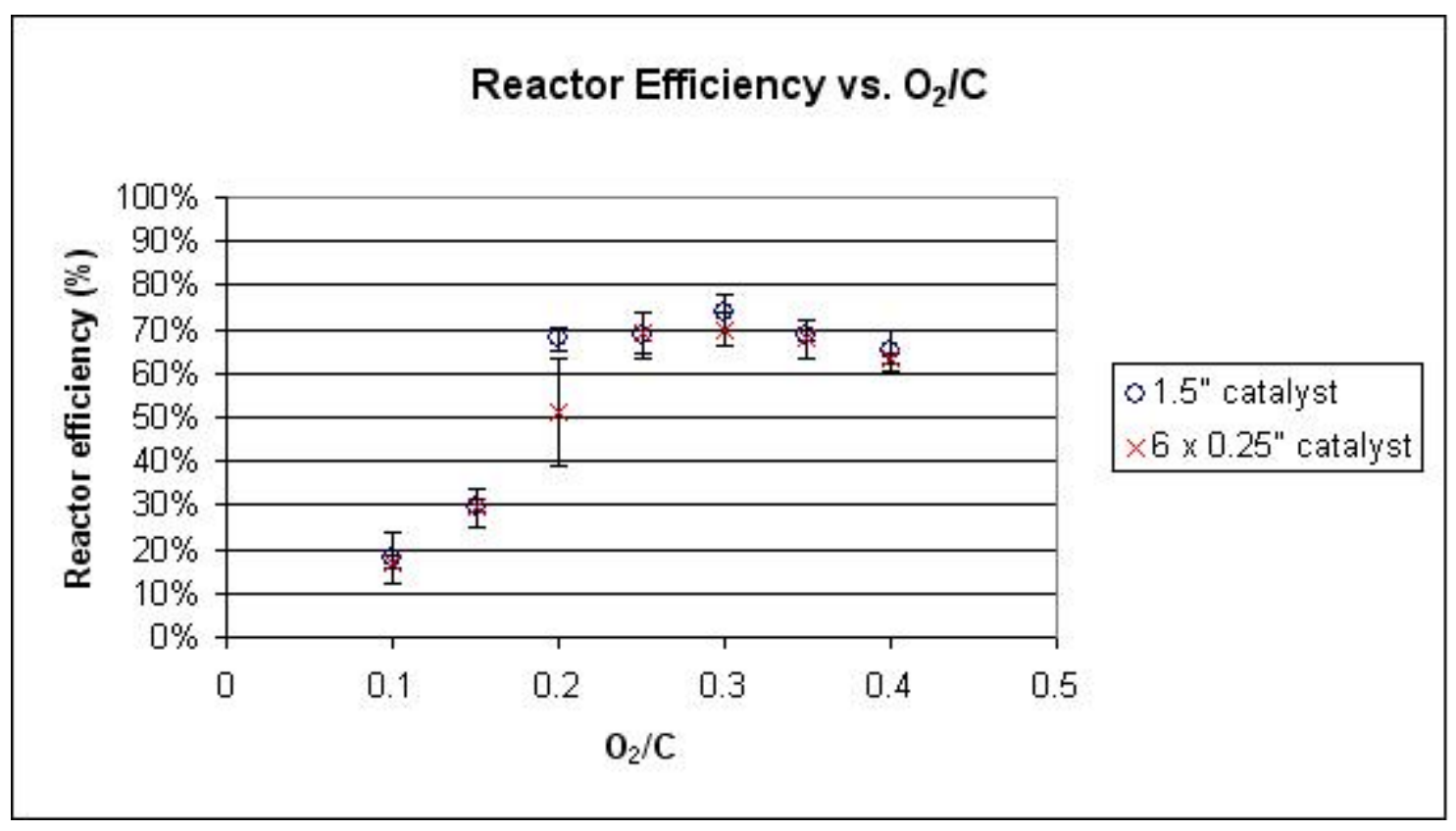

Figure 33: Comparing 1.5” catalyst to six stacked catalyst pieces, equivalent to 1.5”.

From the results of comparing the uniform catalyst bed to a stacked catalyst bed with associated discontinuities, it was assumed that the stacked catalyst pieces reasonably approximate a continuous length of catalyst.

After comparing the remaining catalyst configurations, catalyst bed lengths from $6.35 \mathrm{~mm}$ $(0.25 \mathrm{in})$ to $3.81 \mathrm{~cm}(1.5 \mathrm{in})$, it is apparent that the catalyst bed length has little or no effect on conversion or reactor efficiency. Adjusting the catalyst bed length effectively changes the GHSV by varying the catalyst bed volume. Figure 34 shows that there is no significant difference in fuel conversion over the range of corresponding GHSV's from 9,700 to $58,100 \mathrm{~h}^{-1}$. Above light off, catalyst bed temperatures remained above $550^{\circ} \mathrm{C}$ $\left(1022^{\circ} \mathrm{F}\right)$ and fuel conversion was approximately $99.5 \%$ for all catalyst configurations and $\mathrm{O}_{2} / \mathrm{C}$. 


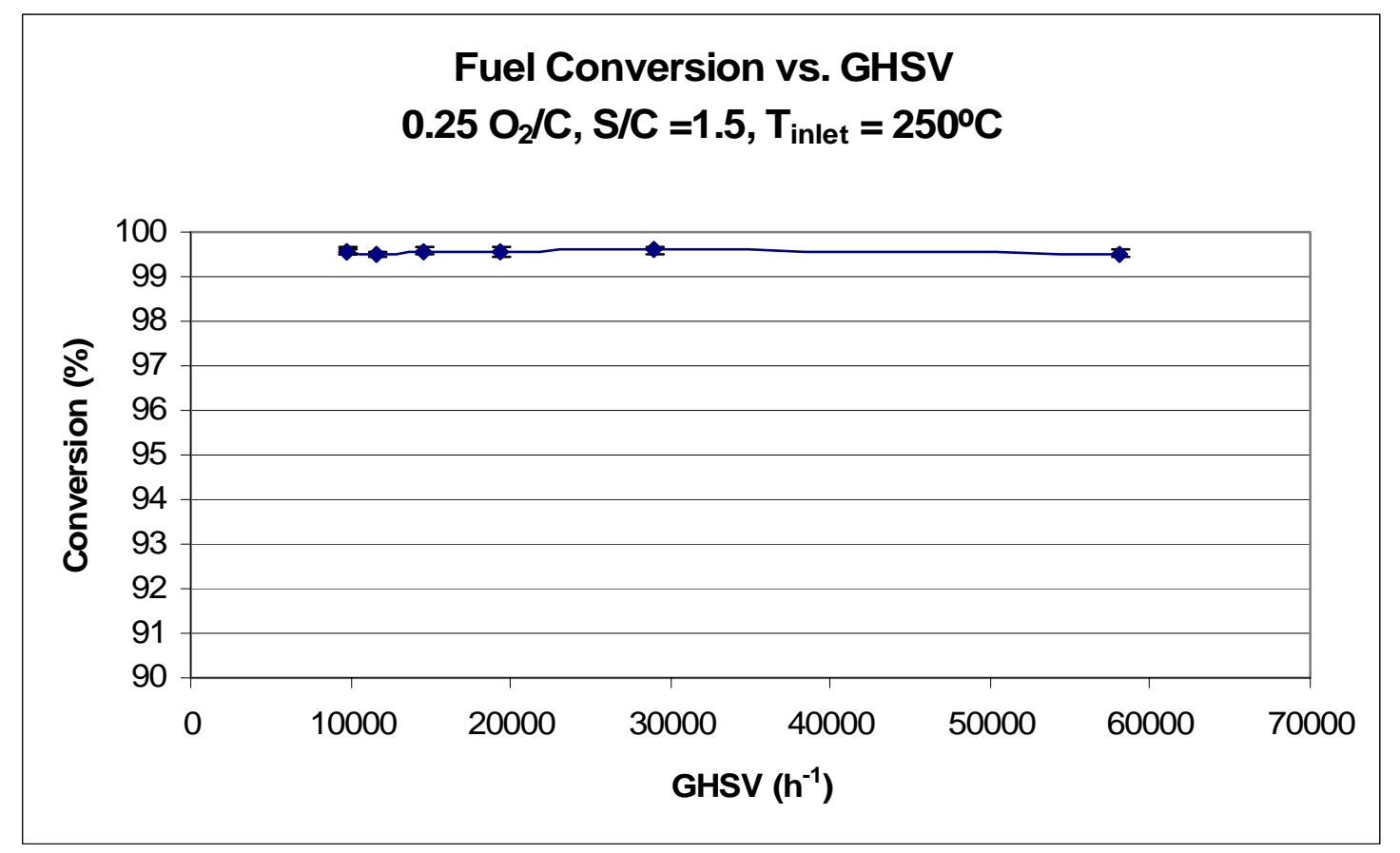

Figure 34: Fuel conversion at 7 different catalyst configurations, GHSV from 9,700 to 58,100.

In order to find the upper limit of GHSV for ATR with the selected catalyst, preliminary testing was performed with a $6.35 \mathrm{~mm}(0.25 \mathrm{in})$ length catalyst bed, $3.81 \mathrm{~cm}(1.5 \mathrm{in})$ in diameter, at varying reactant flowrates. Stoichiometry was held constant at $\mathrm{S} / \mathrm{C}=1.5$, $\mathrm{O}_{2} / \mathrm{C}=0.23$. The highest GHSV of $140,000 \mathrm{~h}^{-1}$ was obtained at a premix flowrate of $21.8 \mathrm{ml} / \mathrm{min}$, and air flowrate of 9.0 SLPM. Reactant flowrates were limited to this level due to the capacity of the air MFC's and excess heat in the reactor exhaust which caused valves to malfunction. As expected, the conversion appears to start diminishing at GHSV's upwards of $100,000 \mathrm{~h}^{-1}$. However, the reduction in conversion is a mere 1 to $1.5 \%$ (from $99.5 \%$ to 98.5 or $98 \%$ ), and without having collected multiple data samples, it is difficult to place any confidence in these results. These results do indicate that an upper limit may indeed be found at higher GHSV's, but a redesign of reforming equipment is necessary to raise reactant flowrates sufficiently. Specifically, a higher capacity air MFC would need to be installed. An exhaust cooling unit is currently being designed upstream of the ball valves to reduce exhaust temperatures.

\section{Possibility of Operating in Steam Reforming Mode}

One way that autothermal reforming might be used is to help overcome the insufficient dynamic capabilities of steam reforming. A possible operating scheme might use ATR to provide rapid dynamic responses when needed, while at steady state the reactor would operate in a more efficient SR mode. Some preliminary testing performed with the ATR reactor provides some insight to the possibility of operating an ATR catalyst in SR mode.

During preliminary testing, some ATR experimental runs were performed at a $350^{\circ} \mathrm{C}$ $\left(662^{\circ} \mathrm{F}\right)$ reactant inlet temperature. This data was compared to the data collected at the $250^{\circ} \mathrm{C}\left(482^{\circ} \mathrm{F}\right)$ reactant inlet temperature. Figure 35 shows a plot of the resulting fuel 
conversion as a function of $\mathrm{O}_{2} / \mathrm{C}$ for the two reactant inlet temperatures, one at $250^{\circ} \mathrm{C}$ $\left(482^{\circ} \mathrm{F}\right)$ and the other at $350^{\circ} \mathrm{C}\left(662^{\circ} \mathrm{F}\right)$. By means of extrapolation, a predicted $20 \%$ fuel conversion is obtained at an $\mathrm{O}_{2} / \mathrm{C}=0.0$, steam reforming mode. From the data collected during preliminary ATR testing, it was found that increasing reactant inlet temperature to $350^{\circ} \mathrm{C}\left(662^{\circ} \mathrm{F}\right)$ results in concomitant increases in fuel conversion below the light off point. As seen in Figure 35, the higher inlet temperature shifts the critical $\mathrm{O}_{2} / \mathrm{C}$ (where light off occurs) from 0.20 to 0.15 . Fuel conversion below the light off point also shifts such that higher conversions are achieved at lower $\mathrm{O}_{2} / \mathrm{C}$. If this trend continues as inlet temperature increases, it is conceivable that eventually $100 \%$ conversion is obtained at an $\mathrm{O}_{2} / \mathrm{C}$ of zero, or in steam reforming mode.

Keeping in mind that the conversion in $\mathrm{SR}$ mode at $250^{\circ} \mathrm{C}\left(482^{\circ} \mathrm{F}\right)$ is estimated based on linear extrapolation. Based on these results, it is believed that the ATR reactor could possibly operate in SR mode at elevated temperatures. From the data presented earlier, SR mode might be successful around temperatures of $650^{\circ} \mathrm{C}\left(1202^{\circ} \mathrm{F}\right)$.

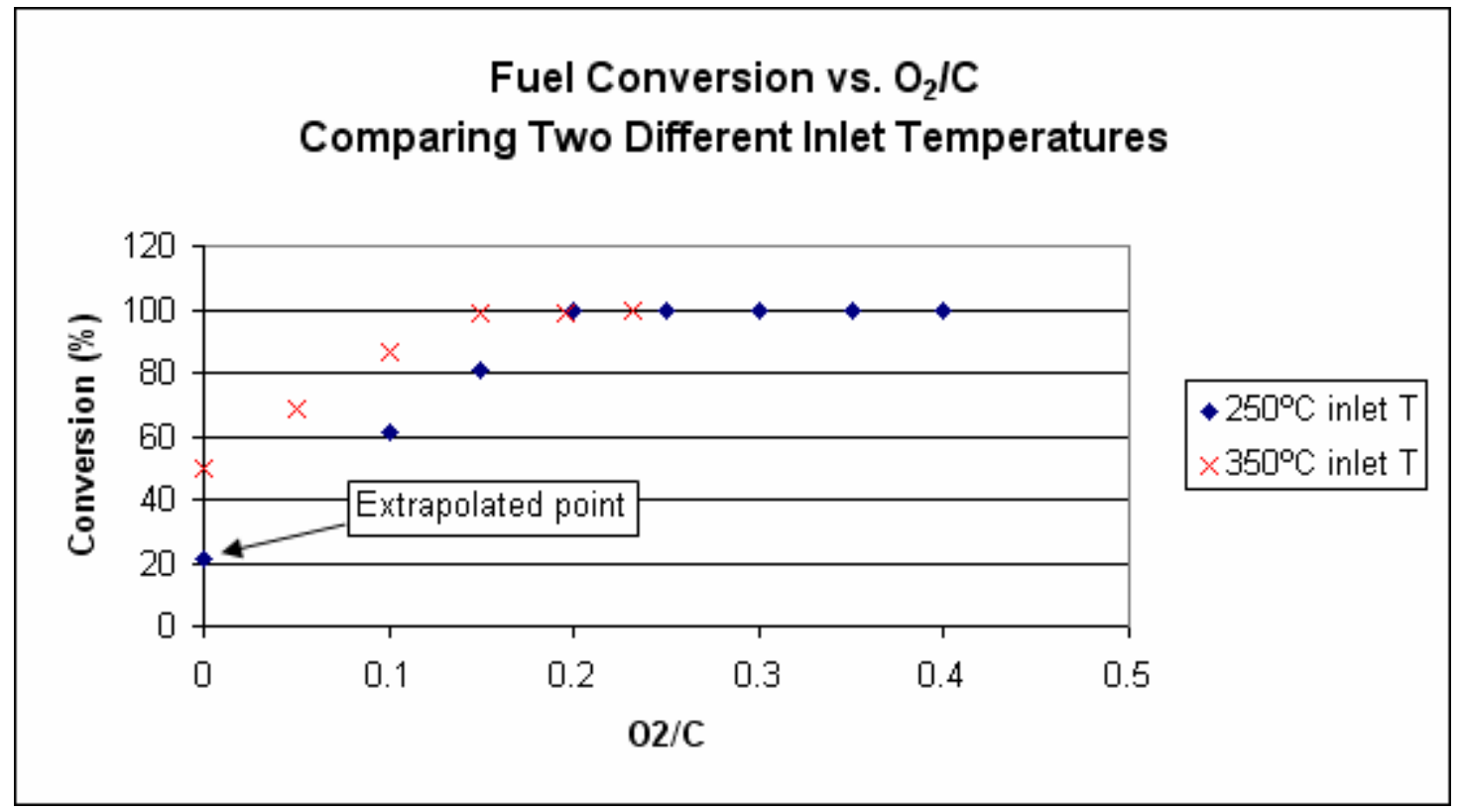

Figure 35: Comparing effects of inlet temperature on fuel conversion, 1.5” catalyst .

Currently the catalyst substrate, a ceramic material with low thermal conductivity, and insulating wrapping material inhibit heat transfer from the reactor walls to the reaction site. This transfer of energy is vital to carry out the endothermic steam reforming reaction. However, if the ATR catalyst were to be supported on a different substrate that facilitates heat transfer and does not require an insulating wrapping material, it is possible that the increase in heat transfer would be sufficient to significantly increase conversion in SR mode. Reactant mixing upstream of the catalyst bed could further improve the fuel conversion at a given inlet temperature by ensuring an even distribution of thermal energy. The possibility of operating an ATR reactor in SR mode has great potential to reduce the start up time and increase dynamic capabilities of a reformer that operates primarily in a highly efficient SR mode. 


\section{Thermal Profile Experimental Results}

A preliminary in-situ comparison of the standard probes to two variations of the support tube probe design has been completed showing significantly reduced effects from sheath conduction. This preliminary experiment suggests that the effects of sheath conduction near the outer wall of the reactor may be skewing the measurements by as much as $25^{\circ} \mathrm{C}$, see Figure 36 and Figure 37. Thermocouples of the improved design are currently being fabricated to carry out measurements of a full temperature profile. A complete investigation of the effect of reactor aspect ration and flow rate on the thermal profile is planned. A bench top axial conduction experiment is underway to compare the performance of the different thermocouple types.

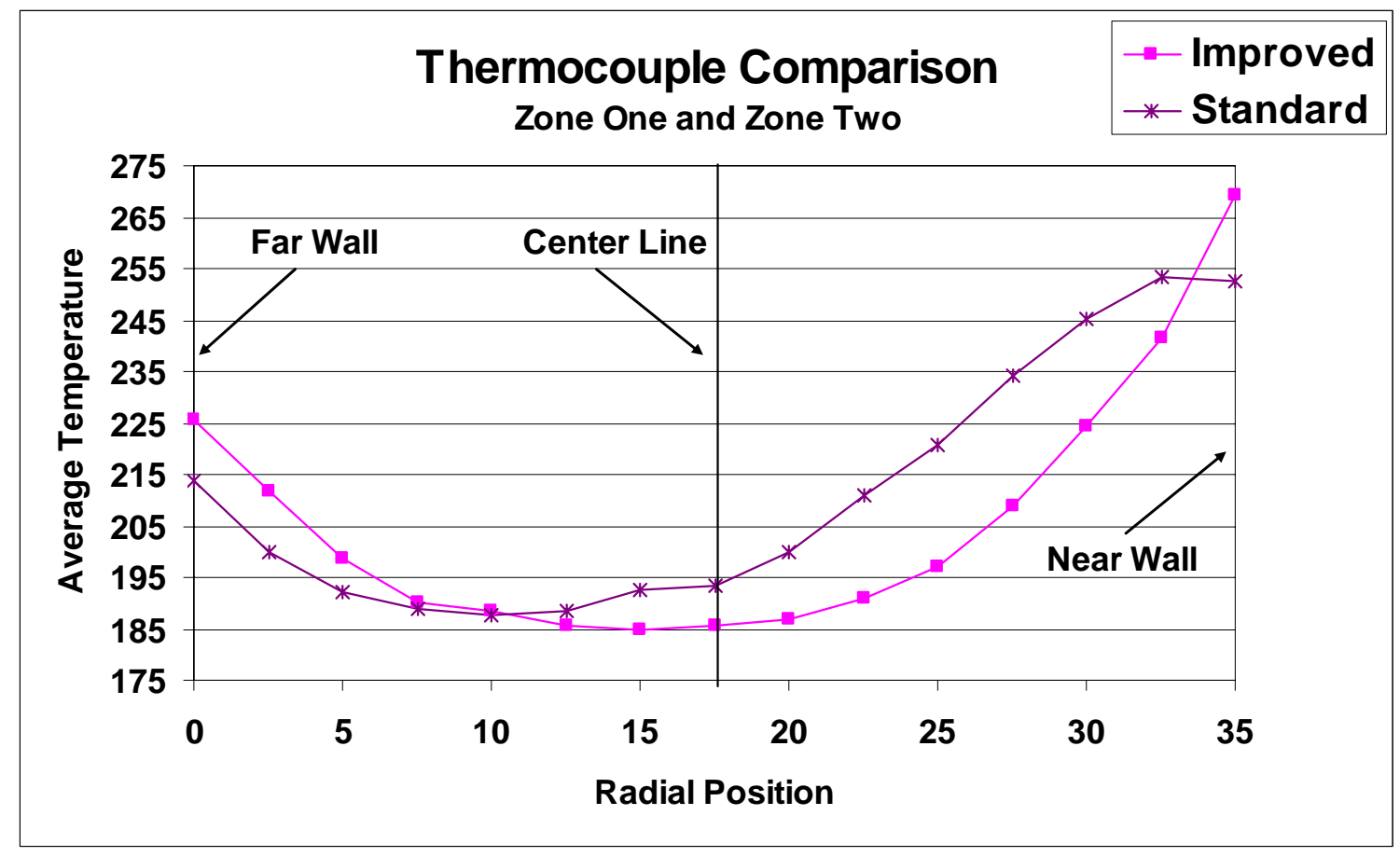

Figure 36: Comparison between standard thermocouples available from OMEGA and improved thermocouples fabricated in house. The two thermocouples are in two different zones of the reactor where the true gas temperature is not exactly the same. 


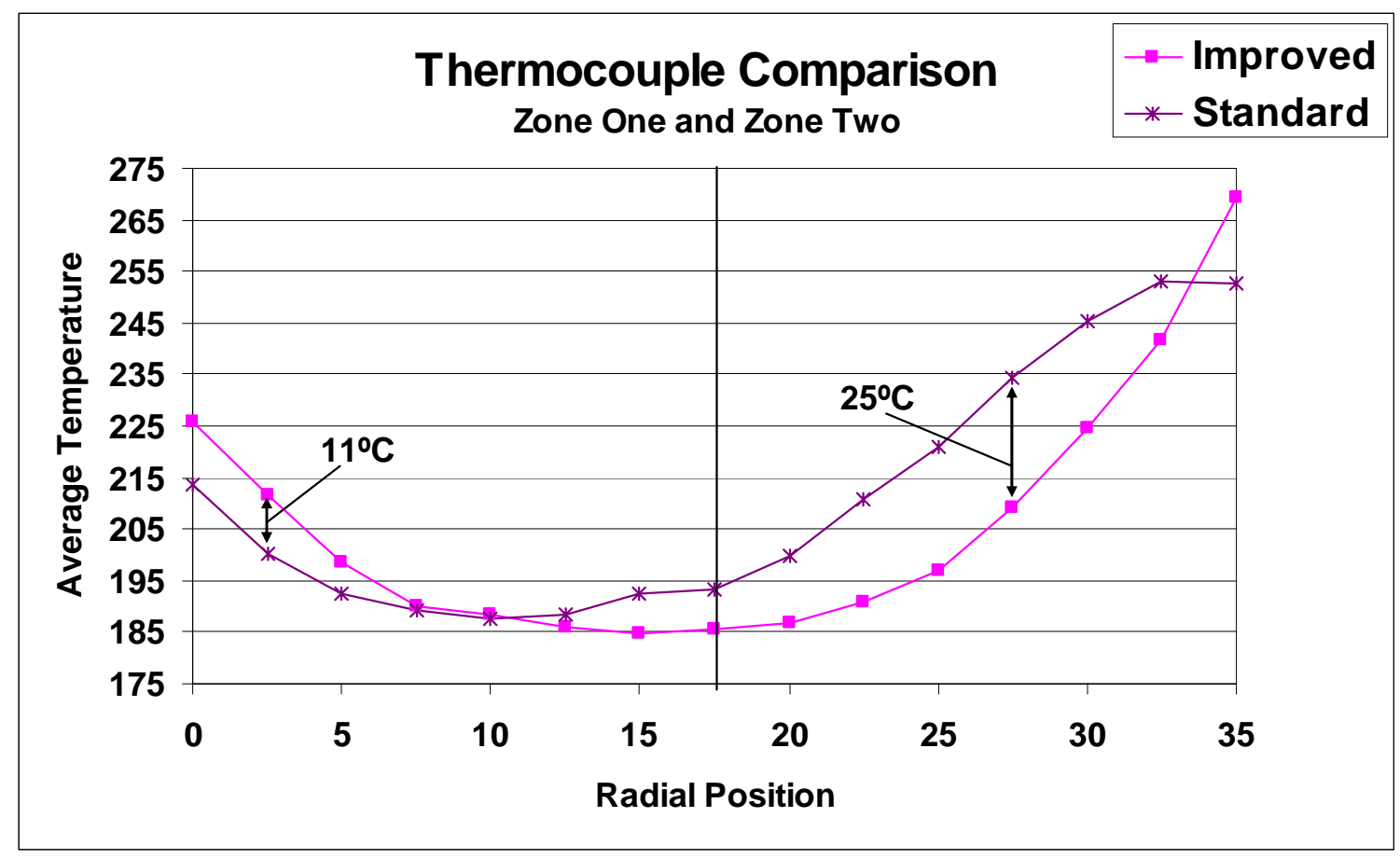

Figure 37 : Temperature differences caused by sheath conduction.

\section{Catalyst Degradation}

In the January $1^{\text {st }}$ to March $31^{\text {st }}$ time frame preliminary investigations were made using the Light Microscopy, Scanning Electron Microscopy, the Electron Dispersive Spectroscopy and the X-Ray Diffraction techniques. The investigations to date have focused on the $\mathrm{CuO} / \mathrm{ZnO} / \mathrm{Graphite}$ catalyst due to its high activity and low operating temperature. The catalyst in the as received oxidized state has a black matte surface on the ends and a black shiny surface around the edges. 


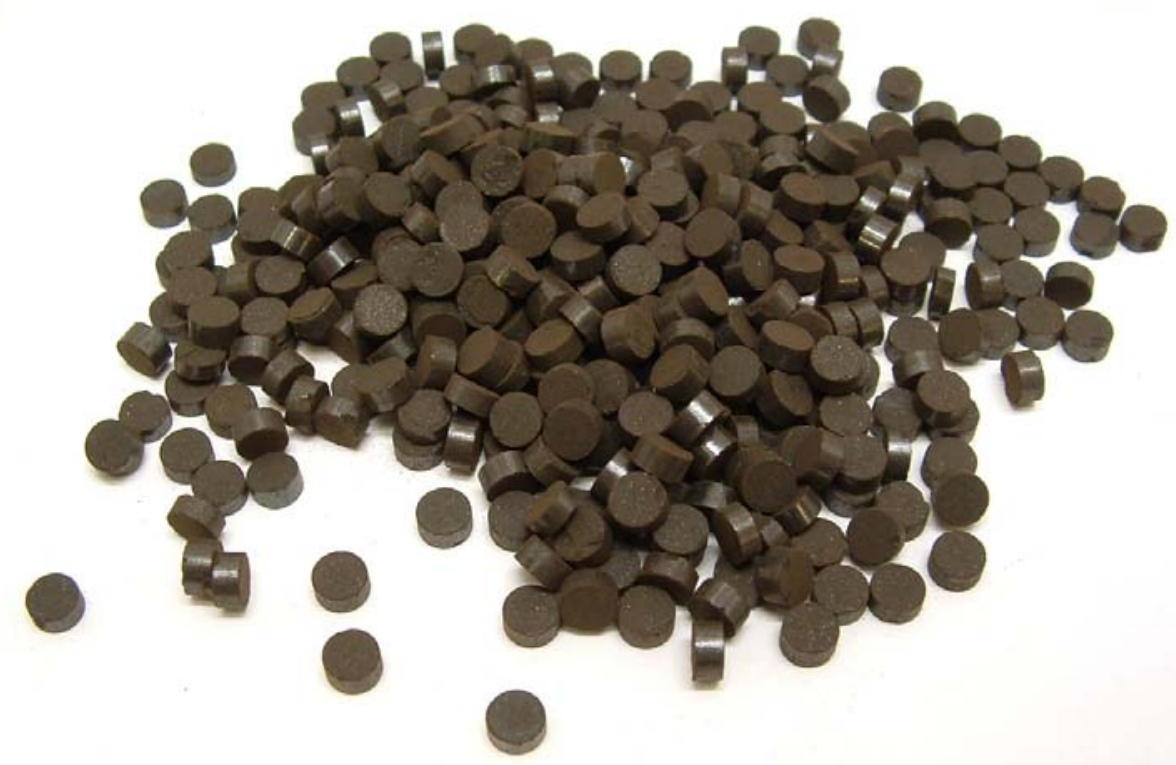

Figure 38: Pelletized catalyst.

Light microscopy results show that the surface is very rough with very small pores penetrating into the pellet, very reflective sections and regions of different colors. For reactor operation the catalyst is reduced and when removed from the reactor the catalyst reoxidizes in air heating up to $190^{\circ} \mathrm{C}\left(374^{\circ} \mathrm{F}\right)$. When the reduced catalyst is removed from the reactor it has a ruby sheen and then as it oxidizes the hottest sections of catalyst turn a pale green color. The difference between these two surfaces can be seen in the light microscope pictures below. Literature investigations suggest that this coloration change may only be related to the reoxidation conditions and may not be caused by chemical changes to the surface of the catalyst during operation. Further work will focus on developing the infrastructure to analyze the catalyst in reduced form in order to make stronger comparisons. 


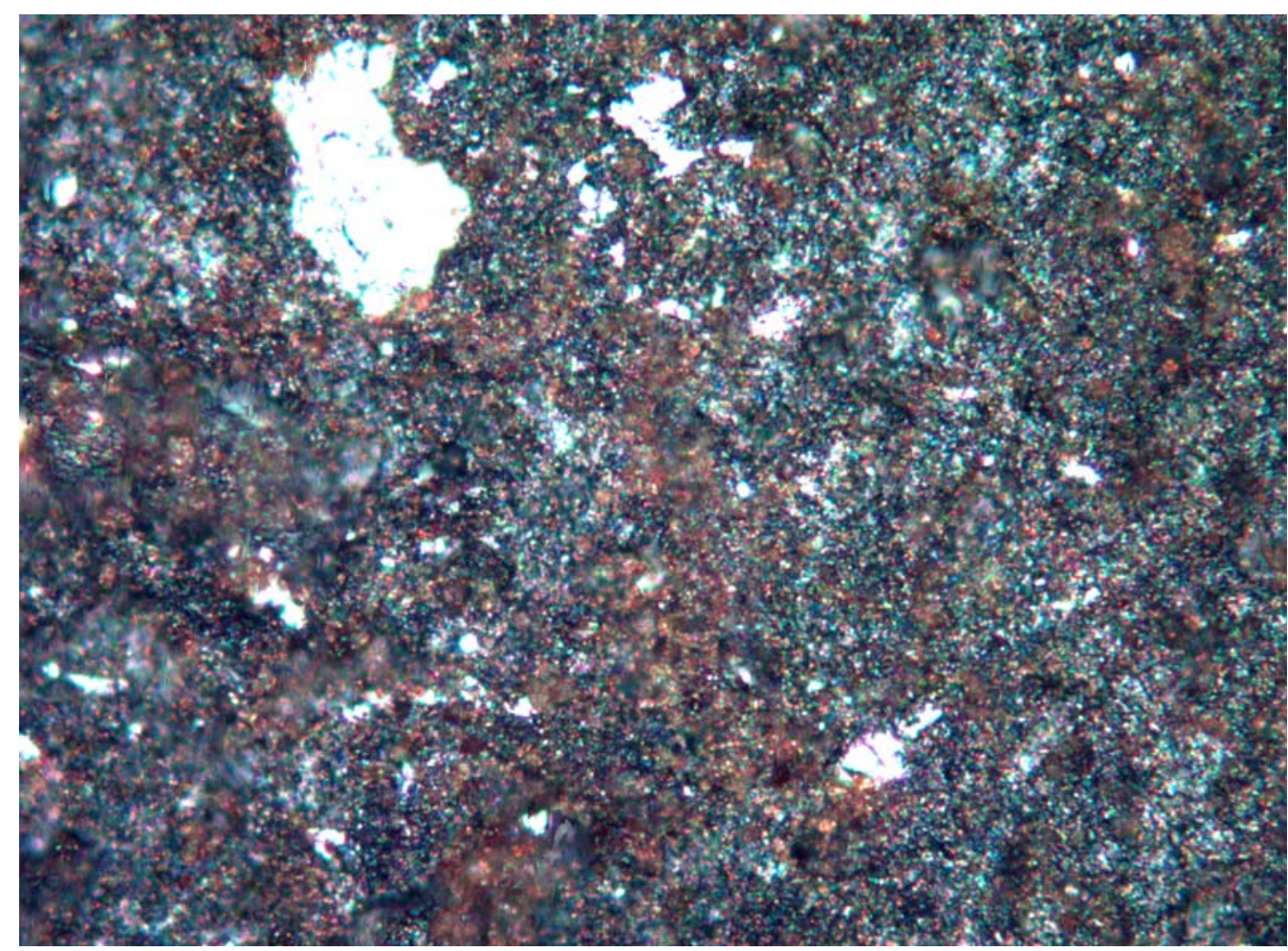

Figure 39: Virgin Catalyst surface at $400 \mathrm{X}$ magnification.

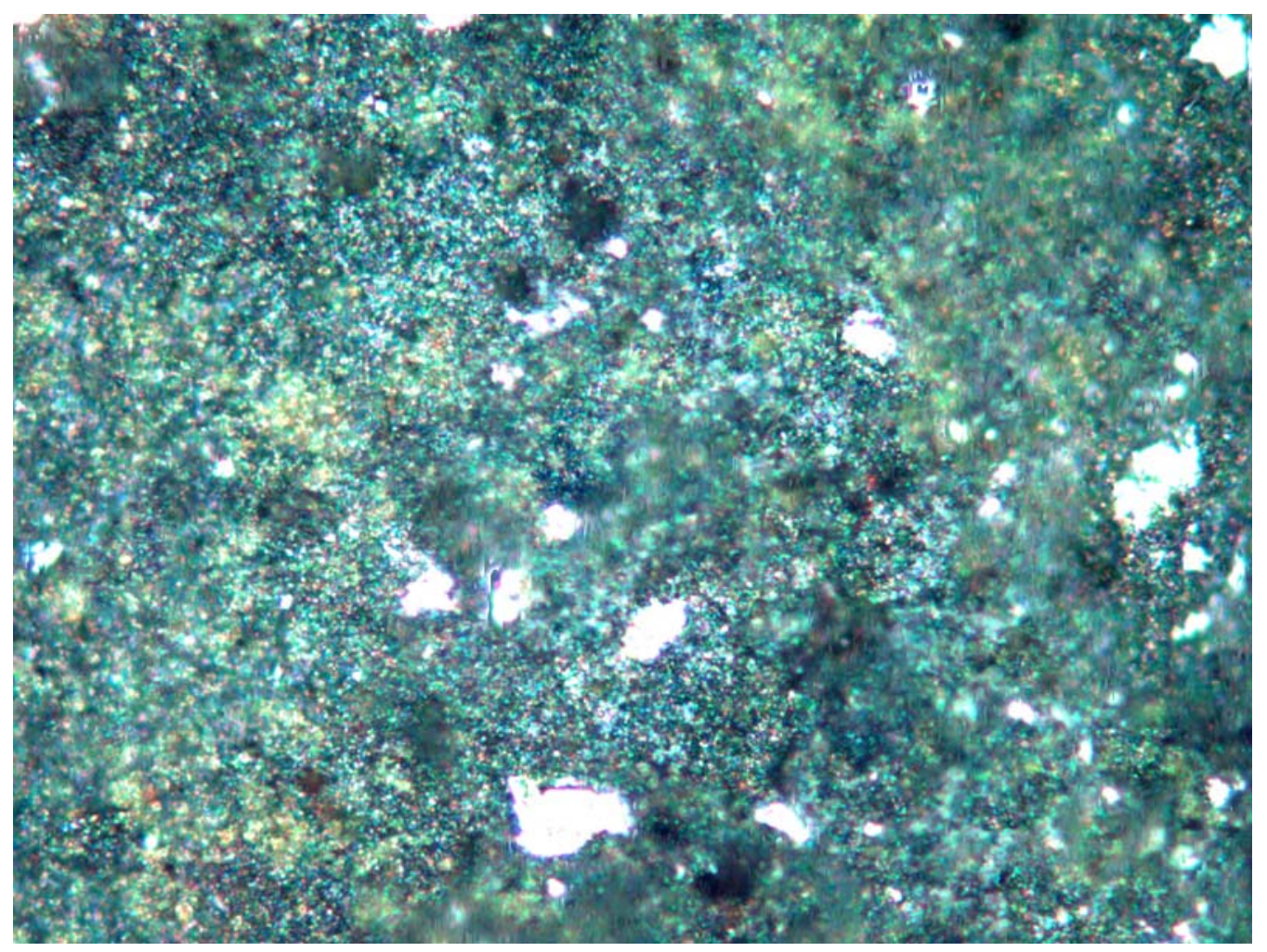

Figure 40: Used Oxidized Catalyst surface at 400X magnification. 
SEM microscopy results have determined that the catalyst particles are composed of consolidated fine particles with particles sizes on the order of nanometers. The catalyst pellets have very fine pore structures with pore diameters on the order of nanometers as well as the larger pores seen in the light microscope images, see figures below. A comparison of the surface of the catalyst pellets before and after use shows some possible loss in surface area although further investigation is required to substantiate this finding. The images below show the surface of a virgin and used catalyst pellet.

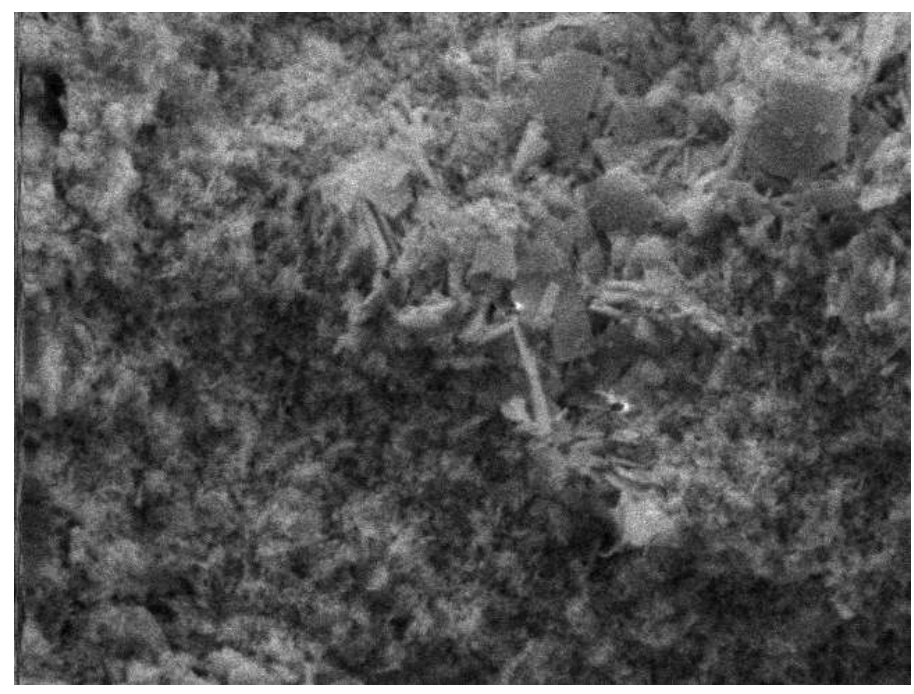

Figure 41: Virgin Catalyst surface.

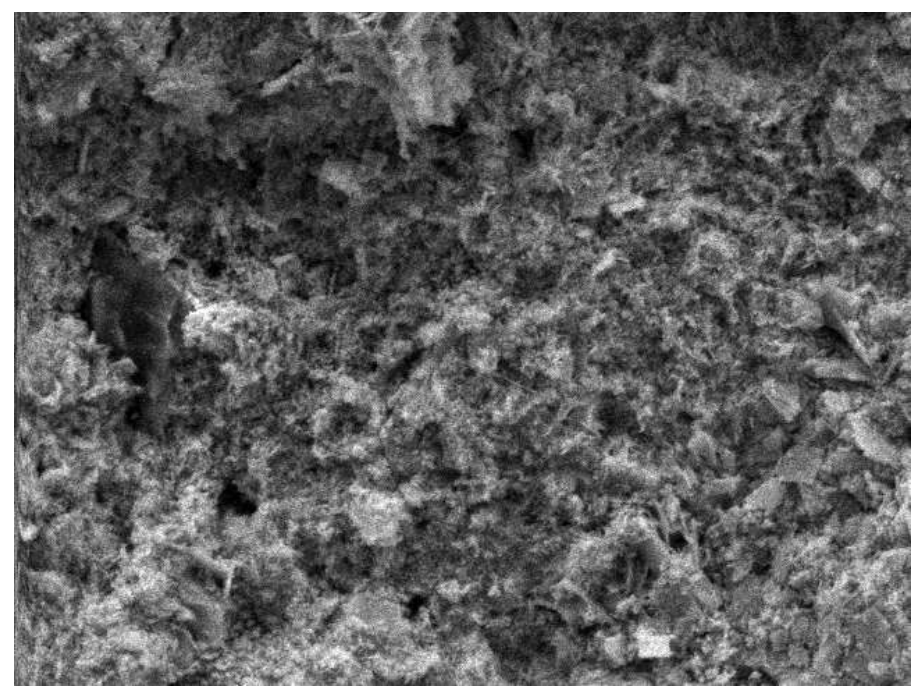

Figure 42: Virgin Catalyst surface. 


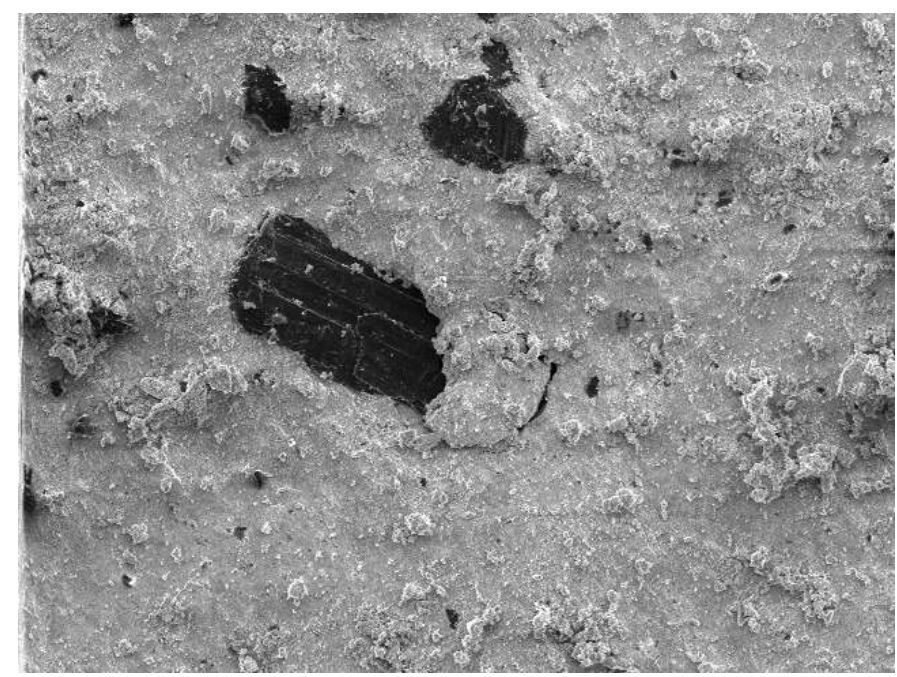

Figure 43: Virgin Catalyst surface.

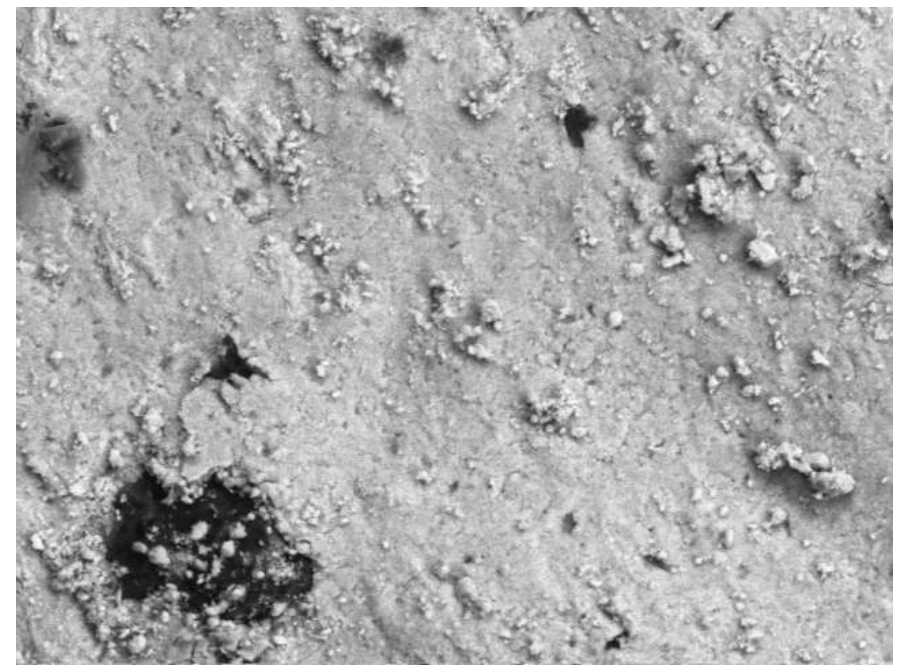

Figure 44: Used Catalyst surface.

EDS results show that the bright white areas in the light microscope pictures and the dark spots in the SEM pictures are graphite islands. The copper and zinc oxides are very evenly distributed across the surface and throughout the interior of the pellets with no identifiable regions rich in either on or the other. This even distribution continues down to minimum spot size of this technique in the micrometer size scale. The figures below show the spectroscopic signatures for Copper, Zinc, Carbon and Oxygen. The distributions for the virgin and used samples tested so far show no identifiable differences. 

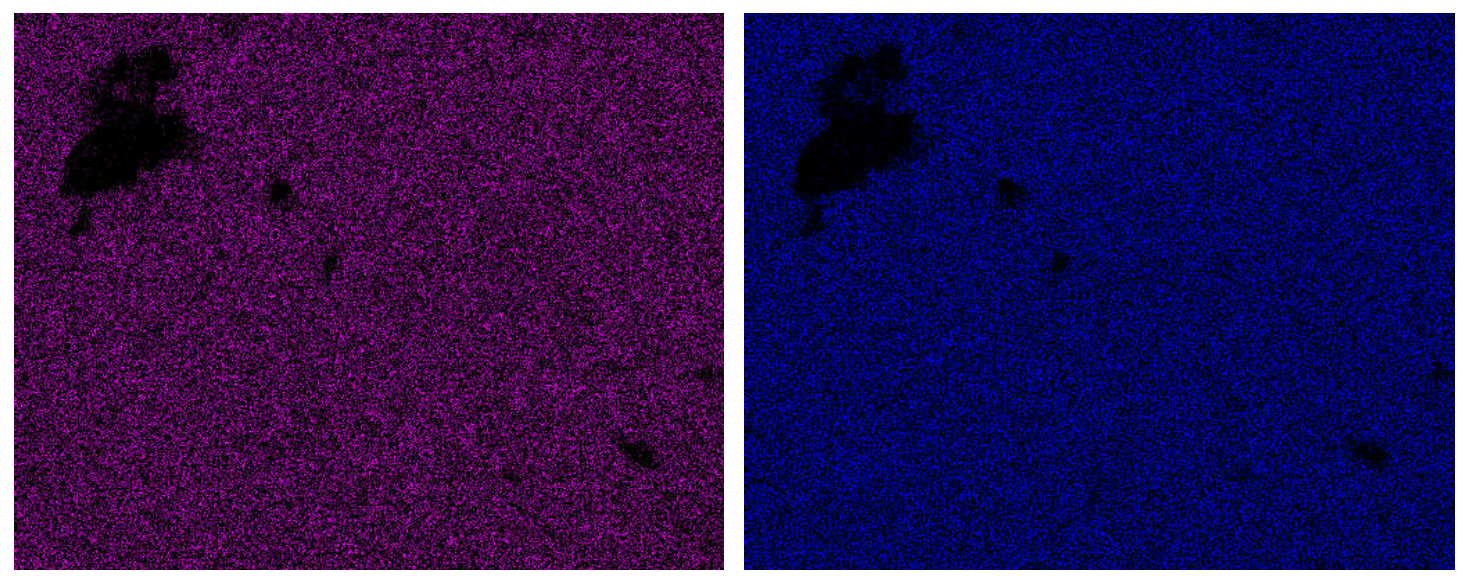

Figure 45: Virgin Catalyst surface, Copper K-alpha wavelength left, Zinc K-alpha wavelength.
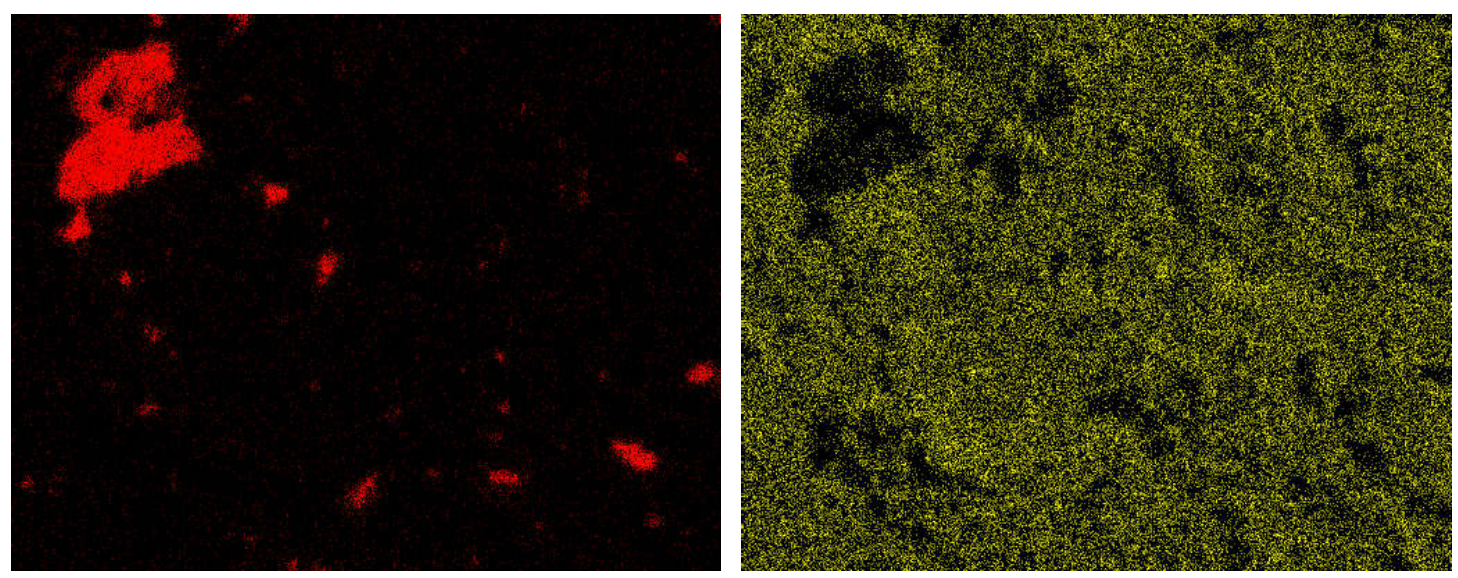

Figure 46: Virgin Catalyst surface, Carbon K-alpha wavelength, Oxygen K-alpha wavelength.

Further work will focus on developing the infrastructure to analyze the catalyst in reduced form in order to make stronger comparisons.

\section{Degradation Experiments}

Catalyst Degradation Experiments were performed with both coal-derived methanol and chemical grade methanol. Much attention was paid to each degradation test to prevent bias of conversion for each of the 70 hour tests. In this experiment, there is only one independent value which is the fuel. Every dependent value was kept identical for each degradation test. The reactor inlet temperature was $250 \sim 253^{\circ} \mathrm{C}\left(482-487.4^{\circ} \mathrm{F}\right)$, and a space velocity of 2.5 LHSV was adopted for this experiment. 


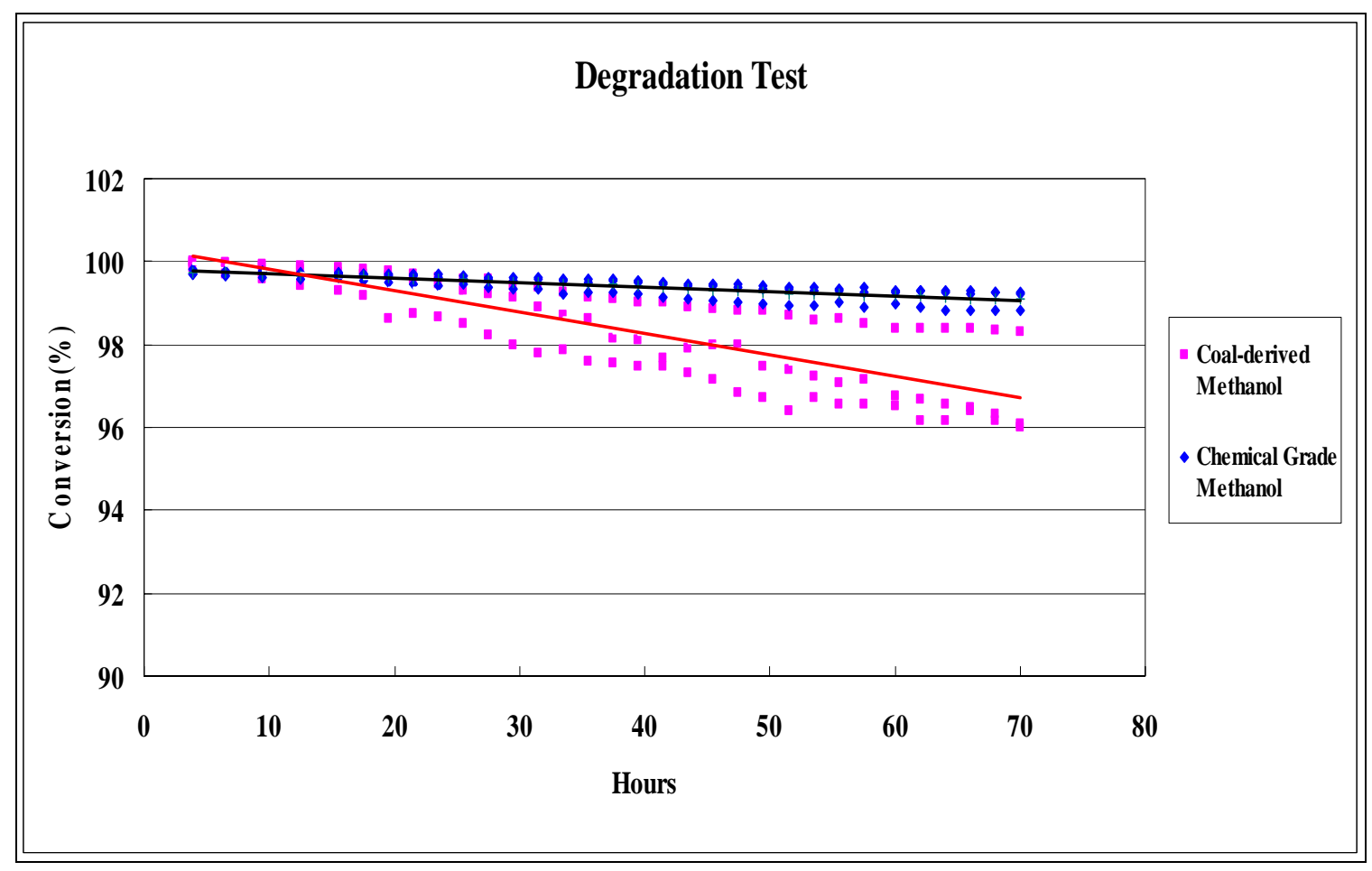

Figure 47: Degradation test for coal-derived methanol and chemical grade methanol for 70 hours.

Figure 47 represents the results of catalyst degradation. In addition, a linear a regression line has been added with regard to the three tests for each methanol fuel. The rate of degradation for the coal-derived methanol is much faster than that of chemical grade methanol. The deactivation rate of coal-derived methanol is roughly $-0.1065 \%$ conversion per hour. On the other hand, the deactivation rate of chemical grade methanol roughly $-0.02196 \%$ conversion per hour. In general, catalyst degradation is usually caused by sintering, fouling, or poisoning. Through our chemical analysis we saw that the coal-derived methanol has more hydrocarbon compounds than does chemical grade methanol. For example, some of the light hydrocarbons could be reformed in our reactor because of the high temperature. However, higher hydrocarbons (over C6) should cause poisoning as well as fouling by chemical reaction with the copper, and physical blocking active of the catalyst pours. To be sure, sulfur and chloride should make catalyst deactivation exacerbated as well, however, it can be assumed that there is little difference in the sulfur and chloride content for both methanols. This was shown through our second external analysis of coal-derived methanol compared with chemical grade methanol. Moreover, by means of the variation of hydrocarbon concentrations (Figure 48) through degradation test, we might come to a conclusion that the difference of hydrocarbon concentrations in each of the methanol fuels cause different deactivation rates at the same conditions.

\section{Hydrocarbon gas concentration}

This is the gas concentration measured after the condenser. The condenser causes the hydrocarbon gases to liquefy, as well as a portion of the unreacted methanol gas. A portion of the unreacted methanol gas does not condense. However, it can be negligible 
for hydrocarbon analysis in that every data point during each methanol degradation test has nearly equal amounts of uncondensed methanol gas in addition to the hydrocarbon gas concentration, in the comparison of coal-derived methanol with chemical grade methanol.

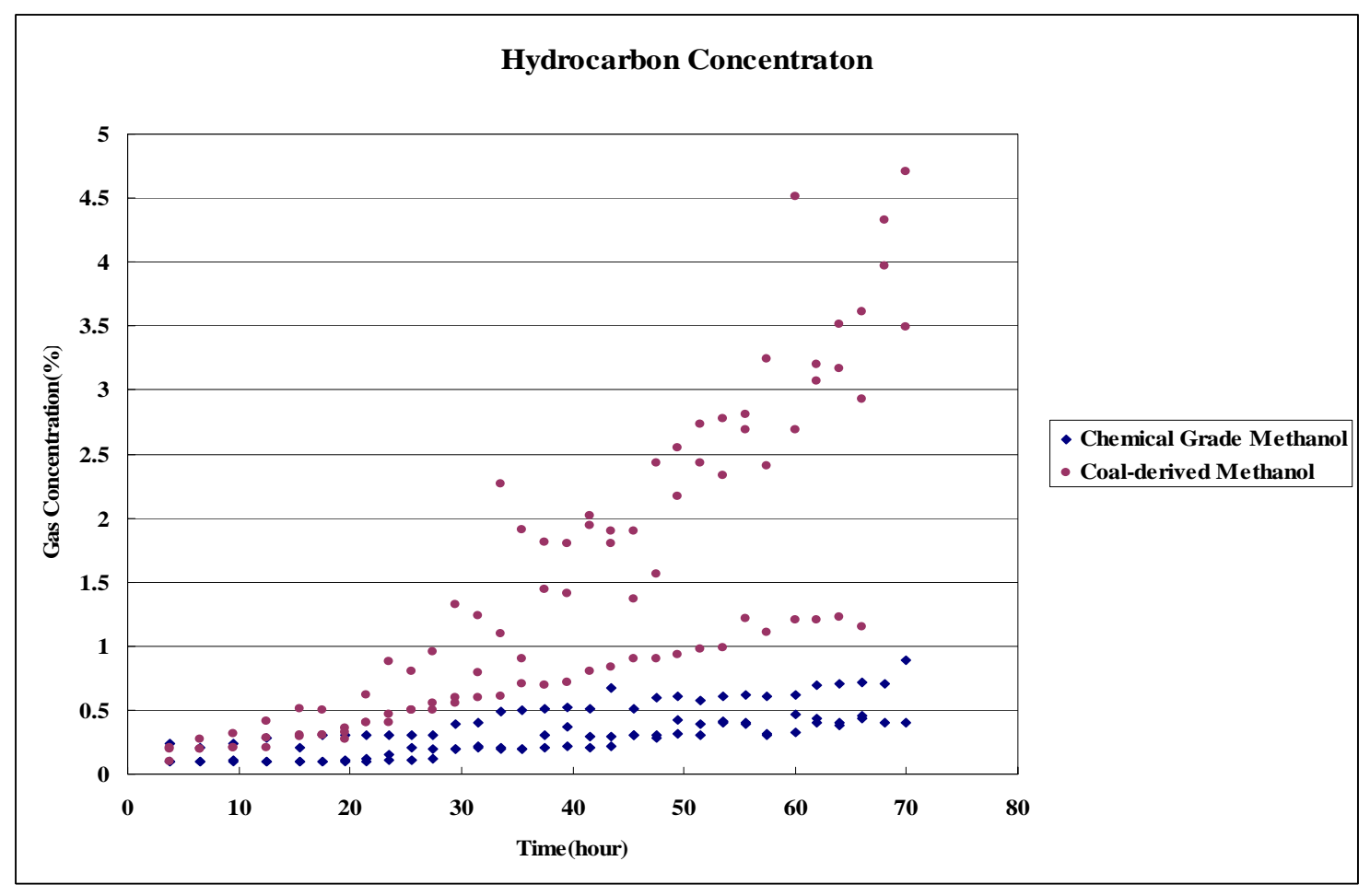

Figure 48: hydrocarbon concentration for both chemical grade methanol and coal-derived methanol for 70 hour degradation tests.

Figure 48 represents of a variation of hydrocarbon concentrations for both chemical grade methanol and coal-derived methanol for each of the 70 hour degradation tests. When measuring hydrocarbon gases by infra red technology, all of these gases absorb IR energy in the same wavelength of 3.4 micron. For the first 12 hours, hydrocarbon gas concentrations of coal-derived methanol are nearly equal to that of chemical grade methanol. However, after around 12 hours, hydrocarbon gas concentration of coalderived methanol increases much faster than that of chemical grade methanol. It definitely can be said that catalyst degradation is occurring in reactor at this point. It could be due to fouling and poisoning from the hydrocarbons. 39g (0.0861b) of catalyst can handle some of the hydrocarbons, however, if hydrocarbons are continuously supplied over some of the hydrocarbons will not be reacted by the catalyst physically and chemically. As the catalyst degradation is continuing the excess hydrocarbons will just pass through the reactor. On the other hand, deactivated catalyst might accelerate the production of by-product hydrocarbon such as methyl formaldehyde and formaldehyde etc. 


\section{Carbon Monoxide and Carbon Dioxide Concentrations}

Carbon monoxide concentrations should be minimized to less than $10 \mathrm{ppm}$ for both PEM (Polymer Electrolyte Membrane) and PAFC (Phosphoric Acid Fuel Cell) applications. Carbon monoxide formation is still controversial for copper based catalysts. In the literature, there are two suggestions associated with reaction pathway for methanol steam reforming and carbon monoxide formation. One is that $\mathrm{CO}$ is primary product from methanol decomposition $[4,5,6,8]$. Another is that $\mathrm{CO}$ is a secondary product produced through a reverse water gas shift reaction $[2,3,7]$. These two suggestions start from two agreements. First, the concentration of $\mathrm{CO}$ is below the thermodynamic equilibrium calculation because the methanol decomposition reaction rate is much smaller than the steam reforming reaction rate. Second, copper based catalyst is used for the water gas shift reaction. In the first suggestion, $\mathrm{CO}$ is produced directly through methanol decomposition and then $\mathrm{CO}$ is converted into $\mathrm{CO}_{2}$ by the water gas shift reactions shown in Equation 5. Methanol decomposition, steam reforming and the water gas shift reaction should be thought of as a combined reaction network $[4,5]$.

$$
\begin{gathered}
\mathrm{CH}_{3} \mathrm{OH}(\mathrm{l}) \rightarrow \mathrm{CO}+2 \mathrm{H}_{2} \\
\mathrm{H}_{2} \mathrm{O}(\mathrm{g})+\mathrm{CO} \rightarrow \mathrm{H}_{2}+\mathrm{CO}_{2} \\
\mathrm{CH}_{3} \mathrm{OH}+\mathrm{H}_{2} \mathrm{O} \rightarrow \mathrm{CO}_{2}+3 \mathrm{H}_{2}
\end{gathered}
$$

Equation 5

Another suggestion proposes that $\mathrm{CO}$ cannot be produced as a primary product of methanol decomposition because there was no $\mathrm{CO}$ produced for short residence times of methanol in the reactor, even though copper catalyst had been used. Therefore, it can be thought of as a secondary product through a reverse water gas shift reaction as seen in Equation $6[2,3,7]$. The methanol decomposition reaction rate is pretty small so that it can be negligible [14].

$$
\begin{aligned}
& \mathrm{CH}_{3} \mathrm{OH}+\mathrm{H}_{2} \mathrm{O} \rightarrow \mathrm{CO}_{2}+3 \mathrm{H}_{2} \\
& \mathrm{CO}_{2}+\mathrm{H}_{2} \rightarrow \mathrm{CO}+\mathrm{H}_{2} \mathrm{O}
\end{aligned}
$$

Equation 6

Figure 49 represents carbon monoxide concentrations of reformed methanol both chemical grade and coal-derived from 70 hour degradation tests. In Figure 49, carbon monoxide concentration continued to decrease for both coal-derived methanol and chemical grade methanol as catalyst degradation progressed. In general, at low temperatures of $220 \sim 280^{\circ} \mathrm{C}\left(428-536^{\circ} \mathrm{F}\right)$, reduced copper has another role which is to facilitate the water gas shift reaction while the steam reforming reaction is occurring. Inside the reactor, there is no specific area for the water gas shift reaction as well as the steam reforming reaction. The reduced copper sites are shared for both reactions $[4,5]$. This means both reactions should be degraded at the same rate even though the water gas shift reaction is an exothermic reaction as opposed to the steam reforming reaction which is endothermic. Therefore, the concentration $\mathrm{CO}_{2}$ produced by the water gas shift 
reaction should be decreased due to deactivated catalyst. However, in Figure 50, we see that the $\mathrm{CO}_{2}$ concentration keeps increasing slowly even though catalyst degradation is taking place. It obviously shows that $\mathrm{CO}_{2}$ cannot be produced by the water gas shift reaction even though copper has the ability to serve as a water gas shift catalyst. This brings us to the conclusion that $\mathrm{CO}$ is a secondary product formed through a reverse water gas shift reaction instead of the normal water gas shift reaction. In comparison coal-derived methanol shows smaller concentrations of $\mathrm{CO}$ than those produced from chemical grade methanol. This is because the reverse water gas shift reaction is deactivated faster in the case of coal-derived methanol than in the case of chemical grade methanol by means of fouling and poisoning of the catalyst from hydrocarbons. During first 10 hours the carbon monoxide concentrations appear to be nearly same (Figure 49). However, after 10 hours, the $\mathrm{CO}$ concentrations from coal-derived deceased a little bit faster than that of chemical grade methanol.

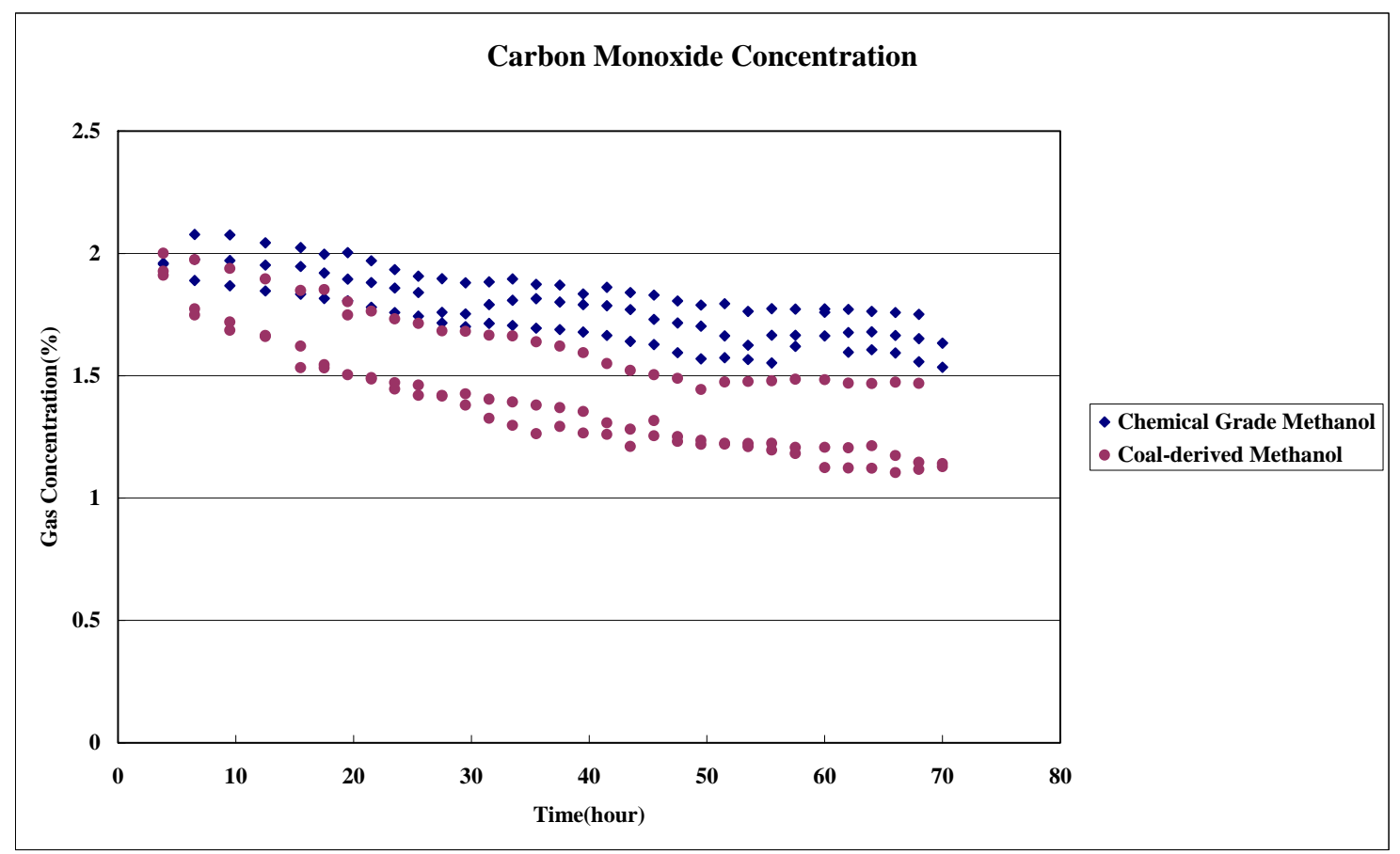

Figure 49: carbon monoxide concentration from reformed chemical grade and coal-derived methanol for 70 hour degradation tests.

The $\mathrm{CO}_{2}$ concentrations of coal-derived methanol are a little bit higher than those from chemical grade methanol as seen in Figure 50. After catalyst degradation begins to take place, some of the $\mathrm{CO}_{2}$ is no longer able to be reacted by the reverse water gas shift reaction due to the reduction of active copper site. Higher degradation rates show more concentration of $\mathrm{CO}_{2}$ 


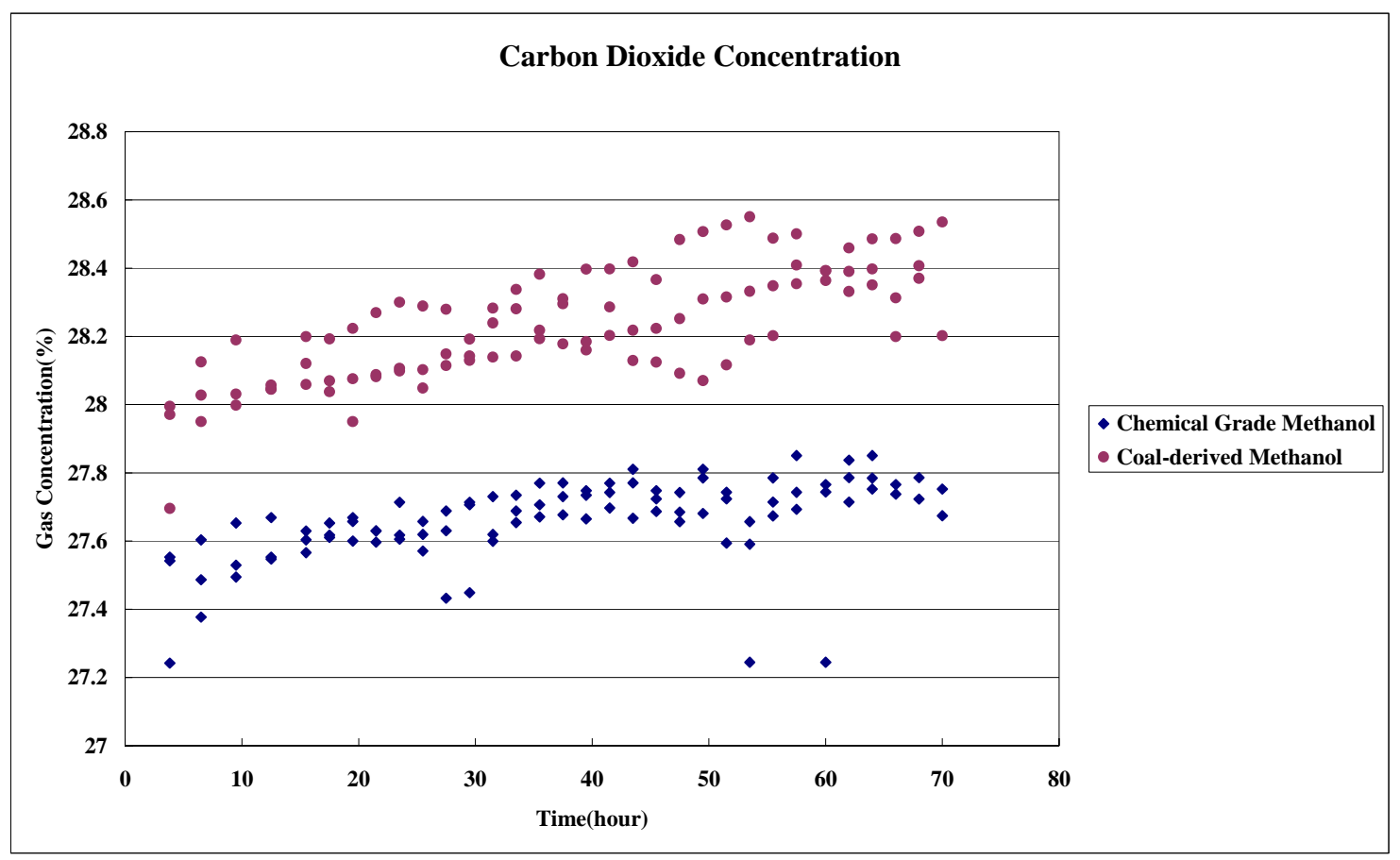

Figure 50: Carbon dioxide concentration from reformed chemical grade and coal-derived methanol for 70 hour degradation tests.

\section{Variation of Temperature}

Steam reforming is a strongly endothermic reaction. As already mentioned above, there is no special place the for reverse water gas shift reaction. It should be happening simultaneously with the steam reforming reaction on the same active copper sites. Figure 51 shows temperature differences between reactors with and without catalyst at the same location. This can explain that zone 1 is the most active site as opposed to zone 2 inside the reactor, based on the endothermic reaction. A large amount of heat energy is consumed in zone 1 compared with zone 2 . However, during catalyst degradation, it can be expected that this active zone should be moved down through the reactor as the most active site degrades. Figure 52 represents the temperature change of each zone during the 70 hour degradation tests. These results support the conclusion that the active zone is moving down toward zone 2 during the 70 hour degradation tests. The zone 1 temperature increases incrementally during the 70 hour degradation tests. On the other hand, the zone 2 temperature decreases slowly during 70 hour degradation tests. In Figure 52, zone 1 temperature shows a faster increase in case of coal-derived methanol than that of chemical grade methanol. This result also supports the conclusion that the degradation rate of coal-derived methanol is faster than that of chemical grade methanol. 


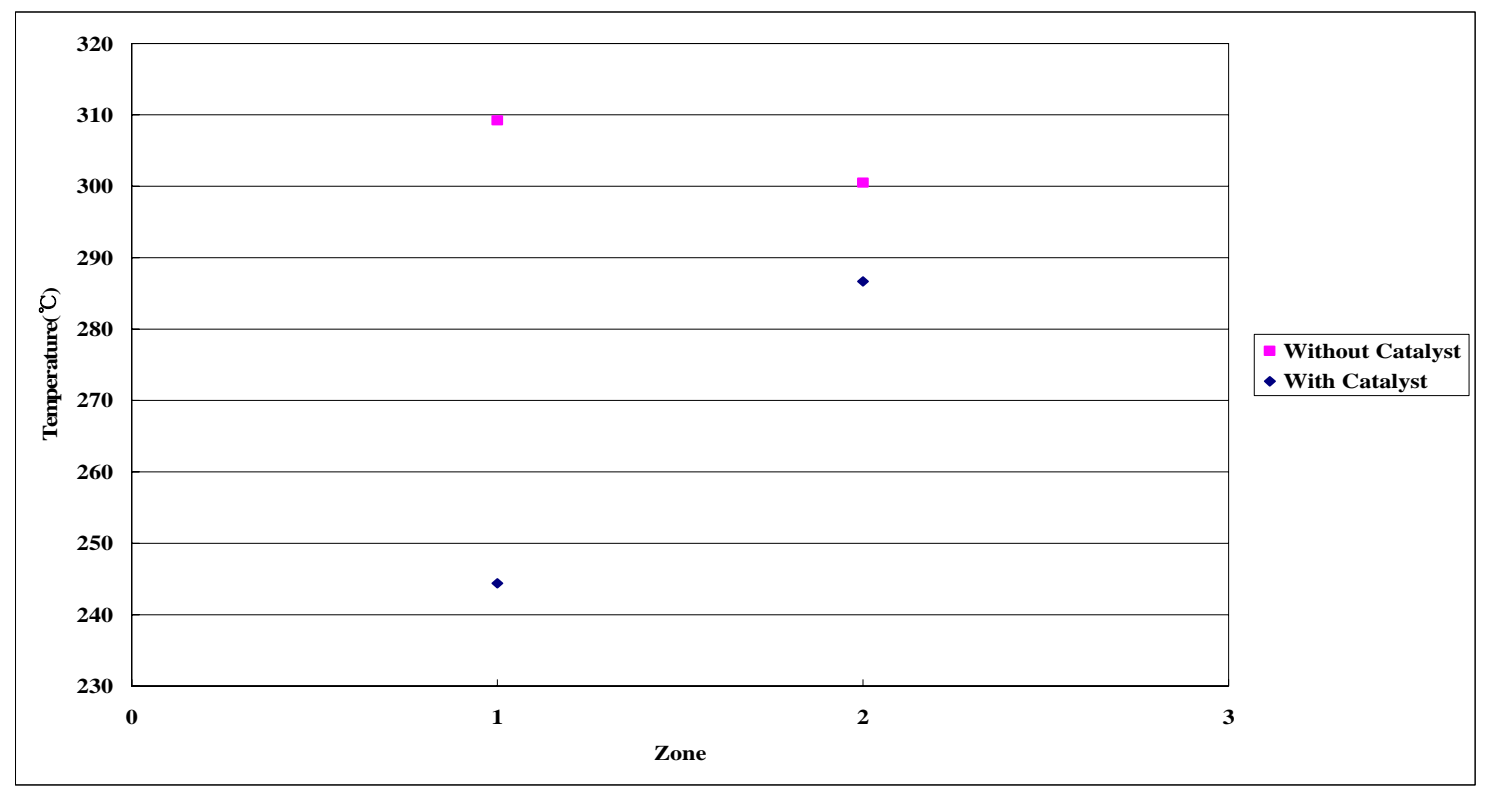

Figure 51: Temperature difference between a reactor with and without catalyst at the centerline.

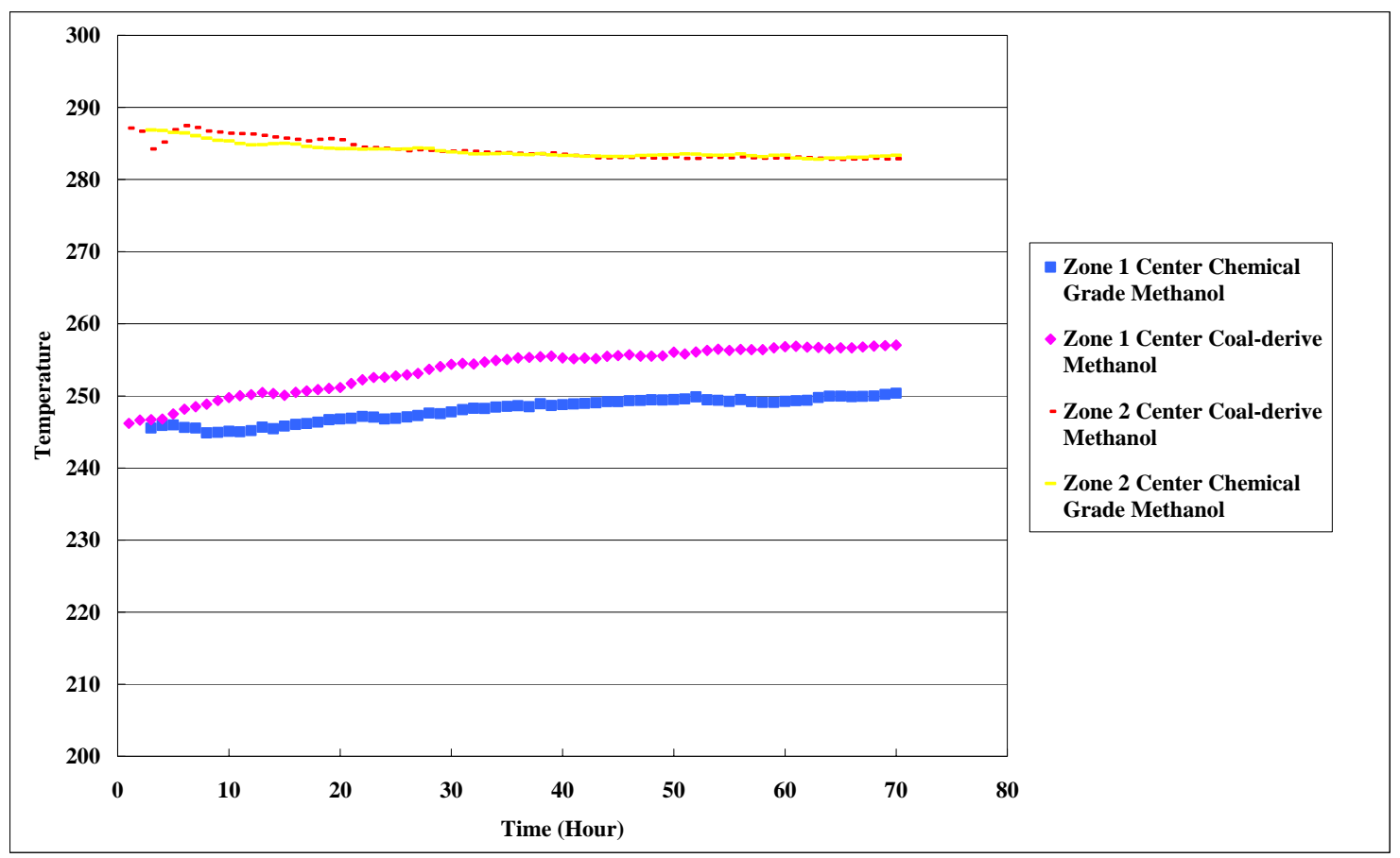

Figure 52: Temperature change of zone 1 and zone2 during 70 hour degradation tests. 


\section{Steam Reformation Enhancement Methods}

\section{Demonstration of Bluff Body Enhancement}

Based on the factorial experiment design, the three independent variables all showed statistically significant effects on the steam reforming processes. The standard to determine if the variable can significantly influence the experiment process or not is to compare its signal-to-noise ratio and student $t$ ratio. The result of this factorial experiment is shown in Table 9.

Table 9: Signal-to-noise, t-ratio and statistical significance 1.

\begin{tabular}{|c|c|c|c|}
\hline & $t^{*}$ & $\begin{array}{c}\text { Significant at } 95 \% \\
\text { Confidence? }\end{array}$ & $\begin{array}{c}\text { Significant at } 99.9 \% \\
\text { Confidence? }\end{array}$ \\
\hline Student $t$-value at $95 \%$ confidence & 2.120 & - & - \\
\hline Student $t$-value at $95 \%$ confidence & 4.015 & - & - \\
\hline Effect of Flow Rate $\left(E_{1}\right)$ & -86.517 & Yes & Yes \\
\hline Effect of Catalyst Dimension $\left(E_{2}\right)$ & -31.973 & Yes & Yes \\
\hline $\begin{array}{l}\text { Effect of Bluff Body Package } \\
\text { Density }\left(E_{3}\right)\end{array}$ & 13.155 & Yes & Yes \\
\hline $\begin{array}{l}\text { Interaction of Flow Rate and } \\
\text { Catalyst Dimension }\left(\mathrm{I}_{12}\right)\end{array}$ & -25.54 & Yes & Yes \\
\hline $\begin{array}{c}\text { Interaction of Flow Rate and } \\
\text { Package Density (Flow Rate and } \\
\text { Package Density }\left(\mathrm{I}_{13}\right)\end{array}$ & 10.654 & Yes & Yes \\
\hline $\begin{array}{l}\text { Interaction of Catalyst Dimension } \\
\text { and Package Density }\left(\mathrm{I}_{23}\right)\end{array}$ & 13.938 & Yes & Yes \\
\hline $\begin{array}{c}\text { Interaction of Flow Rate, Catalyst } \\
\text { Dimension and Package Density } \\
\left(\mathrm{I}_{123}\right)\end{array}$ & 0.13 & No & No \\
\hline
\end{tabular}

The results demonstrated that introducing bluff body packages inside the reactor had a significant effect on the steam reforming process and can improve the fuel conversion. According to this factorial experiment design, a linear fuel conversion model was also developed, given in Equation 7 Equation 7.

$$
\begin{aligned}
& C(\%)=86.39-12.48 X_{1}-4.62 X_{2}+1.90 X_{3} \\
& -3.64 X_{1} X_{2}+1.54 X_{1} X_{3}+2.01 X_{2} X_{3}
\end{aligned}
$$

Equation 7

$\mathrm{X} 1, \mathrm{X} 2$, and $\mathrm{X} 3$ are based on the inputs of independent variables and are derived from Equation 8 through Equation 10.

$$
X_{1}=(\text { Flow Rate }[\mathrm{ml} / \mathrm{min}]-5[\mathrm{ml} / \mathrm{min}]) \cdot \frac{1-(-1)}{20-5}+(-1)
$$




$$
\begin{array}{cc}
X_{2}=(\text { Catalyst Length }[\mathrm{mm}]-2.5[\mathrm{~mm}]) \cdot \frac{1-(-1)}{4.75-2.5}+(-1) & \text { Equation } 9 \\
X_{3}=(\text { Package Number }-2) \cdot \frac{1-(-1)}{8-2}+(-1) & \text { Equation } 10
\end{array}
$$

A verification of this model's accuracy was obtained by comparing the predicted conversion with empirical data collected. The flowrate was held constant at $20 \mathrm{ml} / \mathrm{min}$ (4.0 LHSV-M) to evaluate how well the model predicted percent conversion for different package numbers. The result is shown in Figure 53.

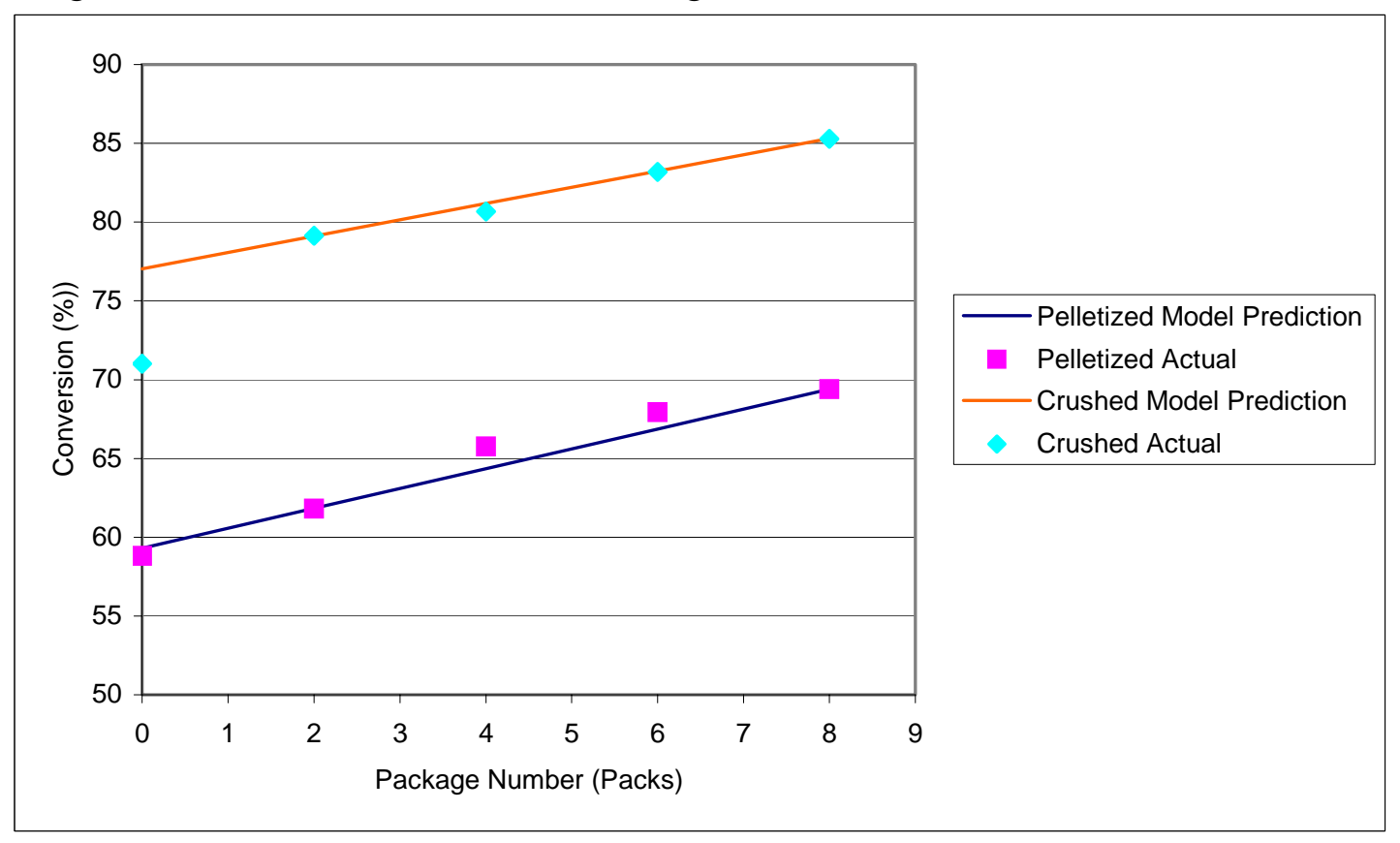

Figure 53: Predicted conversion vs. actual conversion at 4 LHSV-M for different package numbers.

In Figure 53, almost all the empirical conversions are within a tolerable value for twice the pooled standard deviation of $1.32 \%$ except the $4 \mathrm{P}$, which has a larger deviation of $1.42 \%$. However, for zero packages, as it is out of the boundary used for developing the model, the offset is extremely large compared to twice the pooled standard deviation.

\section{Conversion Enhancement}

Figure 54 and Figure 55 give the empirical conversions collected for all the ten experiment configurations at four different space velocities, and show linear regression lines. 


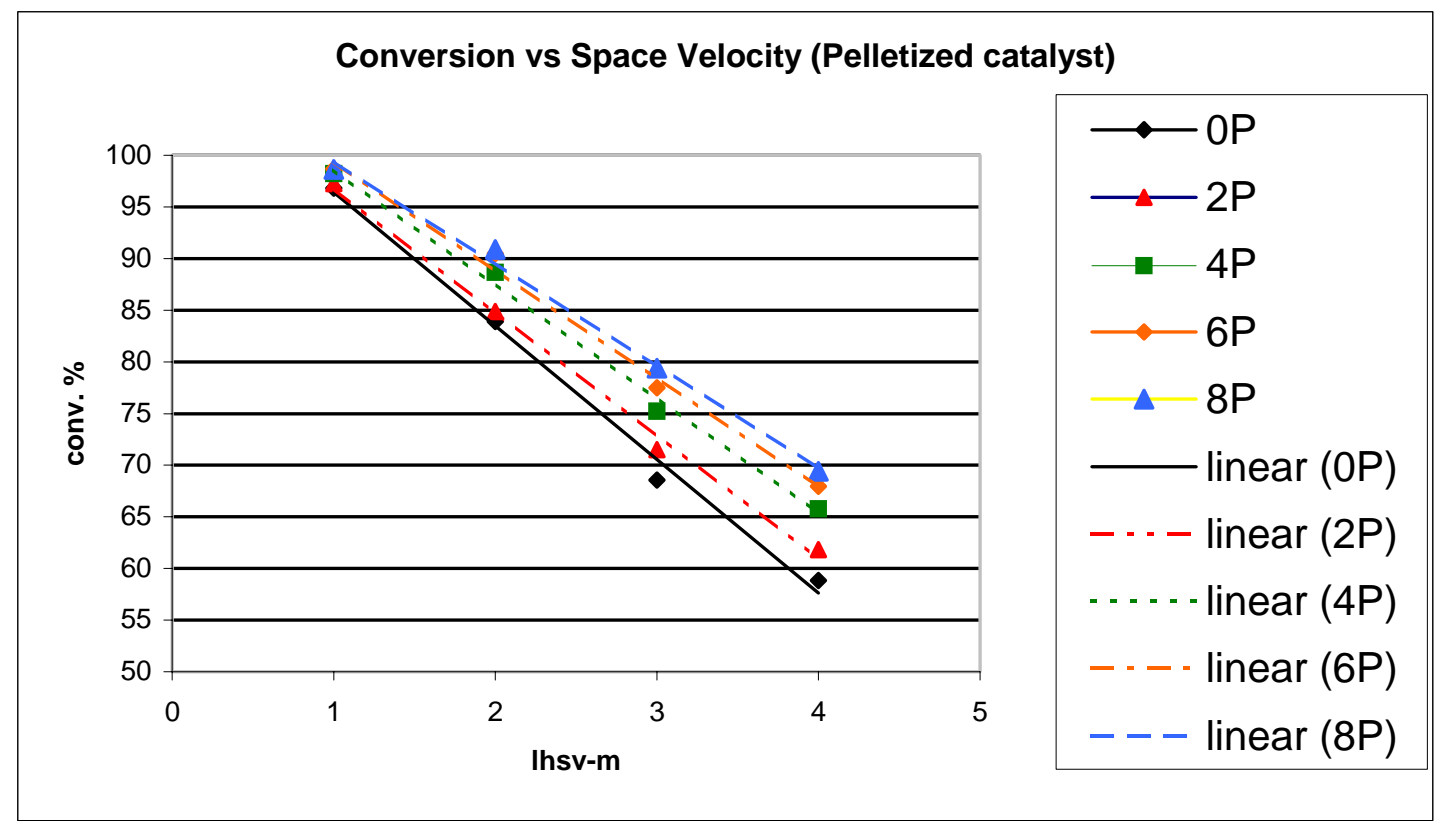

Figure 54: conversion versus space velocity with different package numbers and pelletized catalyst.

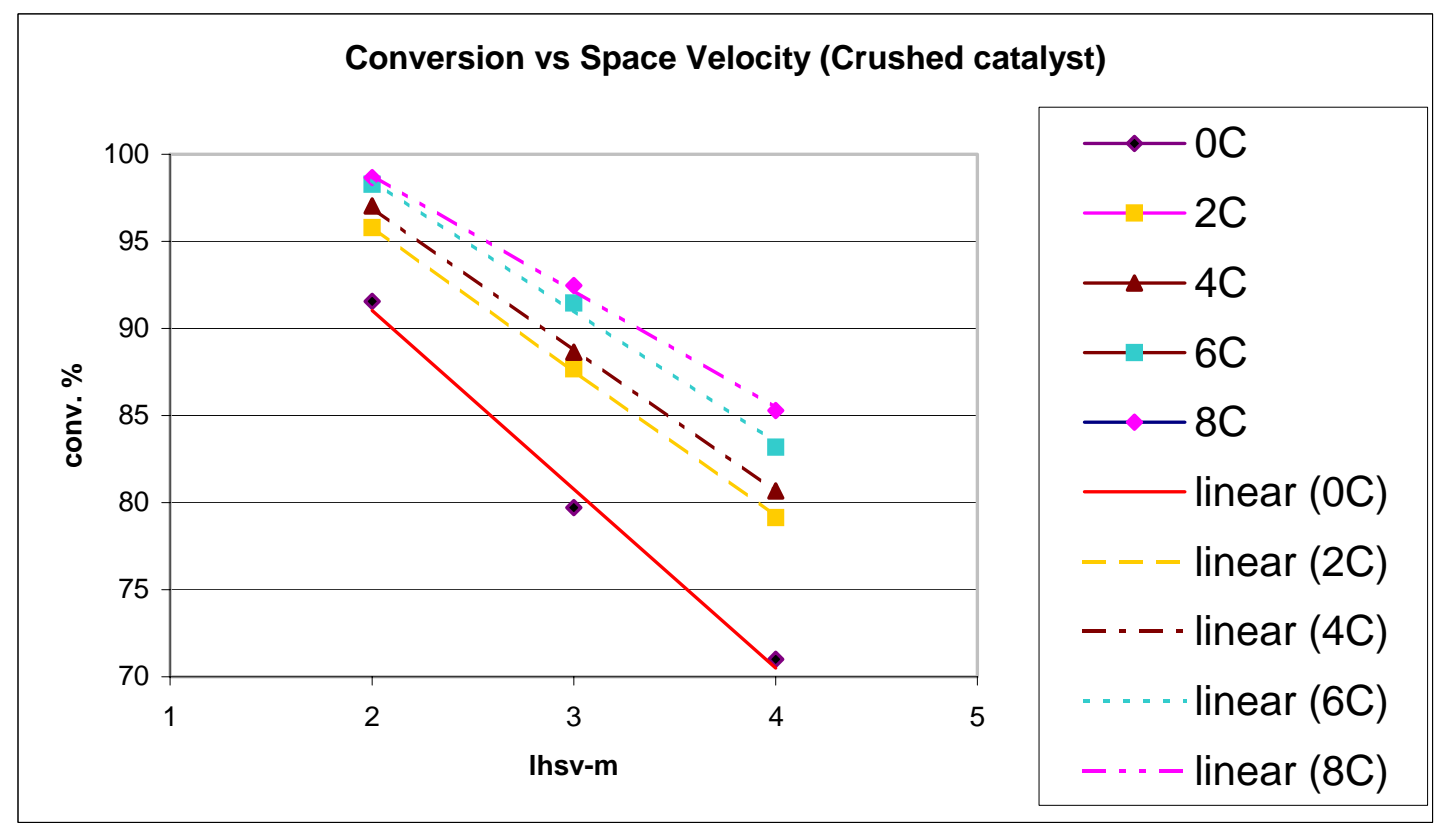

Figure 55: conversion versus space velocity with different package numbers and crushed catalyst.

To give a clear insight of the conversion improvement through the use of bluff bodies, different package number's conversion increase (improvement) compared to zero package configurations are given in Figure 56 and Figure 57 at a flow rate of $5 \mathrm{ml} / \mathrm{min}$ and $20 \mathrm{ml} / \mathrm{min}$ (1.0 and 4.0 LHSV-M respectively). 


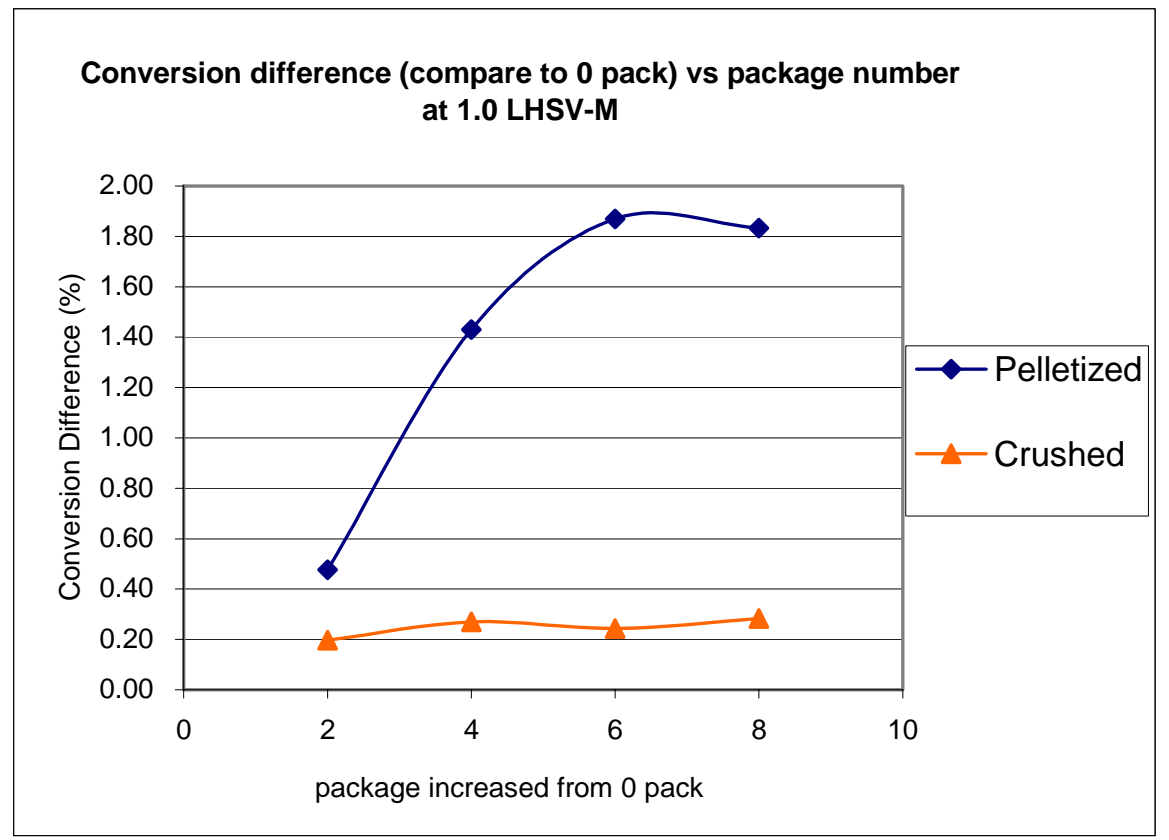

Figure 56: conversion difference versus package number increased at 1.0 LHSV-M.

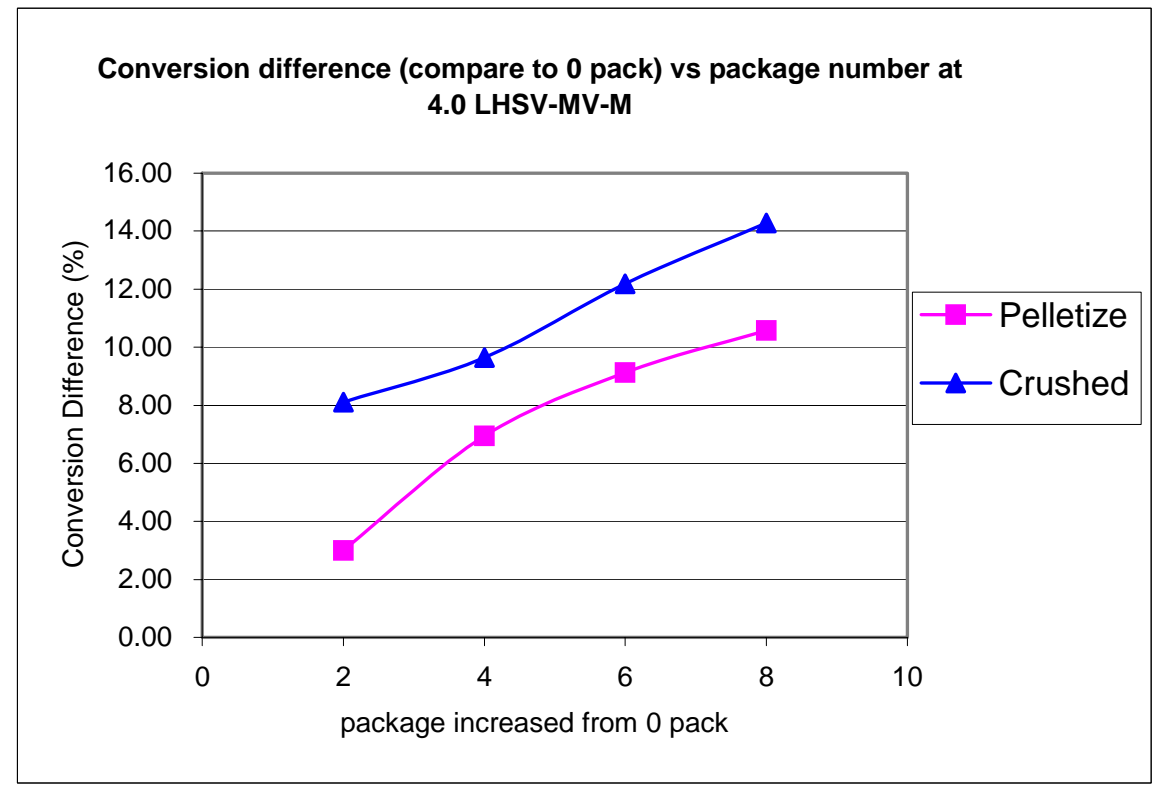

Figure 57: conversion difference versus package number increased at 4.0 LHSV-M.

Comparing Figure 56 and Figure 57, the plots indicate that a high space velocity of 4.0 LHSV-M gave a larger conversion improvement. This phenomenon corresponds to the result concluded by Table 4 that flow rate and bluff body package numbers have a positive interaction thus a positive signal-to-noise ratio. 


\section{Heat Transfer Enhancement}

The fuel conversion enhancement by bluff bodies was mainly due to the heat transfer enhancement inside the reactor. Figure 58 to Figure 61 present the centerline temperatures at different axial locations inside the reactor. Examining these plots, one can see that as the number of bluff body packages increase, the centerline temperatures inside the reactor had an obviously increased. This heat transfer enhancement was visible both in pelletized and crushed catalysts, and also both in high and low space velocities.

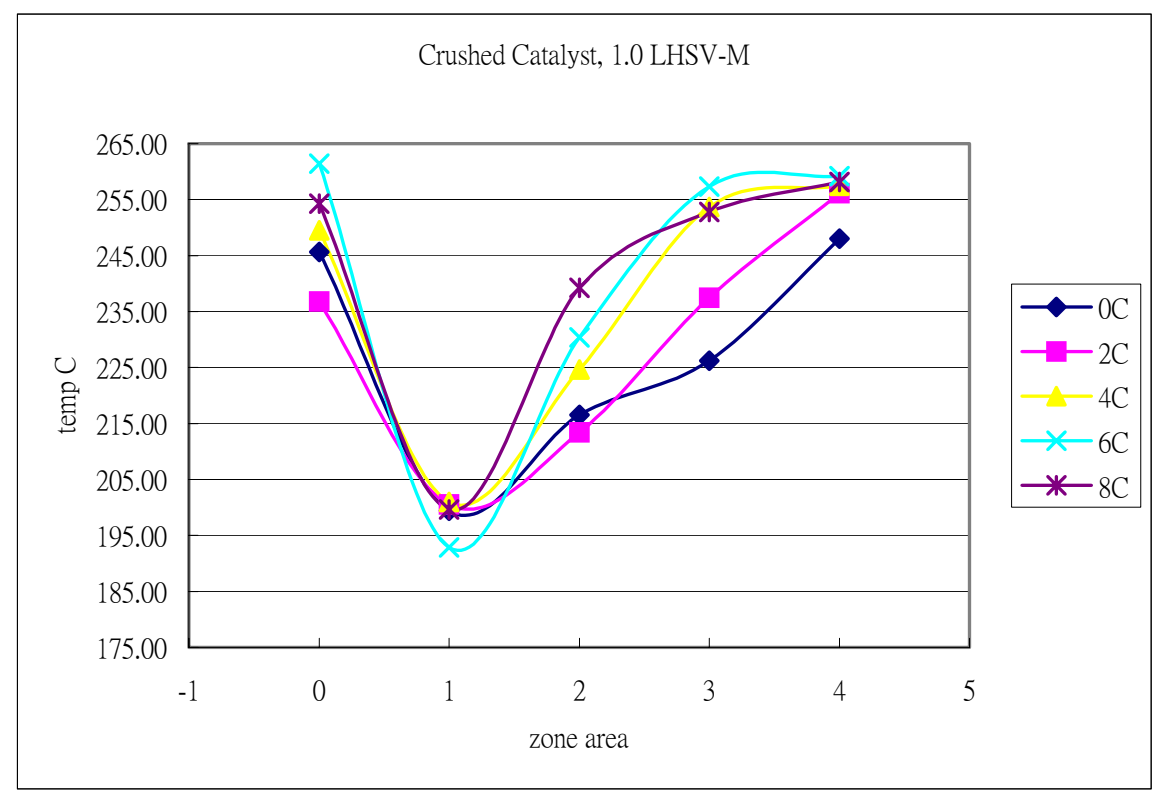

Figure 58: Centerline temperatures versus axial locations for 1 SLHV-M (crushed).

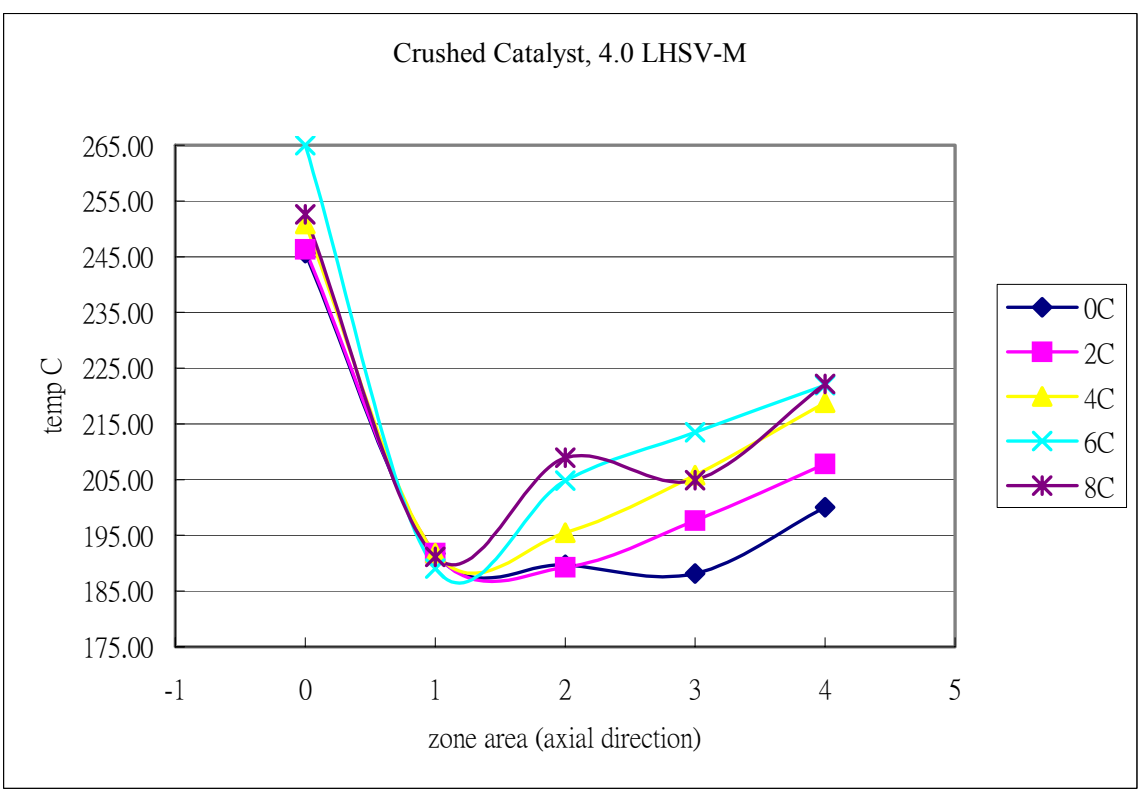

Figure 59: Centerline temperatures versus axial locations for 4 SLHV-M (crushed). 


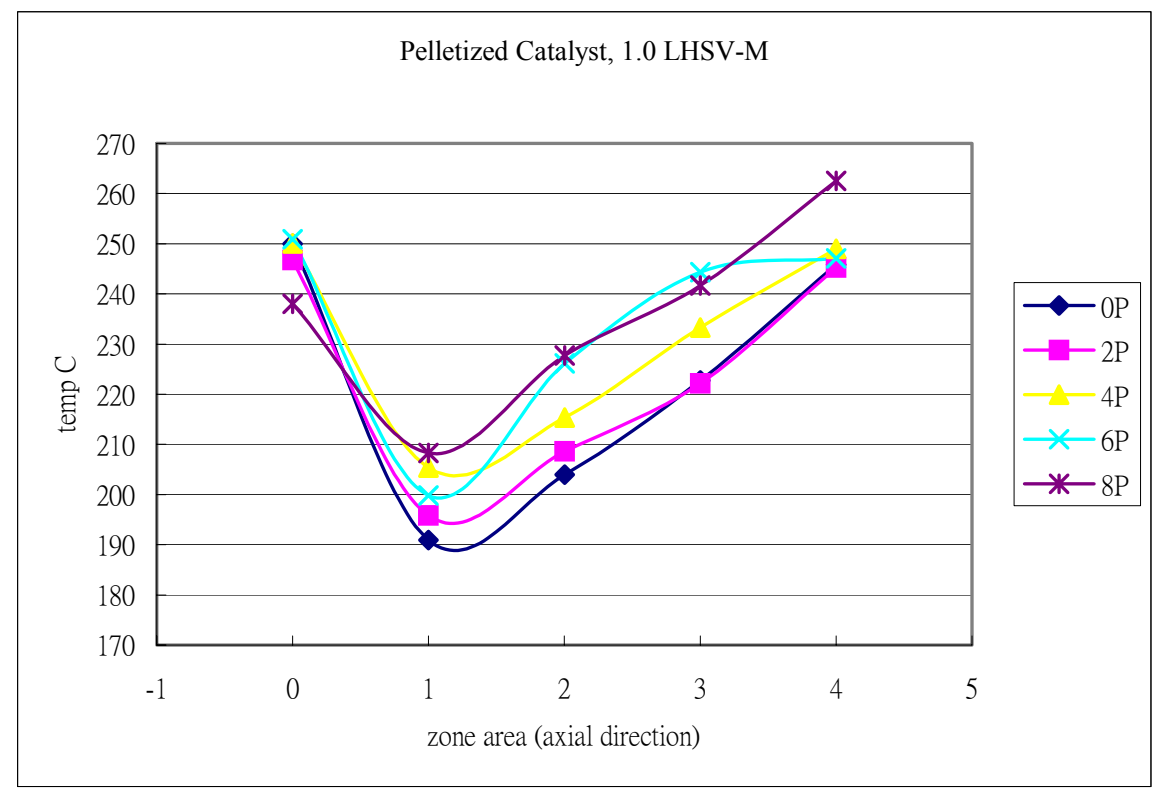

Figure 60: Centerline temperatures versus axial locations for 1 SLHV-M (pelletized).

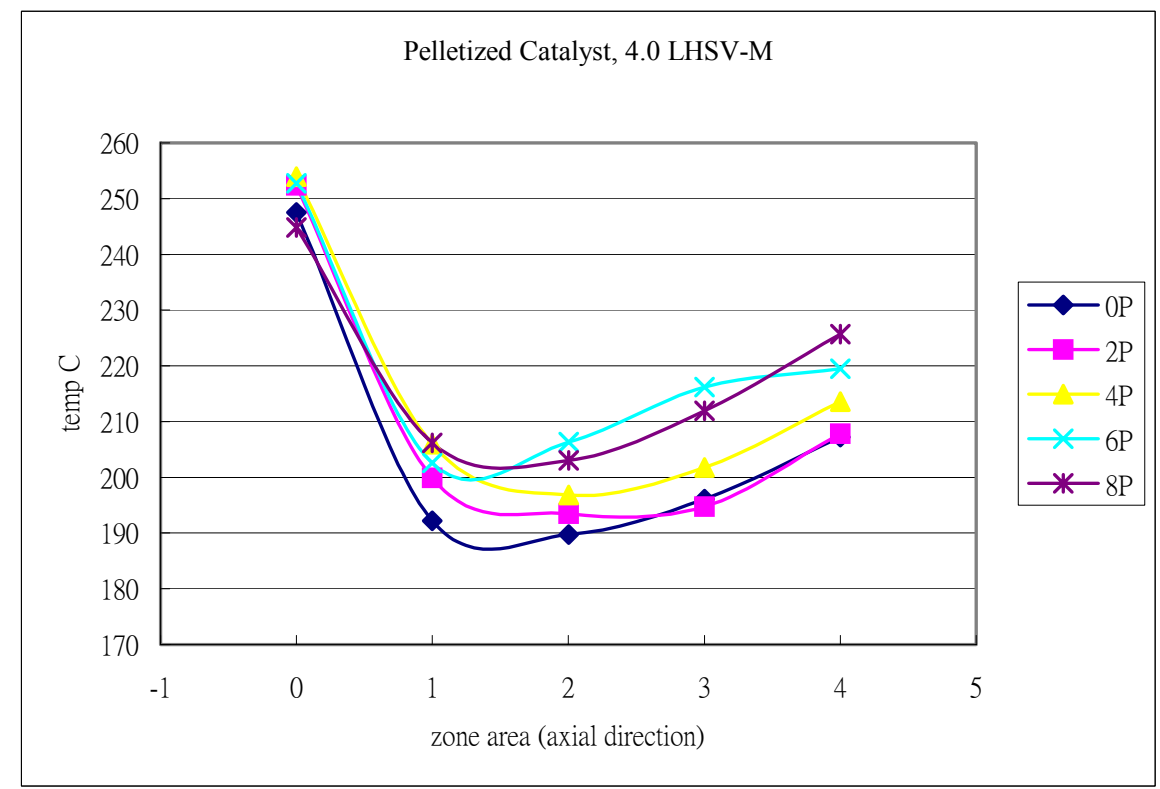

Figure 61: Centerline temperatures versus axial locations for 4 SLHV-M (pelletized).

Temperature profiles in the radial direction of different experiment configurations are presented from Figure 62 to Figure 71. These temperature profiles were based on a linear assumption between the wall temperature and centerline temperature and programmed in LabView software. Even though the linear assumption is not quite correctly to approach the temperature gradient, the profiles could still give a rough image of temperature distribution inside the reactor tube. 
Figure 62: 0 Packages Pelletized Catalyst (0P)

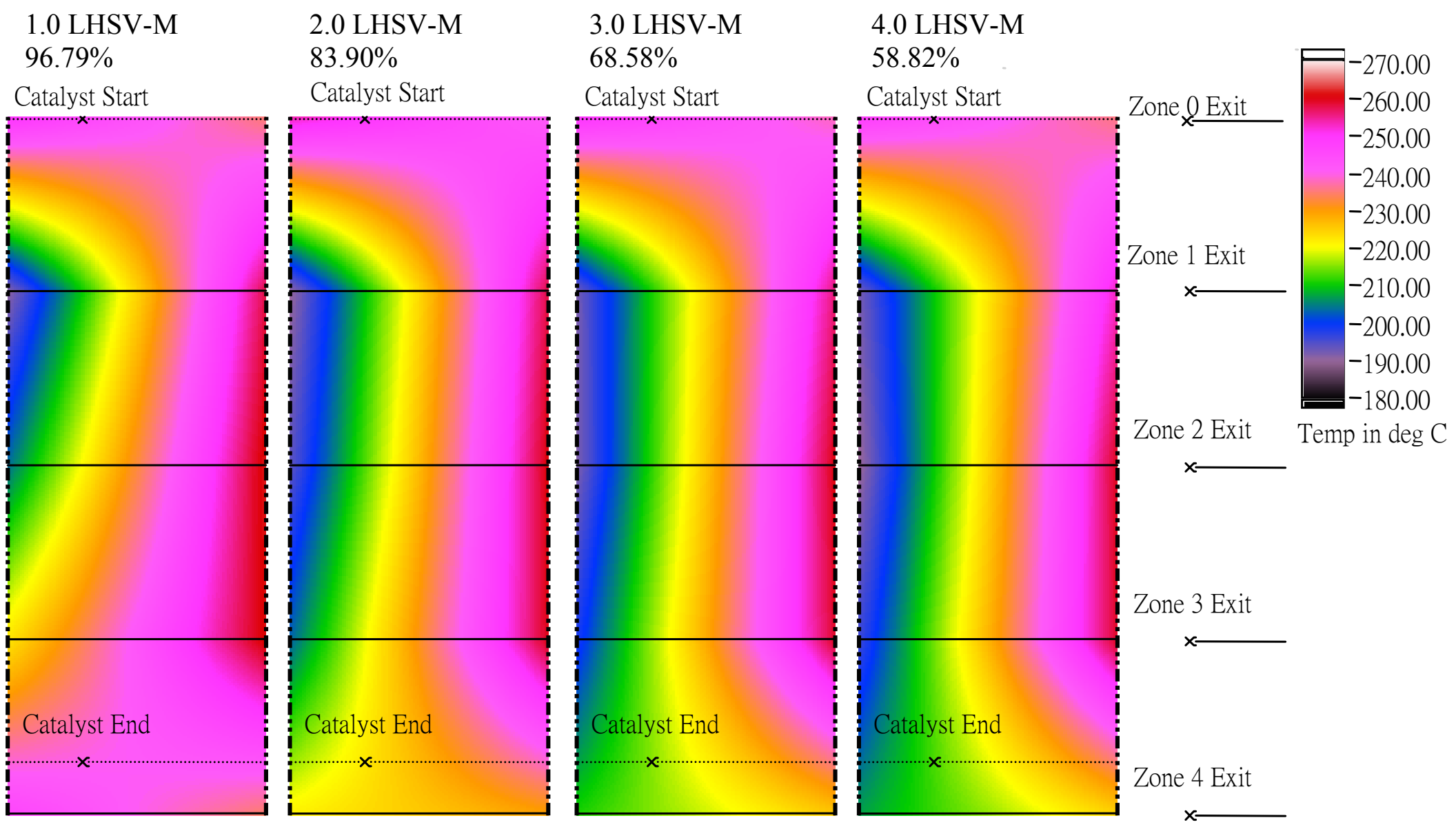


Figure 63: 2 Packages Pelletized Catalyst (2P)

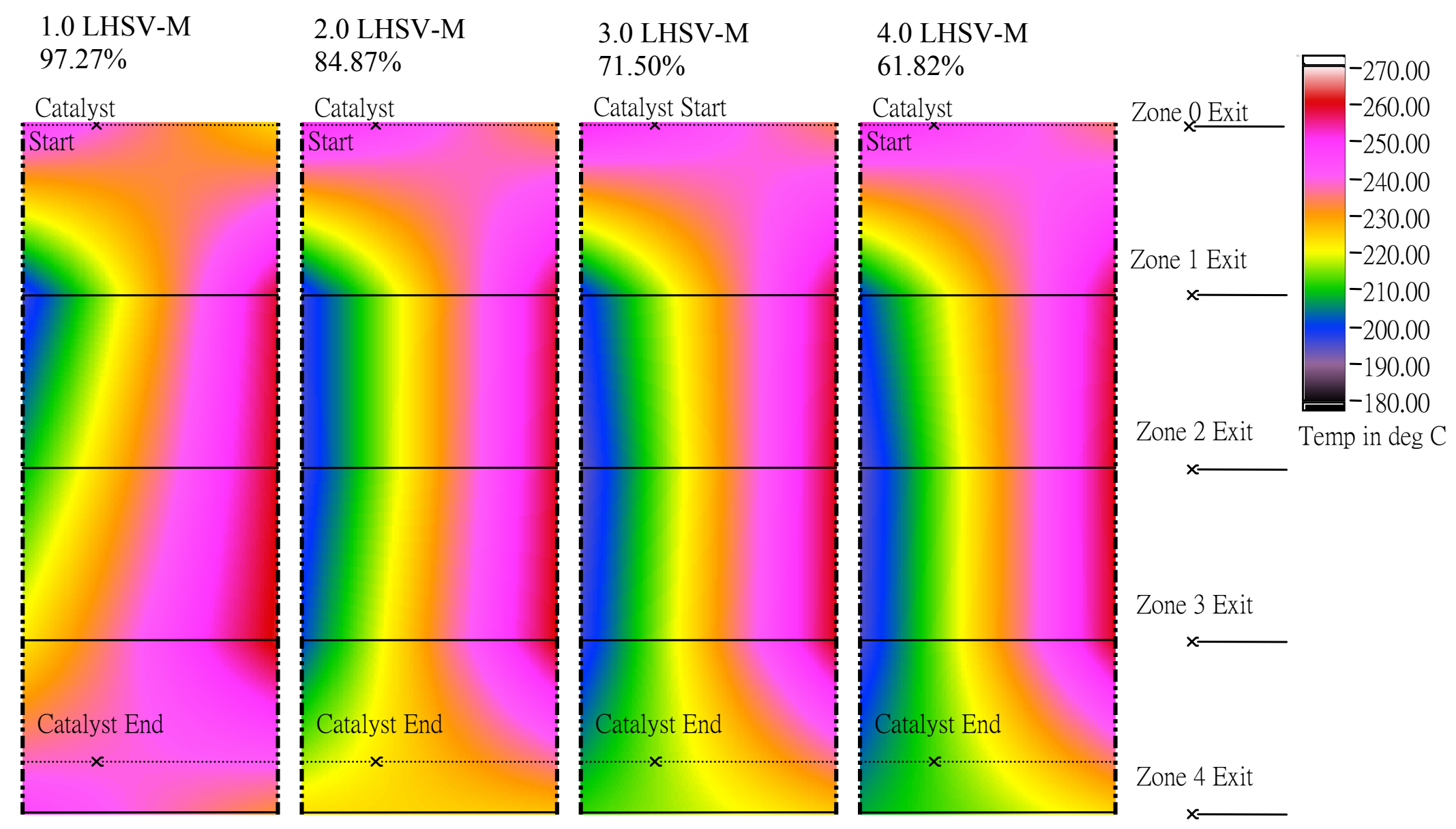


Figure 64: 4 Packages Pelletized Catalyst (4P)

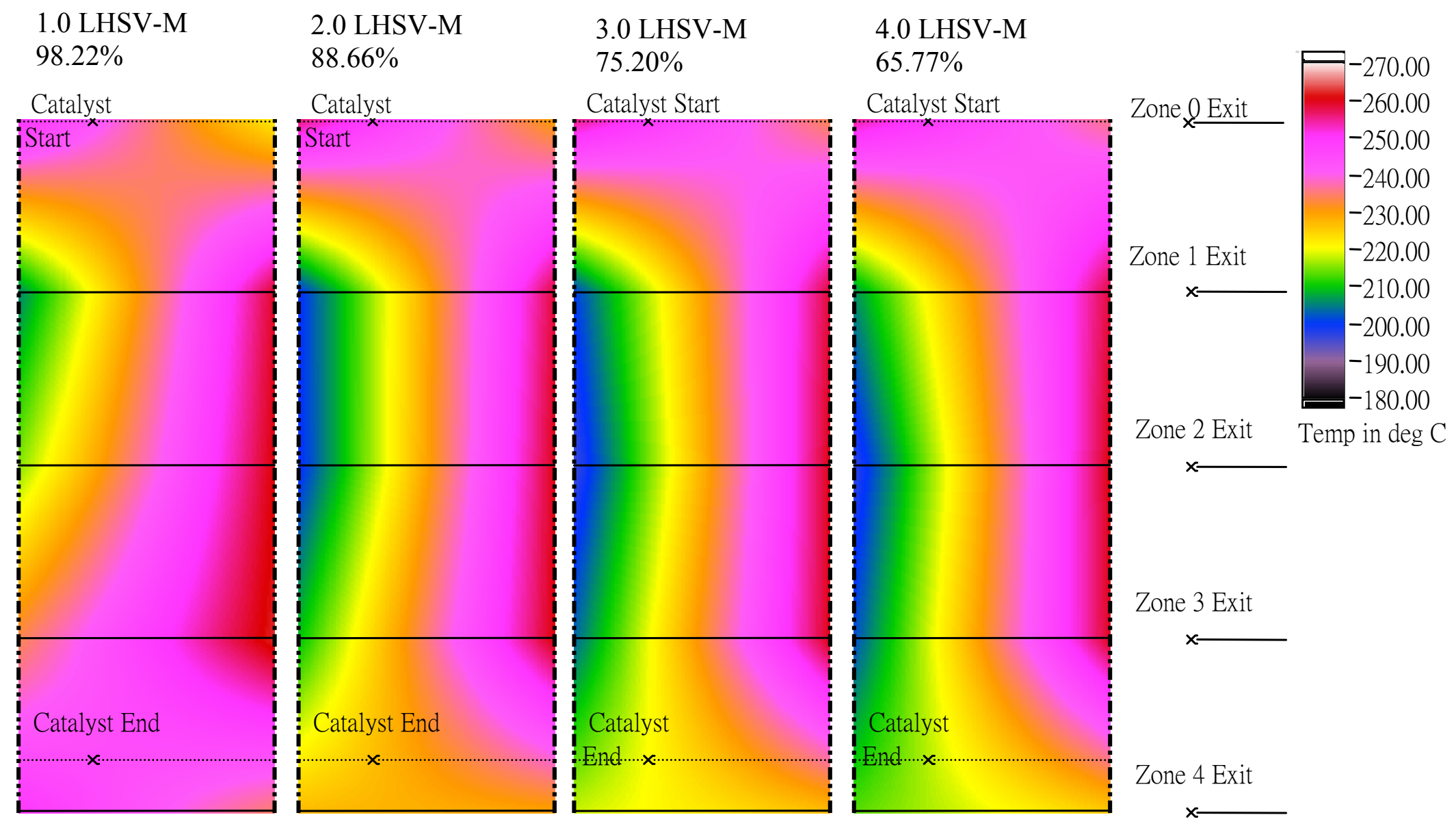


Figure 65: 6 Packages Pelletized Catalyst (6P)

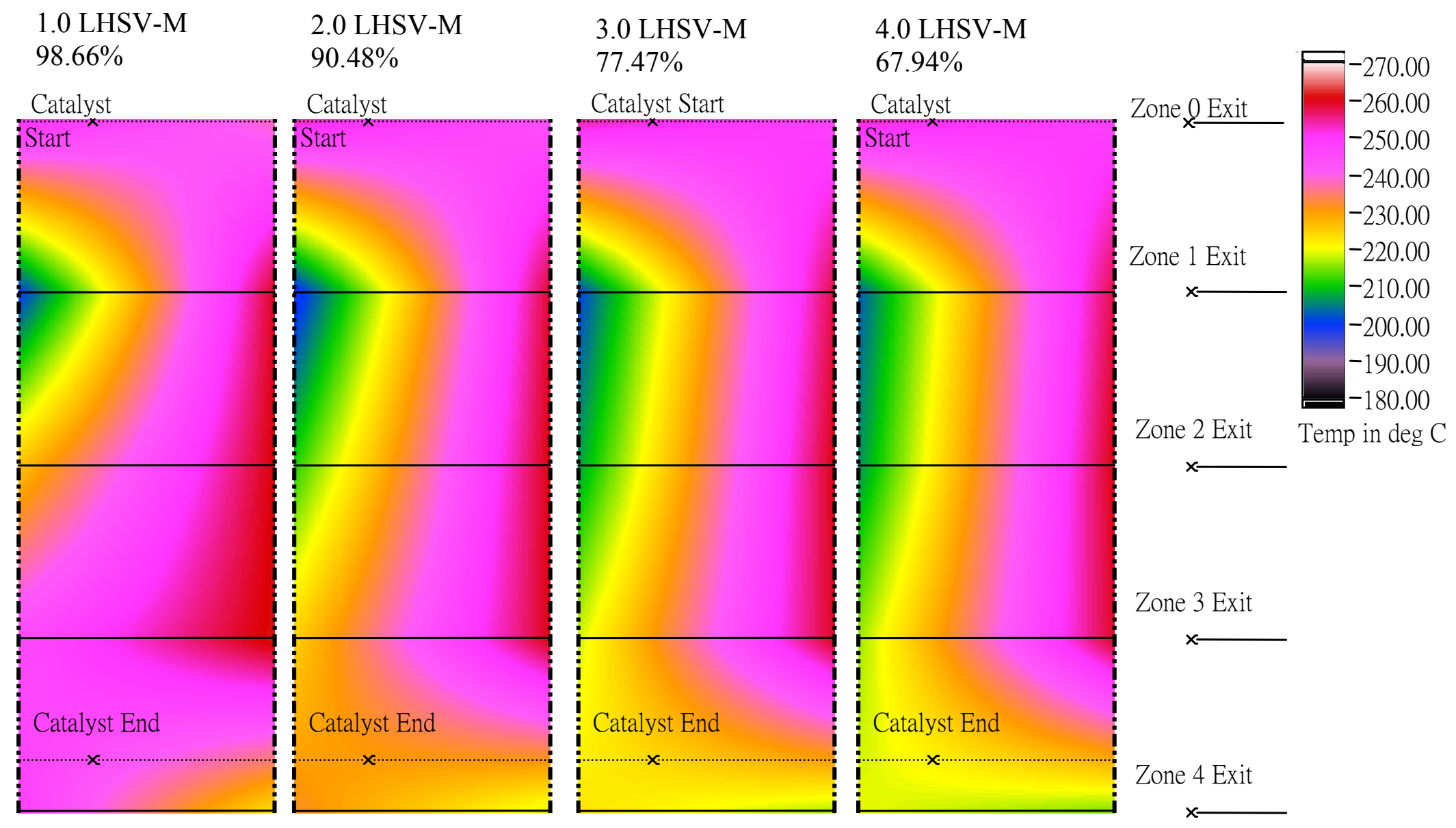


Figure 66: 8 Packages Pelletized Catalyst (8P)

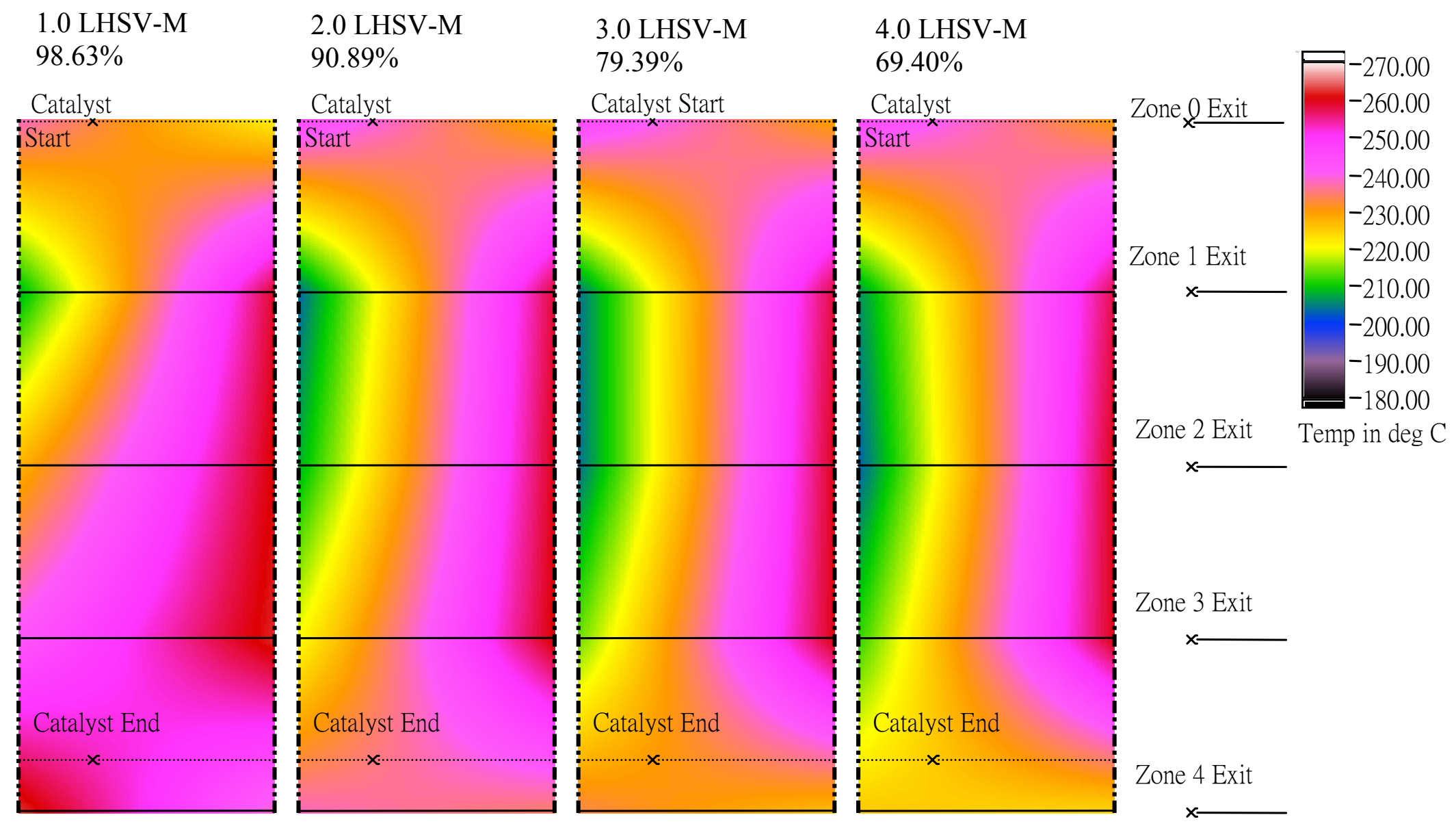


Figure 67: 0 Packages Crushed Catalyst (0C)

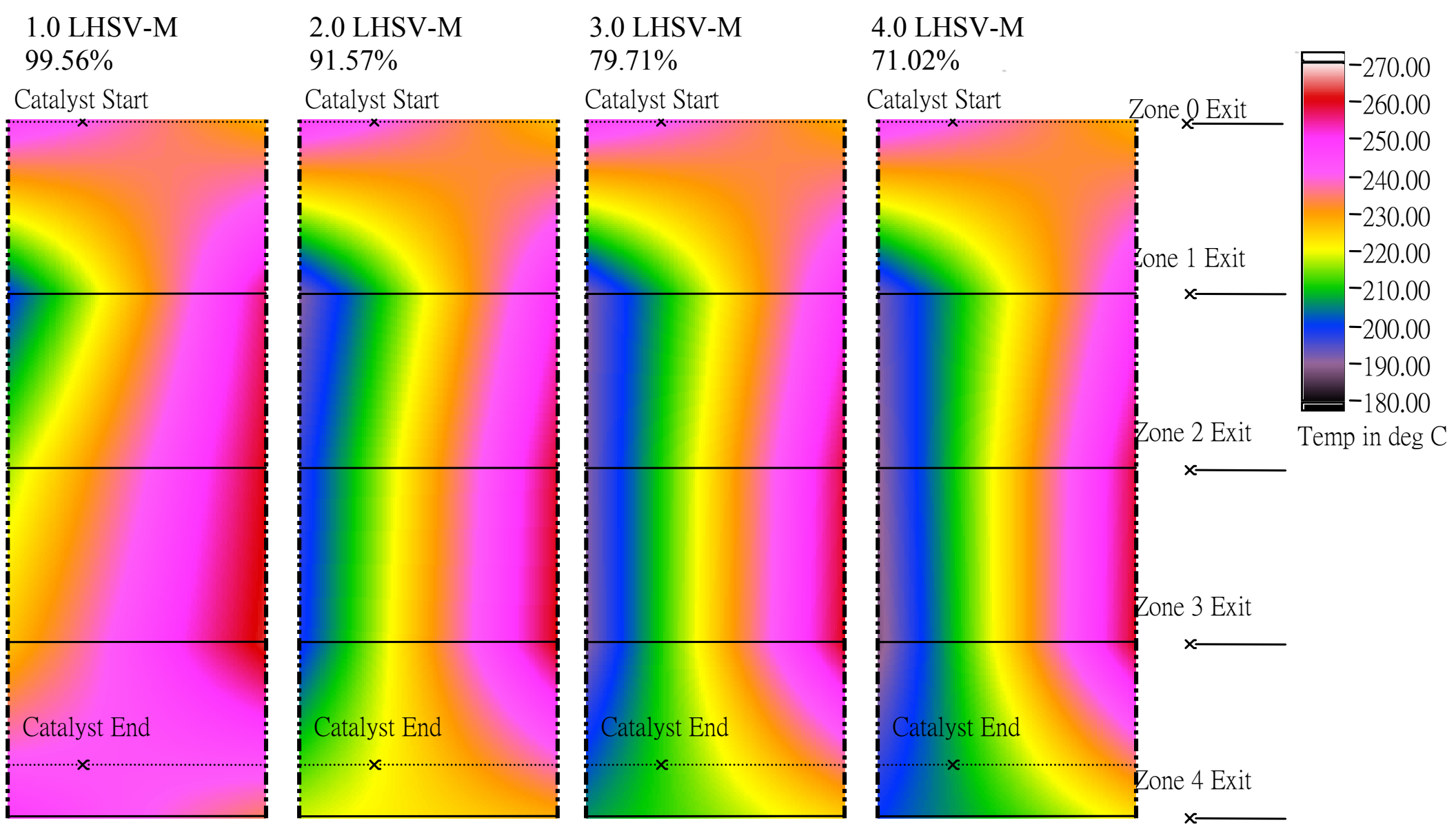


Figure 68: 2 Packages Crushed Catalyst (2C)

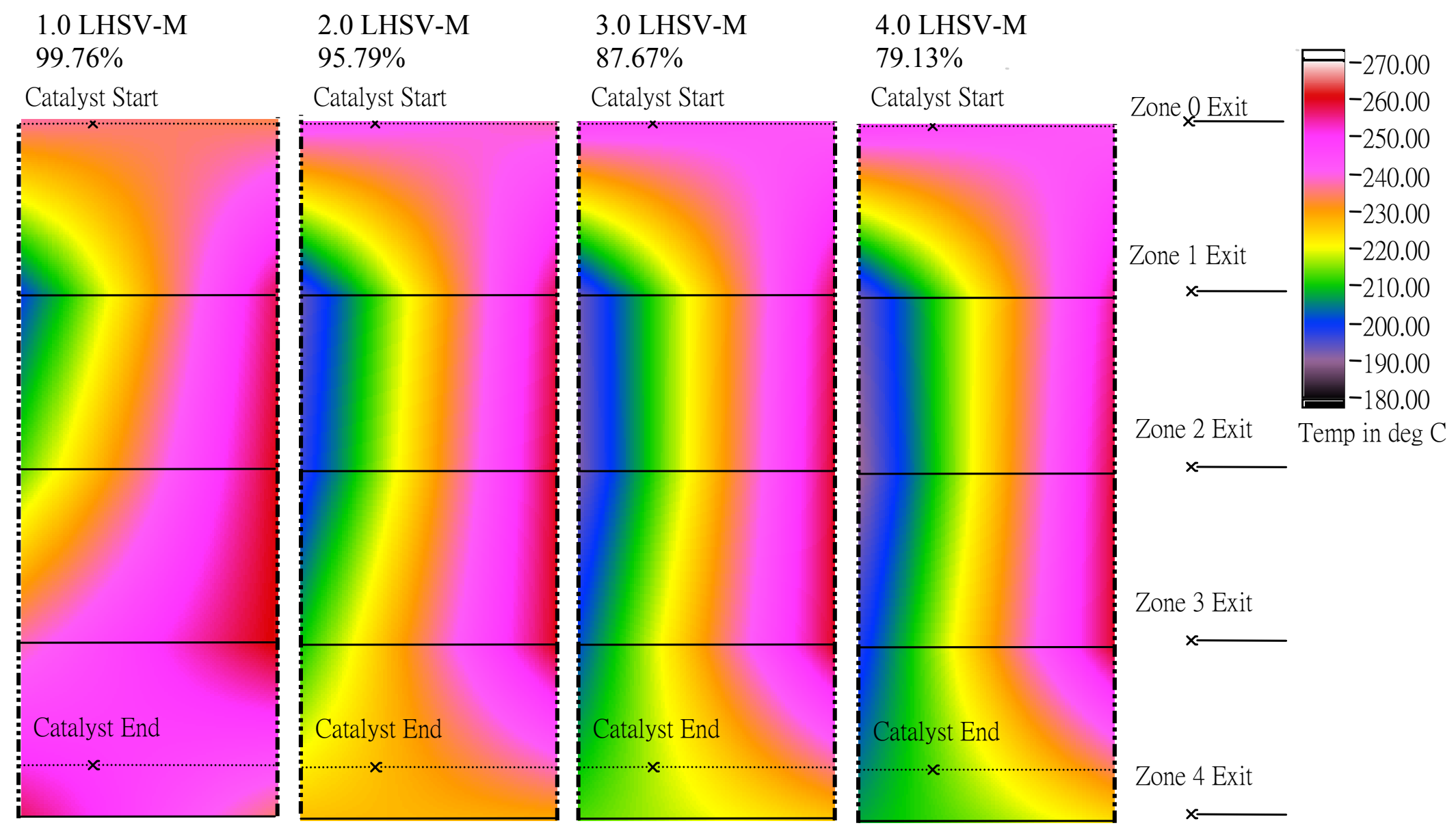


Figure 69: 4 Packages Crushed Catalyst (4C)

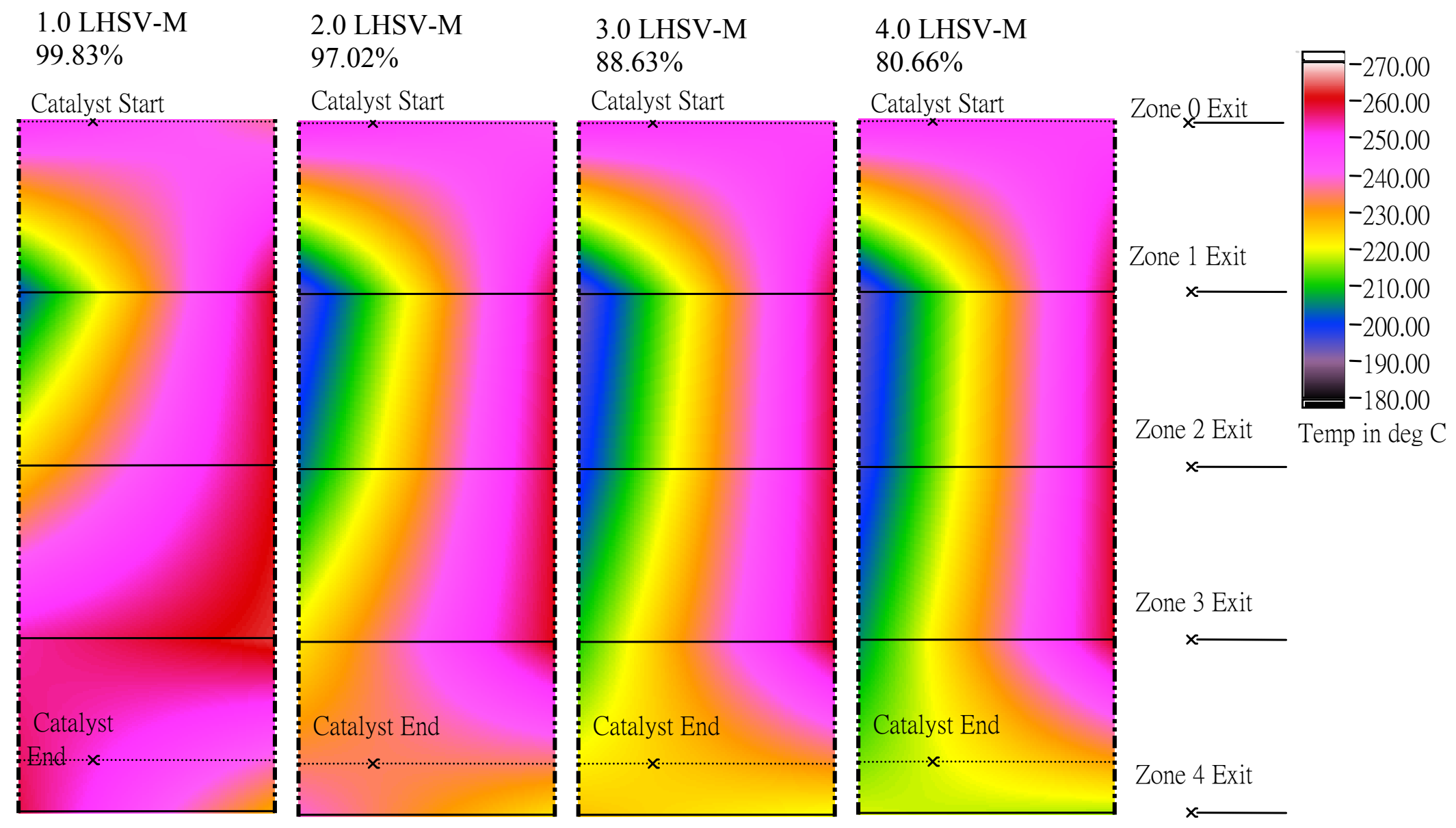


Figure 70: 6 Packages Crushed Catalyst (6C)

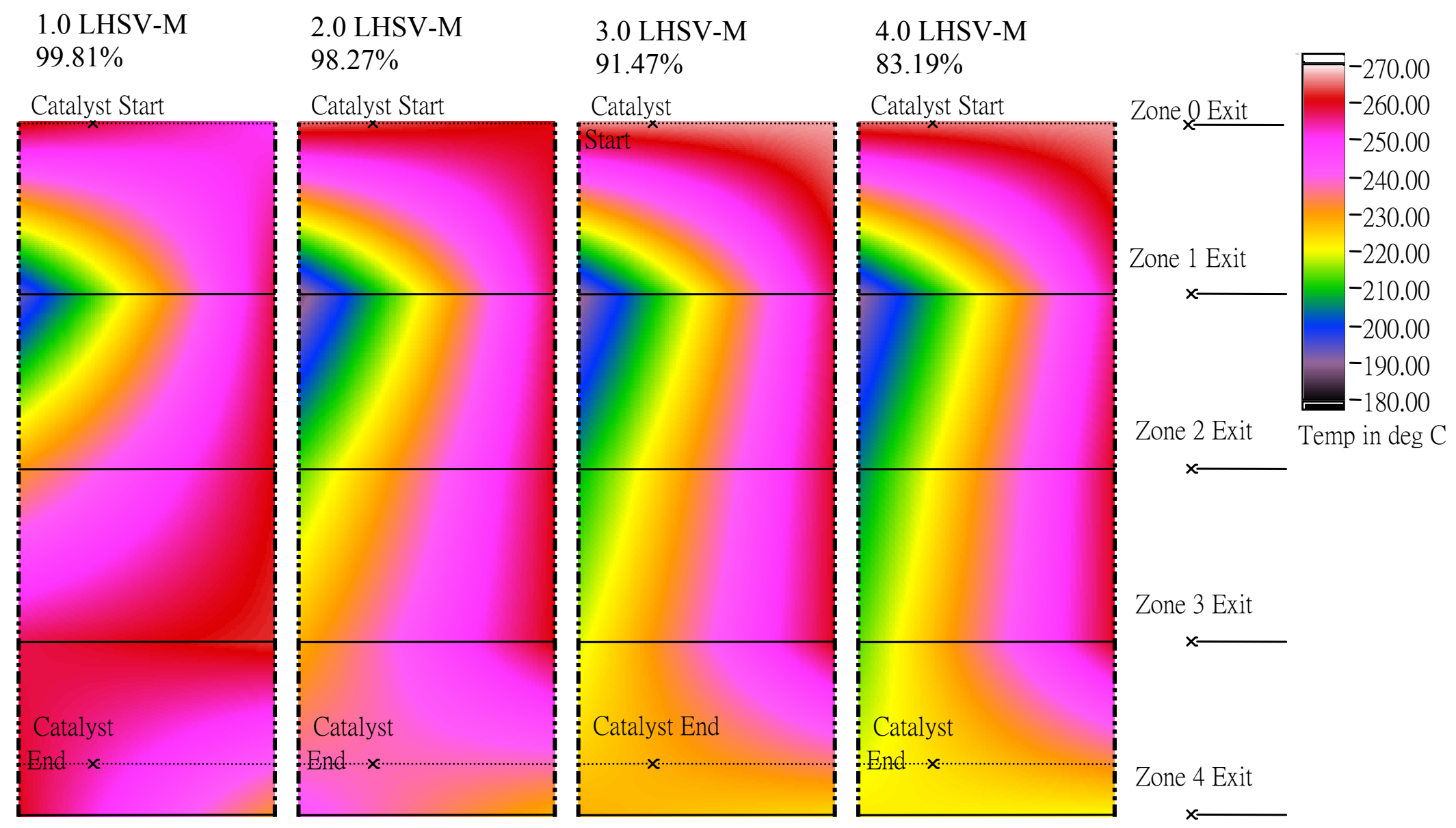


Figure 71: 8 Packages Crushed Catalyst (8C)

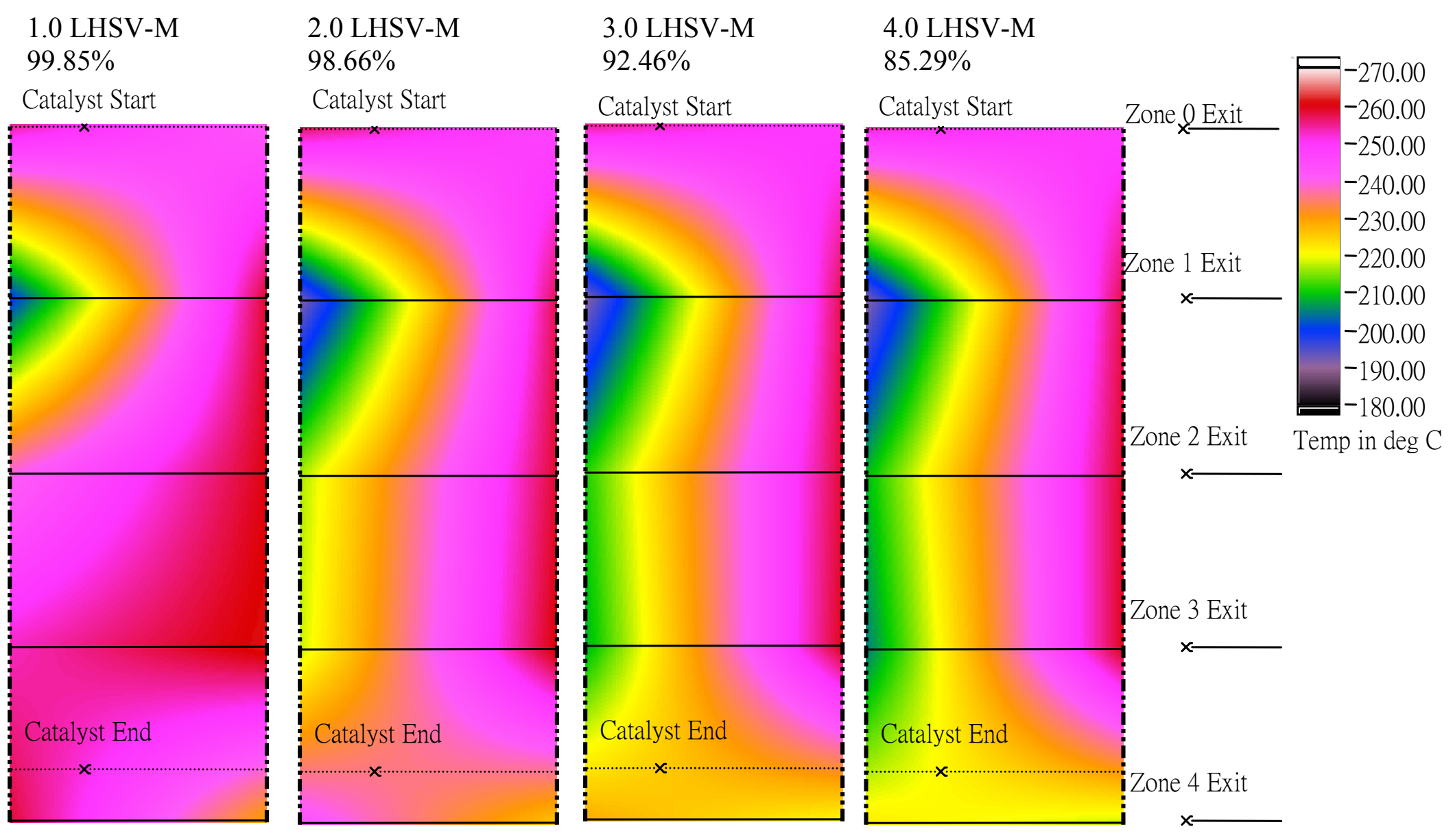


From the temperature profiles shown above, a cold region of around $190^{\circ} \mathrm{C}\left(374^{\circ} \mathrm{F}\right)$ to $200^{\circ} \mathrm{C}\left(392^{\circ} \mathrm{F}\right)$ (blue color region) was formed at the centerline of the reactor in the zero package experiment configuration. When increasing the number of bluff body packages, one can easily see that for pelletized catalyst this cold region shrank and the cold color became green which means the temperature raised to around $210^{\circ} \mathrm{C}\left(410^{\circ} \mathrm{F}\right)$. For the crushed catalyst run, even though the blue color of cold region did not turn completely to green, the size of the cold region did shrink noticeably from zero package to eight packages.

\section{Reformate Concentration Enhancement}

The reacted species were routed to a gas analyzer to analyze its composition after passing through the reactor and a condensing unit. Figure 72 shows the hydrogen volume concentration as a function of space velocity at different bluff body package numbers with crushed catalyst.

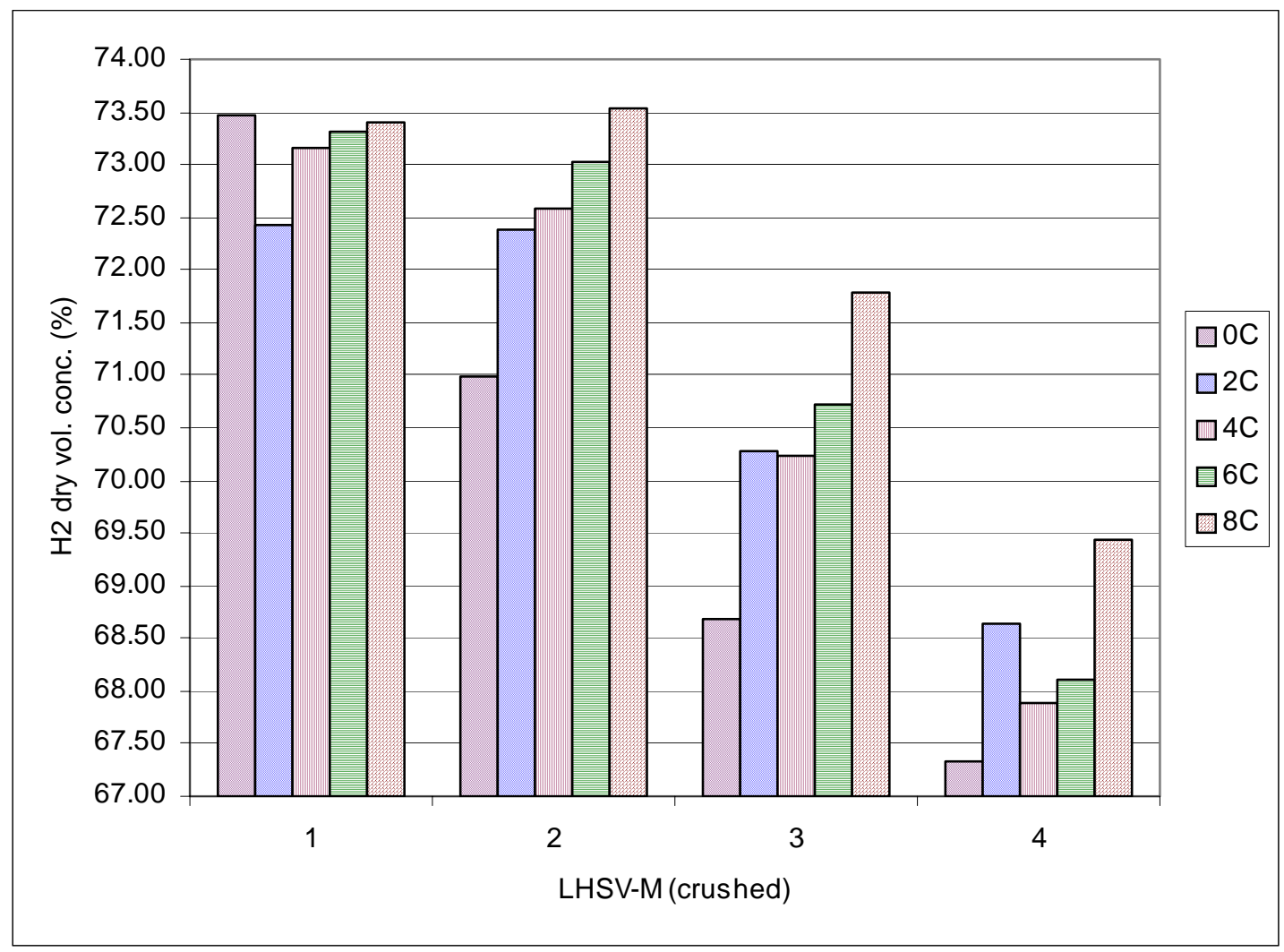

Figure 72: hydrogen dry vol. conc. with different package numbers using crushed catalyst.

Figure 72 shows an increasing trend of hydrogen concentration from zero packages (0C) to 8 packages (8C). If we only look at $1.0 \mathrm{LHSV}-\mathrm{M}$, the concentration increase was not very significant. This is because these five experiment configurations running at 1.0 LHSV-M all had a fuel conversion above $99.5 \%$, thus the conversion did not give a remarkable improvement relating directly to the hydrogen concentrations. Plots of carbon monoxide volume concentrations also yield the same trend as shown in Figure 73. 
This is because more methanol fuel converted, and more carbon monoxide was produced as expected. It is interesting to note the small decrease of carbon monoxide concentration compared to the large increase of hydrogen concentration between $6 \mathrm{C}$ and $8 \mathrm{C}$. A possible explanation for this phenomenon is that there might be more exothermic watergas-shifted reactions happening in the $8 \mathrm{C}$ run producing more hydrogen and less carbon monoxide because the reactant passage way was elongated inside the catalyst bed.

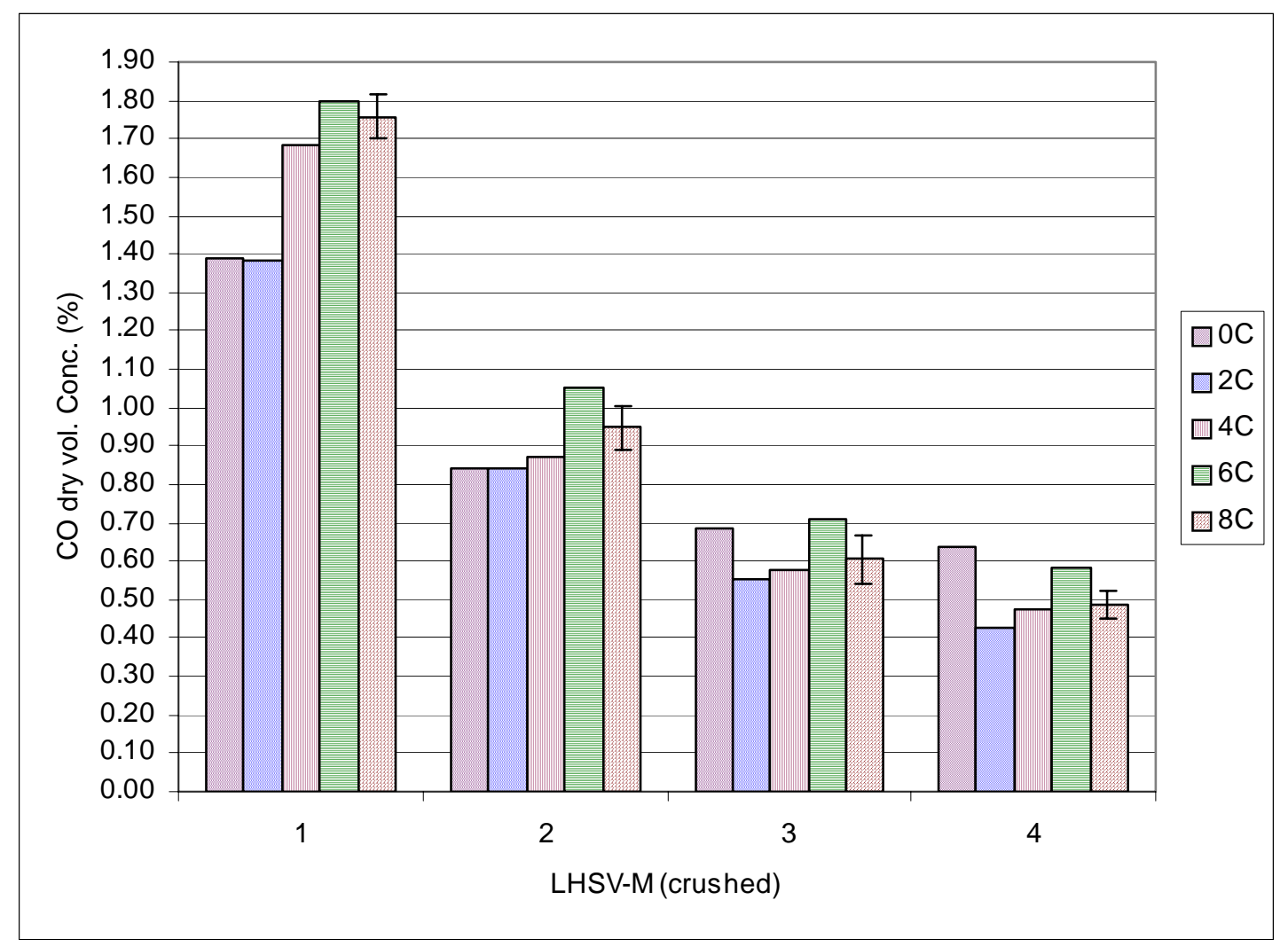

Figure 73: carbon monoxide dry vol. conc. with different package number using crushed catalyst.

\section{Power Consumption Enhancement}

Power draw of the heater bands attached on the reactor is shown in Figure 74 and Figure 75. It is important to note that due to the inconsistency of data acquiring time intervals, the values shown in the figures are not in the power unit of Watts. But the plots still can give a rough comparison of power draw using different bluff body package numbers. 


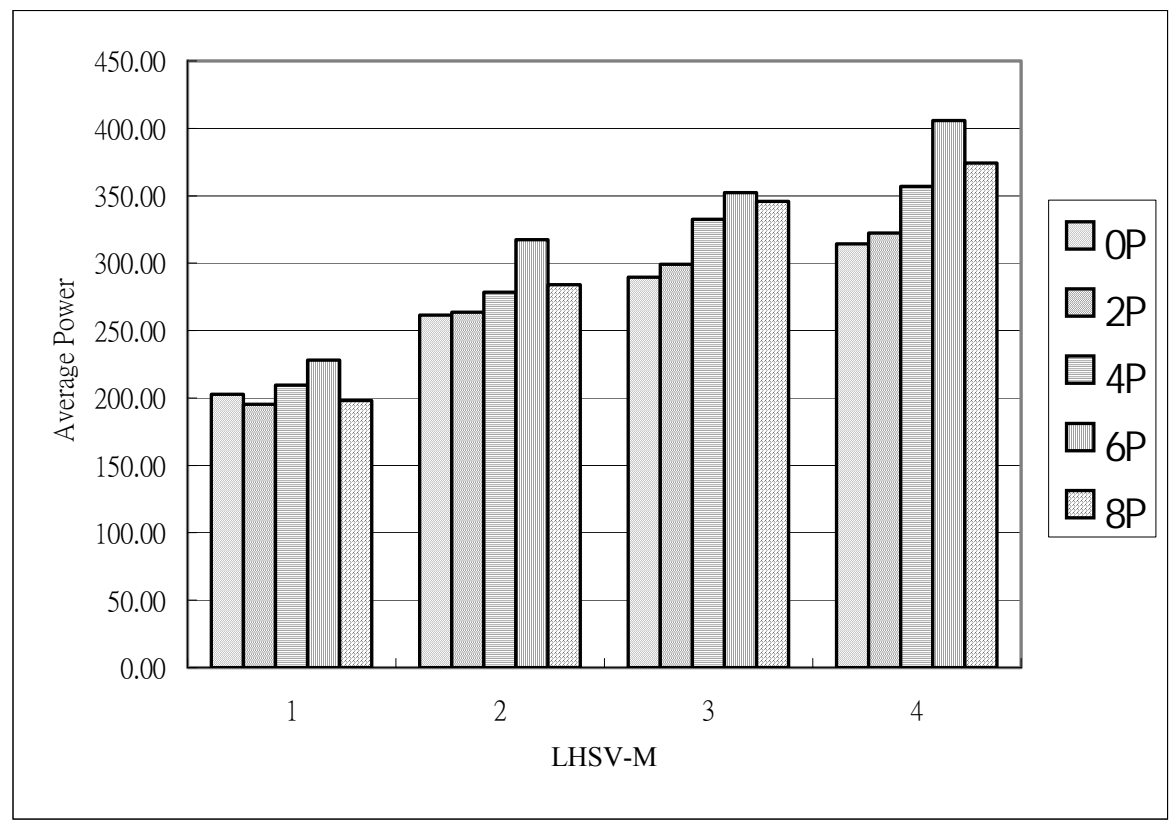

Figure 74: power draw at different space velocity and package numbers with pelletized catalyst 1.

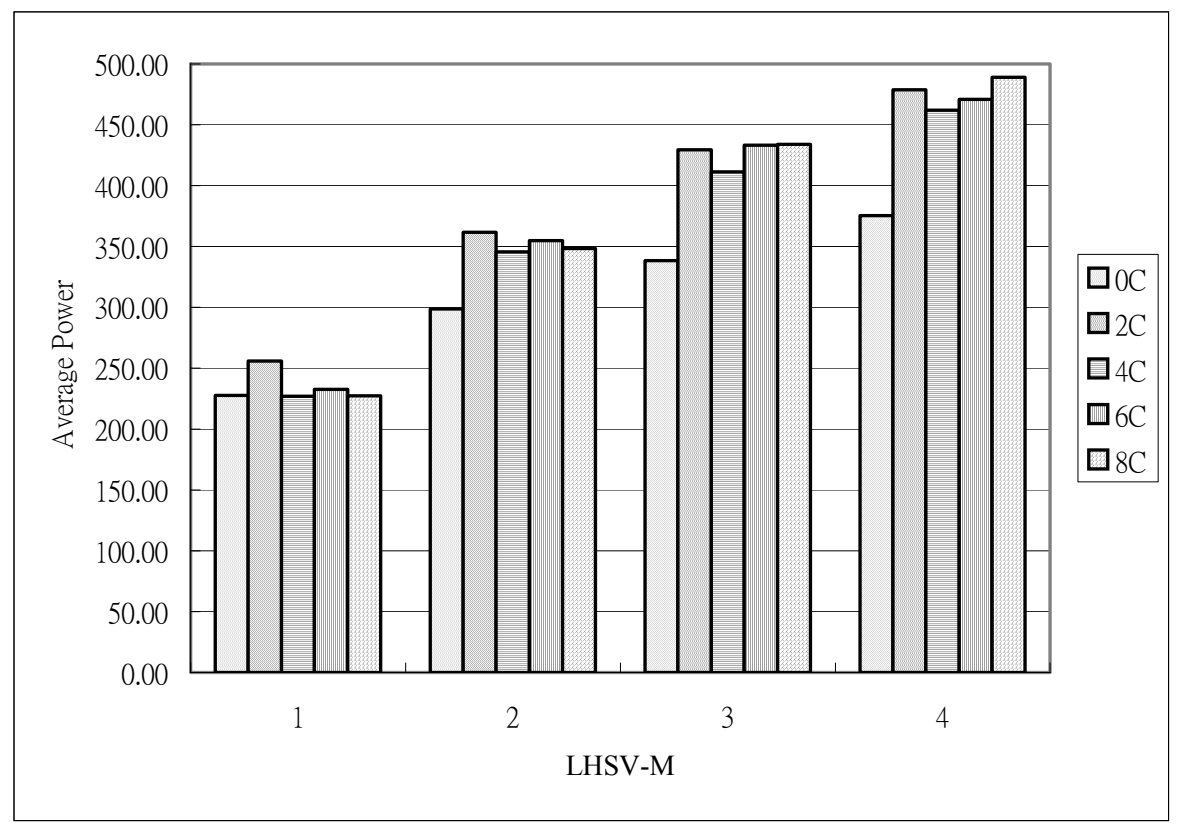

Figure 75: power draw at different space velocity and package numbers with crushed catalyst 2.

Figure 74 and Figure 75 show that power consumed by the heater bands on the reactor increased as more bluff body packages were added. This result is expected as more endothermic reforming reaction took place at higher package numbers and higher fuel conversion. Therefore, the power demand is not significantly affected by introducing bluff bodies inside the reactor. However, if the overall reactor efficiencies are calculated and compared a 5\% efficiency increasing is gained by increasing the bluff body packages 
from two to eight. The reactor efficiencies of $2 \mathrm{P}$ and $8 \mathrm{P}$ at four space velocities are tabulated in Table 10.

Table 10: Reactor efficiency at high and low package density with different space velocity.

\begin{tabular}{|c|c|c|}
\hline & \multicolumn{2}{|c|}{ Reactor Efficiency (\%) } \\
\hline LHSV-M & $2 \mathrm{P}$ & $8 \mathrm{P}$ \\
\hline 1.0 & 58.9 & 64.5 \\
\hline 2.0 & 63.9 & 68.5 \\
\hline 3.0 & 57.1 & 62.2 \\
\hline 4.0 & 51.5 & 56.3 \\
\hline
\end{tabular}




\section{CONCLUSION}

Internal and external evaluations of coal-derived and fuel cell grade methanol are now complete. The two methanols are quite similar in sulfur, and chloride levels with a small but significant difference in trace level higher hydrocarbons. The coal based methanol has approximately 3 times the amount of petroleum hydrocarbons than the fuel cell grade methanol.

Construction of three (3) steam reformers has taken place. Each reformer has a different geometry in order to test the geometric dependencies of reformation. Studies showing a strong dependence of fuel conversion on geometry have taken place. These reformer systems also are utilized for the studies of catalyst degradation and passive heat transfer enhancement. The steam reformers have been used to generate hydrogen from the coalderived methanol supplied. Construction of the autothermal reformer (ATR) is now completed and preliminary testing has begun with fuel cell grade methanol. Initial tests are complete with a catalytic converter grade catalyst to validate the test procedures and have given the research team valuable experience with analyzing both the data and control schemes. Start-up, operation and shut-down procedures have been tested and validated and data collection is proceeding using a specially designed proprietary catalyst specifically designed for autothermal reformation. Parameters of oxygen to carbon ratio have been investigated as well as reaction progression in the catalyst. Theoretical oxygen to carbon ratio underestimates the amount of oxygen required for peak hydrogen efficiency. With the fuel cell grade methanol the autothermal reaction takes place quickly within the first fifteen percent (15\%) of the catalyst bed. The upper level of flow rate has yet to be determined regarding fuel conversion to hydrogen and this ATR method appears very promising for reforming coal-derived methanol.

Due to a careful evaluation of the steam reformer temperature profile it was determined that significant sheath conduction from the wall was biasing the temperature measurements close to the reactor wall. A new thermocouple design utilizing a miniature sheath embedded into an external housing with insulating material was tested. This new thermocouple design had more reliable results than the standard design for determining an accurate temperature profile. This new thermocouple design is being implemented throughout the steam reforming reactors and also into the ATR reactor.

Investigations into methods of enhancing the heat transfer characteristics were also performed. Data has been collected showing enhancement of heat transfer and mass transfer by bluff bodies. This data is being analyzed and is being expanded to include an empirical model of the enhancement process. Several packing densities have been evaluated in steady state with the bluff bodies. Results are very encouraging to the research team and show significant enhancement of conversion.

In addition to the above projects catalyst degradation projects have been started. The catalyst degradation study has monitored conversion while operating in steady state for the two methanol fuels over several continuous 70 hour periods. With heat transfer 
minimized by using a specially designed steam reformer with an internal heater, the coalderived methanol showed significantly faster catalyst degradation than the fuel cell grade methanol. The research team speculates that the increased degradation is due to the higher levels of trace hydrocarbons. This catalyst degradation study will expand as more data become available.

Several projects are scheduled for the next project period including use of the coal-based methanol in the ATR reactor, continued evaluation of coal-based methanol in the steam reformers, validation of heat transfer enhancement methods by use of bluff bodies and measuring the difference in catalyst degradation using the various methanols with combination with the enhancement methods studied.

One paper outlining the overall research direction was presented by the PI to the ASME Power Conference in Baltimore March, 2004. Several papers are in works regarding the steam reformer and the autothermal reformer performance. 


\section{REFERENCES}

[1] Erickson, P.A., Enhancing the Steam-Reforming Process with Acoustics: An Investigation for Fuel Cell Vehicle Applications, doctoral dissertation, University of Florida, Gainesville, FL, 2002

[2] Agrell, J., H. Birgersson, et al. (2002). "Steam reforming of methanol over a $\mathrm{Cu} / \mathrm{ZnO} / \mathrm{Al} 2 \mathrm{O} 3$ catalyst: a kinetic analysis and strategies for suppression of $\mathrm{CO}$ formation." Journal of Power Sources 106(1-2): 249-257.

[3] Breen, J. P., F. C. Meunier, et al. (1999). "Mechanistic aspects of the steam reforming of methanol over a $\mathrm{CuO} / \mathrm{ZnO} / \mathrm{ZrO} 2 / \mathrm{Al} 2 \mathrm{O} 3$ catalyst." Chemical Communications(22): 2247-2248.

[4] Peppley, B. A., J. C. Amphlett, et al. (1999). "Methanol-steam reforming on $\mathrm{Cu} / \mathrm{ZnO} / \mathrm{Al} 2 \mathrm{O}$ 3. Part 1: The reaction network." Applied Catalysis a-General 179(12): 21-29.

[5] Peppley, B. A., J. C. Amphlett, et al. (1999). "Methanol-steam reforming on $\mathrm{Cu} / \mathrm{ZnO} / \mathrm{Al} 2 \mathrm{O} 3$ catalysts. Part 2. A comprehensive kinetic model." Applied Catalysis a-General 179(1-2): 31-49.

[6] R.Peters, H.G. Dusterwals et al. (1999) "Investigating of a methanol reformer concept considering the particular impact of dynamics and long-term stability for use in a fuel-cell-powered passenger car" Journal of Power sources 86 (2000) 507514

[7] Purnama, H., T. Ressler, et al. (2004). "CO formation/selectivity for steam reforming of methanol with a commercial $\mathrm{CuO} / \mathrm{ZnO} / \mathrm{Al} 2 \mathrm{O} 3$ catalyst." Applied Catalysis a-General 259(1): 83-94.

[8] Loffler, D. G., S. D. McDermott, et al. (2003). "Activity and durability of water-gas shift catalysts used for the steam reforming of methanol." Journal of Power Sources 114(1): 15-20.

[9] Lawson, Erjavec, "Modern Statistics for Engineering and Quality Improvement" 
[10] The U.S Department of Energy and Air Products Liquid Phase Conversion Company, L.P Commercial-Scale Demonstration of the Liquid Phase Methanol $\left(\right.$ LPMEOH $^{T M}$ ) Process, Clean Coal Technology

[11] J. Patrick Sterchi, The effect of Hydrocarbon Impurities on the Methanol Steam Reforming Process for Fuel Cell Applications, doctoral dissertation, University of Florida, Gainesville, FL, 2001

[12] Pio Fornzzati, Luca Lietti, Catalyst deactivation, Catalysis today 52(1999) 165-181

[13] Calvin. H. Bartholomew, Mechanism of Catalyst deactivation, Applied Catalysis A: General 212 (2001) 17-60.

[14] C.J. Jiang, D.L. Trimm and M.S. Wainwright, Kinetic mechanism for the reaction between methanol and water over a $\mathrm{Cu}-\mathrm{ZnO}-\mathrm{Al}_{2} \mathrm{O}_{3}$ Catalyst, Applied Catalysis A: General, 97 (1993) 145-158

[15] Martyn V. Twigg and Michael S. Spencer, Deactivation of copper metal catalysts for methanol decomposition, methanol steam reforming and methanol synthesis, Topics in Catalysis Vol.22 .Nos. 3-4 April 2003. 